
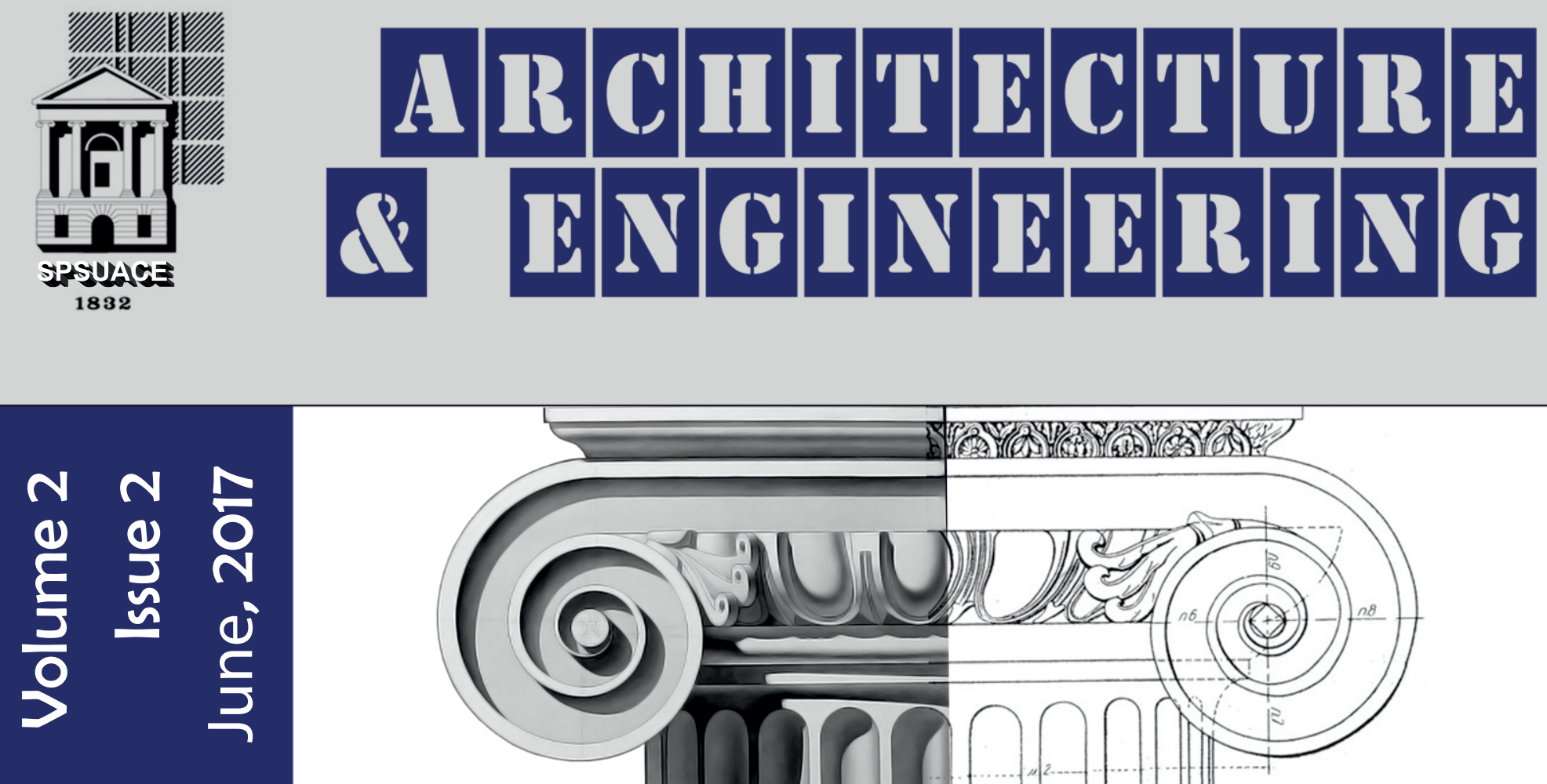

By Architects. For Architects. By Engineers. For Engineers.

Architecture Civil and Structural Engineering Mechanics of Materials Building and Construction Business and Management in Construction Urban Planning and Development Transportation Issues in Construction Geotechnical Engineering and Engineering Geology Designing, Operation and Service of Construction Cite Engines 


\section{Architecture}

and

Engineering

\section{Volume 2 Issue 2}

\section{Editorial Board:}

Prof. A. Akaev (Kyrgyzstan)

Prof. Emeritus D. Angelides (Greece)

Prof. A. Asaul (Russia)

Prof. S. Bertocci (Italy)

Prof. T. Dadayan (Armenia)

Prof. M. Demosthenous (Cyprus)

T. C. Devezas (Portugal) Associate Professor with Habilitation

Prof. J. Eberhardsteiner (Austria)

V. Edoyan (Armenia) Associate Professor

Prof. G. Esaulov (Russia)

Prof. S. Evtiukov (Russia)

Prof. A. Gale (UK)

Prof. G. Galstyan (Armenia)

Prof. Th. Hatzigogos (Greece)

Y. Iwasaki (Japan), Ph.D., Doctor of Engineering

Prof. Jilin Qi (China)

K. Katakalos (Greece) Dr. Engineering

Prof. N. Kazhar (Poland)

Prof. G. Kipiani (Georgia)

Prof. D. Kubečková (Czech Republic)

Prof. H. I. Ling (USA)

E. Loukogeorgaki (Greece) Assistant Professor

Prof. S. Mecca (Italy)

Prof. Menghong Wang (China)

S. A. Mitoulis (UK) Lecturer

Prof. V. Morozov (Russia)

Prof. A. Naniopoulos (Greece)

S. Parrinello (Italy) Architect, Associate Professor

Prof. P. Puma (Italy)

Prof. Qi Chengzhi (China)

Prof. J. Rajczyk (Poland)

Prof. M. Rajczyk (Poland)

Prof. Yu. Safaryan (Armenia)

Prof. S. Sementsov (Russia)

A. Sextos (Greece) Associate Professor

E. Shesterov (Russia) Associate Professor

Prof. A. Shkarovskiy (Poland)

Prof. E. Smirnov (Russia)

Prof. Emeritus T. Tanaka (Japan)

Prof. S. Tepnadze (Georgia)

M. Theofanous (UK) Lecturer

G. Thermou (Greece) Assistant Professor

Prof. R. Tskhevadze (Georgia)

Prof. L. Ungváry (Germany)

I. Wakai (Japan) Dr. Eng, Lecturer

Prof. A. Zhusupbekov (Kazakhstan)

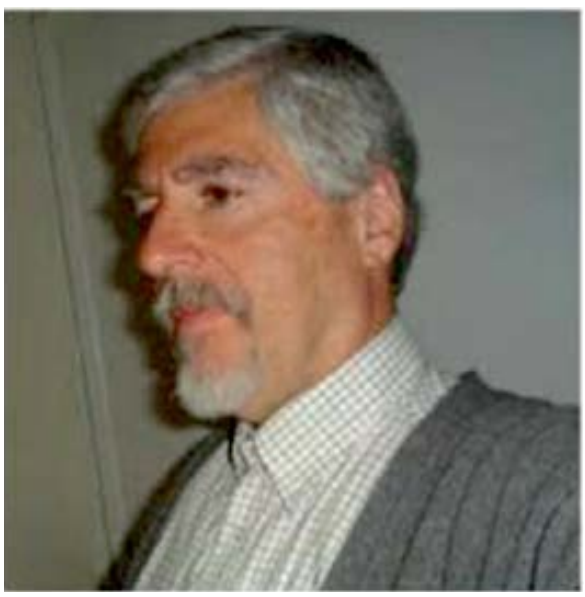

Editor in Chief:

Prof. Emeritus G. C. Manos (Greece)

Associate editor:

Viktoriya Rapgof (Russia) Executive Editor

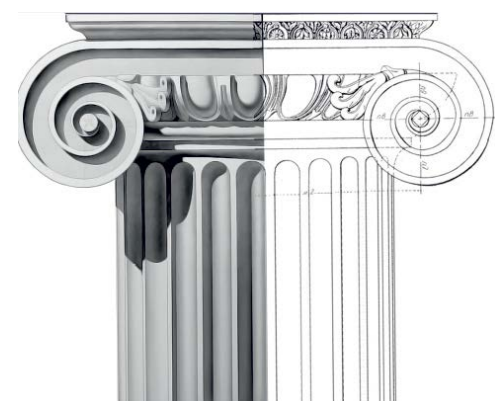




\section{CONTENTS}

\section{Aleksey Kharitonov}

Structural Approach for Numerical Internal Strain Modelling of Conglomerate Structures

Mikhail Kirsanov, Sergei Astahov

The mathematical model of dome covering industrial facility

Jurij Kotikov

Estimation of Transportation Energy Efficiency by Bartini Criterion L6T-4

Viktor Kuzmichev, Vladimir Verstov

Vessel mexers with vibration activator in construction engineering

\section{Sandro Parrinello, Francesca Picchio}

Databases and complexity. Remote use of the data in the virtual space of reliable 3D models

\section{Dmitrii Urazgildeev, Grigorii Belyi}

Stability calculation of rod elements of solid-wall arches by the flexuraltorsional form

\section{Antonina Yudina, Rafael Oganyan}

Technology of Winter Concreting of Monolithic Constructions with Application of Heating Cable 


\title{
STRUCTURAL APPROACH FOR NUMERICAL INTERNAL STRAIN MODELLING OF CONGLOMERATE STRUCTURES
}

\author{
Aleksey Kharitonov \\ Saint Petersburg State University of Architecture and Civil Engineering \\ Vtoraja Krasnoarmejskaja ul. 4, St. Petersburg, Russia \\ peepdv@mail.ru
}

\begin{abstract}
The paper defines the principles for structure-simulation modelling of conglomerate material properties by an example of cement compositions. The constitutive essence of the principles consists in generation of hierarchical models of individual structural levels (including a sub-microstructural level) based on material structure data. Parameters of properties, determined for models of the previous structural level, are used as input data of continuum environment, which forms a matrix element for models of the following level.

Detailed development of a general model for a composition makes it possible to correlate structural features at the level of a nanometer with material macro properties. Algorithms simulating physical and mechanical processes and phenomena, typical of cement systems individual properties (dry shrinkage, straining under load), are implemented based on the finite element method by determination of corresponding external and internal loads.

Application of the finite element method makes it possible to completely maintain geometrical and physical "reality" of the model describing specific features of the structure under study; and enables solutioning, with a high degree of confidence, of theoretical and practical issues related to determination of quantitative effect of structure discrete parameters on various material properties.
\end{abstract}

\section{Keywords}

Concrete, Dry Shrinkage, Simulation Modeling, Finite Element Method.

\section{Introduction}

It is known that properties of conglomerate materials are directly attributed to their structure. Meanwhile, upon development of materials exhibiting the required values for individual properties a situation may occur when structure parameter requirements are in conflict with other structure parameters. Thereby, a problem is originated concerning development of a system with required property values that correspond to a defined set of operating conditions.

Solving of the said problem is complicated with the fact that investigation of conglomerate system properties (e.g., concretes or soils) is mainly based on empirical approaches which are not always suitable for determination of quantitative relation between the discrete parameters of the structure and various properties of the material. Experiments, as a rule, provide an integral estimate of structure impact on the property under investigation.

The required relation expressed in mathematical terms could be obtained by computer simulation modeling which involves creation of composite structure simulation models (Bentz, 2011; Buffo-Lacarrière et al., 2007).

This publication is devoted to methodologies for cement conglomerate material properties forecasting and control on the basis of structure-simulation modeling which consists of presentation of the structure components distribution, mutual orientation and integration, as well as their combined action at different levels using numerical methods.

The research is carried out in accordance with research activities plan NIR No. 7.546.2011 "Development of fundamental basis and practical principles applicable to creation of engineering structures with improved serviceability and security" under government task (Reg. No. 01201257464).

\section{Background}

Analysis of the research results in the field of mathematical representation of composite material properties in conjunction with their structure allowed to select a main line for solving a problem of cement system properties forecasting. The solution involves generalization of known regularities in a form of numerical simulation models (Garbocz et al., 2000; Haecker et al., 2005; Jennings et al., 2007; Kharitonov, 2007; Kharitonov, 2008). The advantage of such models as compared with statistical and phenomenological concepts is in possible explicit consid- 
eration of structure parameters and simulation of physical nature of phenomena using numerical methods. The most advanced and proven method for solution of differential equations describing continuous medium behaviour is finite element method (FEM).

In order to implement the abovementioned line, it is required to develop a methodology for cement composition properties modeling based on presentation of material structure in a form of hierarchical model of individual structural levels that simulates physical and mechanical processes and phenomena (Sychev, Badin, 2016).

Two main approaches in development of computer model of cement system structures and investigation of properties based on such model can be pointed out at the present period:

- development of a kinetic simulation model for cement hydration and application of FEM based on this model in order to describe main properties attributed to material at individual time segments of structure formation;

- application of discrete structure models, the construction algorithm for which is based on stochastic filling of some volume with geometric features according to pre-determined distribution of their form, size and orientation. Further composite properties modeling is related to implementation of the effective medium theory or FEM.

Both given modeling lines consider cement grains as the smallest structure elements at best, without considering the cement gel. The mentioned disadvantage is attributable to attempts to simultaneously include structural inhomogeneities of wide-range size into the model, thus making calculations more complicated and roughening the results of material properties modeling.

The first approach obviously has great importance for understanding and practical application for modeling of physical and chemical processes of cement hydration. Currently, development of this approach is at the stage of concept implementation.

This article is concerned with investigations made in the view of the second approach related to creation of models based on data on hardened cement stone (within 28 days). Prior information is required for this purpose, pertaining compositional analysis, quantitative and geometry parameters of structure elements, as well as consideration of stochastic nature of their distribution within the material volume. At that, kinetic aspect of structure formation becomes insignificant, but mixed results of hydration process simulation are excluded.

\section{Methods}

For the purpose of this paper, modeling is based on two-dimensional presentation of structure components. But this approach also demands for the trade-off between the intent to represent component shapes, structure peculiarities and computer capabilities. Nevertheless, two-dimensional task allows to investigate internal stresses under various factors, with consideration of stochastic nature of structure components mutual location and their links.

At the first stage of such simulation, a nanostructural model of cement stone, corresponding to $\mathrm{C}-\mathrm{S}-\mathrm{H}$ phase, was developed. The model is based on the results of physical and chemical investigations of 28-days cement stone, with consideration of various technology factors (hardening conditions, water-cement ratio, additives availability). The following were considered as main parameters: total porosity and pore size-distribution. Porosity is determined as per the methods based on proton magnetic resonance (PMR), benzene desorption and mercury porosimetry.

Size-distribution of cement gel pores determined with PMR showed that, irrespective of technology factors, considerable volume of cement stone pore space is represented with pores with the radius of about $0.85 \mathrm{~nm}$.

The factors under investigation showed their influence over the volume of such pores by changing the degree of cement hydration. However, quality of $\mathrm{C}-\mathrm{S}-\mathrm{H}$ structure (concerning pore parameters) remains unchanged. Total volume of pores with the above stated size equals $18 \%$ of the cement stone volume on the average, and $65 \%$ of all pore volume.

Availability of pores with the radius of about $0.85 \mathrm{~nm}$ points out to the size of individual elements of gel structure, which is about $4-5 \mathrm{~nm}$. Similar results for the gel hard phase size evaluation are obtained with small angle neutron scattering (Leitea et al., 2004).

Investigation of cement stone porosity with benzene adsorption and mercury porosimetry methods allowed to determine large volume of pores with the radius of 3-5 nm. This fact, in its turn, proves a suggestion of agglomeration of gel individual elements: clusters of $40-50 \mathrm{~nm}$ provide for origination of pores with the stated radius; and this corresponds to experimental data (Pucharenko et al., 2013).

With regard to large-size pores $(5-10 \mathrm{~nm})$, no unambiguous conclusion could be made, but it is possible to name pore size ranges common for all investigated compositions: $7-10 \mathrm{~nm}, 12-16 \mathrm{~nm}, 21-26 \mathrm{~nm}, 41-44 \mathrm{~nm}, 70-73 \mathrm{~nm}$.

\section{Case history}

Modeling of properties, phenomena and processes typical for cement systems presents independent tasks. The reason for this is that algorithms describing appropriate properties and their mechanisms are implemented at the final stage of model development. For example, algorithms describing strength properties are completely different from those for shrinkage deformation.

The stage of creation of various structural level models is a common stage at modeling of any property. A source model is being created at this stage, which approximates elastic properties and links between individual components, as well as entire cement system.

At the first stage material structure levels are established and physical and mechanical parameters of individual level components are determined. Then, with consideration of applied mathematical tools and computer capabilities, geometry models of various scale are created for the structure with consideration of stochastic nature of structure components location.

The next stage of numerical model creation is implementation of FEM processes that allow to represent the model as an integrated system consisting of components 
with different physical and mathematical parameters (modulus of elasticity, Poisson ratio, etc.). General elasticity characteristics used as parameters of a continuous medium (matrix) for each subsequent scale approximation are determined for each model. Creation of a model of the largest scale is considered as completion of the first stage. Validity of structure level models is verified by comparison of design parameters with experimental results.

The second stage of modeling is associated with investigation of particular properties of cement systems under consideration, i.e. development of algorithms for material properties presentation, that are based on conventional theories and ideas. In the context of simulation modeling, these algorithms are related to determination of loads effective within models of different levels, evaluation of load effect results and initial modeling transformation, if required. An integrated response corresponding to the property under investigation is considered as a result.
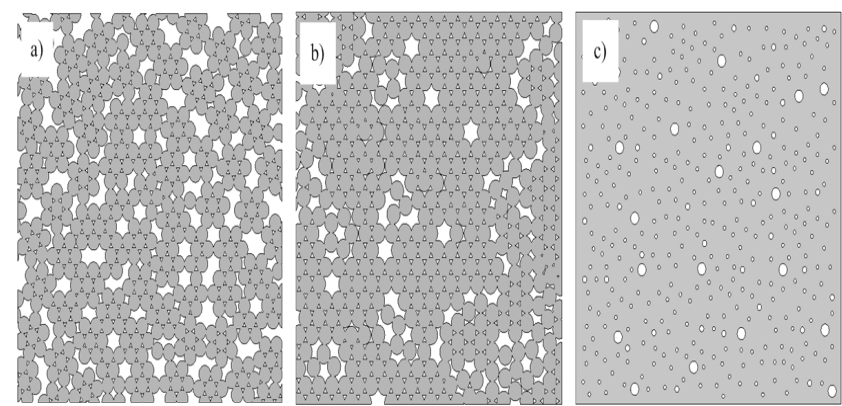

Figure 1. Geometry model of nanostructure. Model sizes a) $200 \times 200 \mathrm{~nm}$; b) $800 \times 800 \mathrm{~nm}$; c) $5 \times 5 \mu \mathrm{m}$

\section{Results}

We developed a flat three-level numerical model of cement stone nanostructure (the cement stone is of normal moist curing) (Figure 1).

The first level model gives an idea of gel as a system consisting of particles with diameter of 4.4 . $\mathrm{nm}$ and pores primarily having the radius of about $0.85 \mathrm{~nm}$ (Figure 1a).

This does not preclude laminated nature of individual particles interior, but this fact is not considered in calculation due to extremely small size of interlayer space.

The model of the second level structure (Figure 1b) represents a formation of aggregate individual particles with the diameter of $40 \mathrm{~nm}$. The model covers the pore size range of 5 to $30 \mathrm{~nm}$. Pores having the radius of 30 to $80 \mathrm{~nm}$ and distributed within the matrix are considered as elements of the third level (Figure 1c).

In order to obtain stochastic distribution of structure elements within created simulation models, we developed "PoreSolution" software which implements Monte Karlo method (Pucharenko, Morozov, 2013).

When creating a microstructure model, we considered portlandite, ettringite and also unhydrated clinker as the most important structural elements. Content of portlandite $(\sim 20 \%)$ and ettringite $(\sim 10 \%)$ within the cement stone
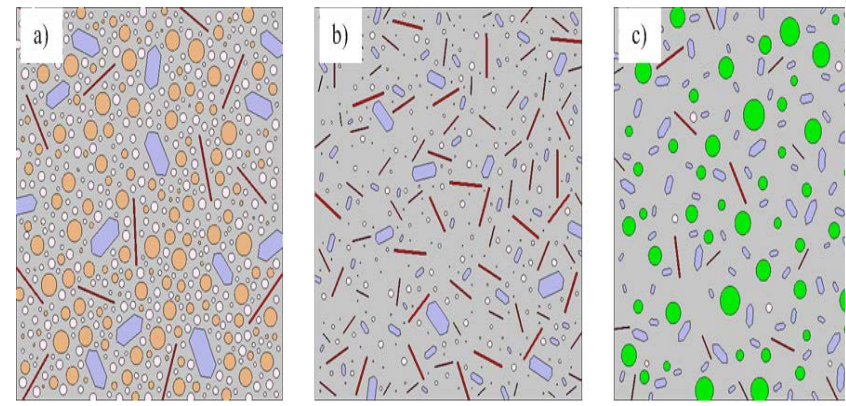

Figure 2. Cement stone microstructure model. Model sizes: a) $50 \times 50 \mu \mathrm{m}$; b) $100 \times 100 \mu \mathrm{m}$; c) $200 \times 200 \mu \mathrm{m}$

Needle-like elements - ettringite; hexagonal elements portlandite, circles - clinker and pores (white color)

under modeling was determined by quantitative X-ray phase and thermographic analysis.

Figure 2 shows the microstructure model of a cement stone (water-cement ratio $=0.28$ ), consisting of three different scale approximations.

The meso-level model (Figure 3) shows four phases: matrix (cement stone), sand grains, contact zone with the thickness of $20 \mu \mathrm{m}$ and pores.

Pores distribution within real concrete was determined stereometrically. Sand grain content equals $48 \%$, that is about 1:2.5 ratio of cement and sand weight in concrete.
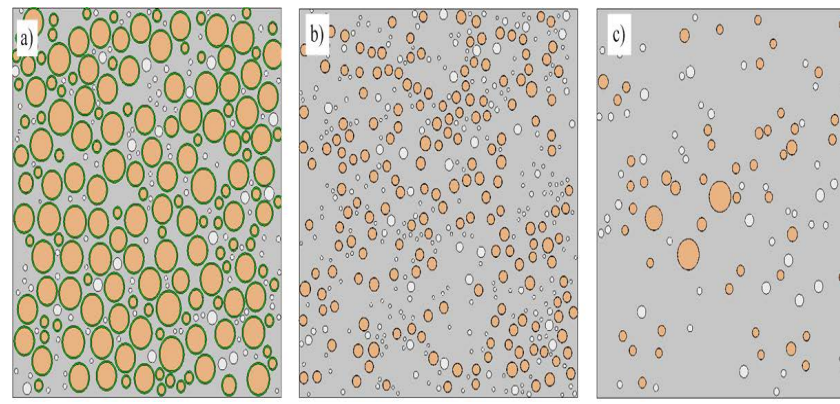

Figure 3. Concrete meso-level model. Model sizes: a) $5 \times 5 \mathrm{~mm}$; b) $25 \times 25 \mathrm{~mm}$; c) $50 \times 50 \mathrm{~mm}$

One of the stages of design model creation at each scale was implementation of FEM algorithm. When assigning elastic properties for a model, it was taken into account that physical properties of the next level matrix would inherit properties of the entire previous level system.

Table 1 gives designed properties for model discrete levels.

Modulus of elasticity $(E)$ and Poisson ratio $(\mu)$ are taken on the basis of the following data (Pukharenko, Aubakirova, 2016) and equal to: for C-S-H elements, $\mathrm{E}=84.5 \mathrm{GPa}, \mu=0.45$; for portlandite, $\mathrm{E}=42.3 \mathrm{GPa}, \mu$ $=0.324$; for ettringite, $E=25.0 \mathrm{GPa}, \mu=0.25$; for clinker, $E=117.6 \mathrm{GPa}, \mu=0.314$; for sand, $\mathrm{E}=72.8 \mathrm{GPa}, \mu=0.167$.

We formulated calculation methods for modeling of dry shrinkage behavior. This behavior is based on thermodynamic equilibrium between the system and medium; also capillary pressure and change in free surface energy are taken into account (Shahsavari, 2011). The calculation method involves determination 
of water-filled pore radius and capillary pressure in such pores under appropriate relative humidity. Capillary pressure acts as a load applied to finite elements along pore surfaces. Then change in surface energy and appropriate deformations due to this energy are calculated. Obtained deformation values are set in the matrix of the structure model. In addition to deformations at each designed humidity level, determined for a discrete model, model deformations of the previous level are added.

Table 1. Physic and mechanical properties of discrete models

\begin{tabular}{|c|c|c|c|c|c|}
\hline \multicolumn{2}{|c|}{ Model Scale } & \multicolumn{2}{|c|}{ Porosity, \% } & \multirow{2}{*}{$\begin{array}{c}\text { Modulus of } \\
\text { Elasticity, } \\
\text { GPa }\end{array}$} & \multirow{2}{*}{$\begin{array}{c}\text { Poisson } \\
\text { Ratio }\end{array}$} \\
\hline & & General & Model & & \\
\hline \multirow[t]{3}{*}{ nano- } & $\mathrm{a}$ & 24.0 & 24.0 & 35.1 & 0.38 \\
\hline & $\mathrm{b}$ & 36.0 & 15.8 & 15.0 & 0.30 \\
\hline & $\mathrm{c}$ & 39.2 & 5.0 & 13.1 & 0.29 \\
\hline \multirow[t]{3}{*}{ micro- } & $a$ & 34.4 & 1.5 & 14.2 & 0.29 \\
\hline & $\mathrm{b}$ & 30.9 & 0 & 15.4 & 0.29 \\
\hline & $\mathrm{c}$ & 26.7 & 0 & 17.3 & 0.29 \\
\hline \multirow[t]{3}{*}{ meso- } & $a$ & 18.0 & 3.4 & 21.3 & 0.28 \\
\hline & $\mathrm{b}$ & 19.4 & 4.4 & 22.0 & 0.27 \\
\hline & $c$ & 20.3 & 2.4 & 21.1 & 0.27 \\
\hline
\end{tabular}

\section{Conclusion}

Comparison of design and experimental data on shrinkage dependence from relative humidity (Figure 4) proves validity of the suggested cement stone model and shrinkage calculation algorithm.

The design shrinkage values also correspond to the results obtained by other authors (Smirnova, 2012; Sychev, Badin, 2016; Tennis, Jennings, 2000; Wittmann, 1984).

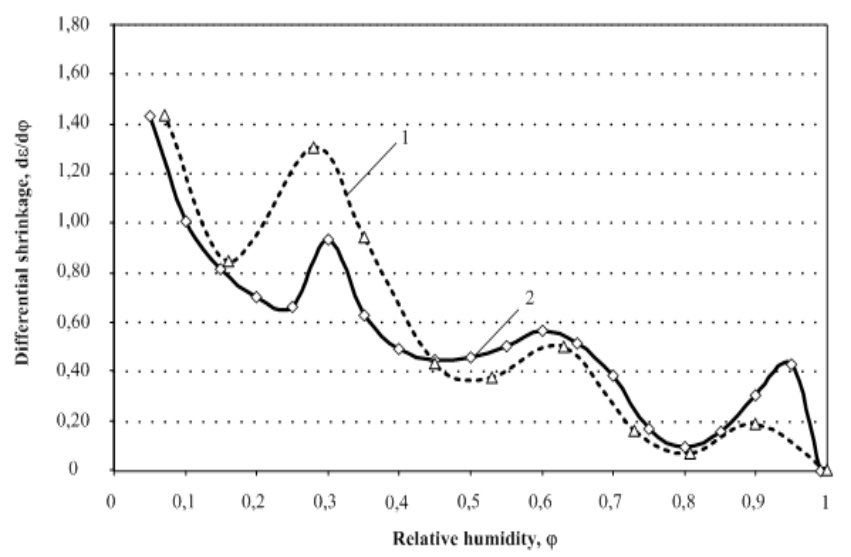

Figure 4. Differential shrinkage. 1 - experimental work; 2 - calculation
The developed two-dimensional models of concrete structure which explicitly include structural elements at different scales of $25 \mathrm{~nm}$ to $5 \mathrm{~mm}$ describe real material properties.

The advantage of the suggested modeling method is in possible quantitative evaluation of material properties with consideration of close relation between different structure levels - from nanometer to millimeter. This approach allows to investigate the degree of effect of various structure-determining factors on material properties that are of investigator's interest.

The algorithm of dry shrinkage behaviour modeling, which considers capillary pressure and deformations attributed to change in free surface energy depending from environmental relative humidity, shows a real situation with own concrete deformations in view of comparison of modeling results with experimental determination results for dry shrinkage. 


\section{References}

Bentz, D.P. (2011). Critical Observations for the Evaluation of Cement Hydration Models. International Journal of Advances in Engineering Sciences and Applied Mathematics, 2(3), pp.75-82.

Buffo-Lacarrière, L., Sellier, A., Escadeillas, G., Turatsinze, A. (2007). Multiphasic finite element modeling of concrete hydration. Cement and Concrete Research, 7, pp.131-138. DOI: 10.1016/j.cemconres.2006.11.010

Garbocz,i E.J., Bentz, D.P., Frohnsdorff, G.J. (2000). The Past, Present, and Future of the Computational Materials Science of Concrete. In: Proceedings of the Center for Advanced-Cement-Based Materials (ACBM).

Haecker, C.-J. et al. (2005). Modeling the linear elastic properties of Portland cement paste. Cement and Concrete Research, 35, 1948-1960. DOI: 10.1016/j.cemconres.2005.05.001

Jennings, H.M. et al. (2007). A multi-technique investigation of the nanoporosity of cement paste. Cement and Concrete Research, 37, pp.329-336. DOI: 10.1016/j.cemconres.2006.03.021

Kharitonov, A. (2007). Nanostructured model cement stone. Popular concrete, 16, pp.23-25.

Kharitonov, A. (2008). Modeling of cement stone structure at the nanoscale processes and shrinkage "PoreSolution". Saint Petersburg.

Kharitonov, A., Komokhov, P. (2009). The influences of internal and external factors on a dry shrinkage of cement systems. Academia. Architecture and Construction, 2, pp.77-80.

Leitea, J.P.B., Slowik, V., Mihashi, H. (2004). Computer simulation of fracture processes of concrete using mesolevel models of lattice structures. Cement and Concrete Research, 34, pp.1025-1033.

Pucharenko, Y., Chrevko, S., Suvorov, I. (2013). Influence of composition on shrinkage of Fiber - foam Concrete. Bulletin of Civil Engineers, 41, pp.109-112.

Pucharenko, Y., Morozov, V. (2013). A Structural Model and Strength Predicting of Fiber-Reinforced Concrete. Word Applied Sciences Journal, 23, pp.111-116.

Pukharenko, Yu., Aubakirova, I. (2016). Structural Features of Nanomodified Cement Stone. Architecture and Engineering, 1(1), pp.66-70. DOI: 10.23968/2500-0055-2016-1-1-66-70

Shahsavari, R. (2011). Hierarchical modeling of structure and mechanics of cement hydrate. Massachusetts: Massachusetts Institute of Technology.

Smirnova, O. (2012). Dependence of the strength of concrete with polycarboxylate-based additives on the properties of Portland after low-temperature thermal-curing. Proceedings of the universities - Civil Engineering, 9, pp.20-27.

Sychev, S., Badin, G. (2016). An interactive construction project for method of statement based on BIM technologies for highspeed modular building. Architecture and Engineering, 1(4), pp.36-41. DOI: 10.23968/2500-0055-2016-1-4-36-41

Tennis, P.D., Jennings, P.D. (2000). A model for two types of calcium silicate hydrate in the microstructure of Portland cement pastes. Cement and Concrete Research, 30, pp.855-863.

Wittmann, F.H., Roelfstra, P.E., Sadouki, H. (1984). Simulation and analysis of composite structures. Material Science Engineering, 68, pp.239-248. 


\title{
THE MATHEMATICAL MODEL OF DOME COVERING INDUSTRIAL FACILITY
}

\author{
Mikhail Kirsanov', Sergei Astahov² \\ 1,2 Moscow Power Engineering Institute (National Research University) \\ 14 Krasnokazarmennya str., Moscow, Russia
}

c216@ya.ru'

\begin{abstract}
A statically determinate flat truss models the industrial facility's arch. To derive dependence of structural deflection on the number of panels in a span, the Maxwell-Mohr equation, computer mathematics system Maple and the induction method are applied. Forces in the rods are determined by the method of cutting nodes. Several cases of loading are considered: uniformly distributed along the top and bottom chords, uniformly distributed along the lateral surface, and by concentrated force. For analytical assessment of the structural strength, equations for forces in the most compressed and tensioned rods and equation for support displacement are derived. Asymptotics of the solution for the number of panels at the fixed span length, and total load is found.
\end{abstract}

\section{Keywords}

Truss, deflection, induction, exact solution, Maple.

\section{Introduction}

The calculation of framed structures with a large number of elements is usually made in specialized packages based on finite elements method. Without prejudice to the role of numerical calculations (Samofalov, Ziukas, 2015) we shall note that recently, with development of computer mathematics methods (Maple, Mathematica, Maxima, etc.), a real possibility to perform analytical calculations with compact resulting equations for forces in critical (the most compressed or tensioned) rods, deflection and support displacement (Kirsanov, 2012) has appeared. Solutions for regular periodic structures, for which a natural parameter being equal, for example, to the number of periodicity cells can be introduced into the solution as well, are the most effective. The induction method is also efficient in case if the system has two independent periodicity parameters. An example of a solution for such problem is presented below. Without considerable changes, the algorithm can be also implemented in other computer mathematics systems.

\section{Subject, tasks and method}

A truss in Figure 1 represents a model of the industrial facility's roof arch. Parameter $n$ defines the number of panels in a truss half-span, parameter $m$ defines the number of panels along the vertical of supporting elements. A symmetric structure consists of two trusses-posts and a collar-beam truss. Horizontal and vertical dimensions of panels forming these parts are accepted as identical. On the one hand, this is determined by unification of elements facilitating installation, transportation and production. On the other hand, the calculation is simplified considerably. In any case, the obtained equation will be intended for estimate but rather accurate characterization of a structure. The accuracy of the analytic equations obtained by the induction method (llin, Kirsanov, 2016; Kirsanov, 2016b; Ponamareva, 2016) particularly manifests itself for structures with a large number of elements where numerical methods (with the solution of a linear equation system as their integral part) have a tendency to accumulate roundoff errors.

The calculation is performed for several types of loading. The truss contains $k=8(n+m+1)$ rods including three support ones. Forces in the rods are calculated according to the program (Kirsanov, 2012). The input of the data in the program begins with assignment of hinge coordinates (Figure 2). Let us give a program fragment in Maple language as an example. The coordinates of nodes in regular (periodic) systems are assigned in cycles. This simplifies the data input:

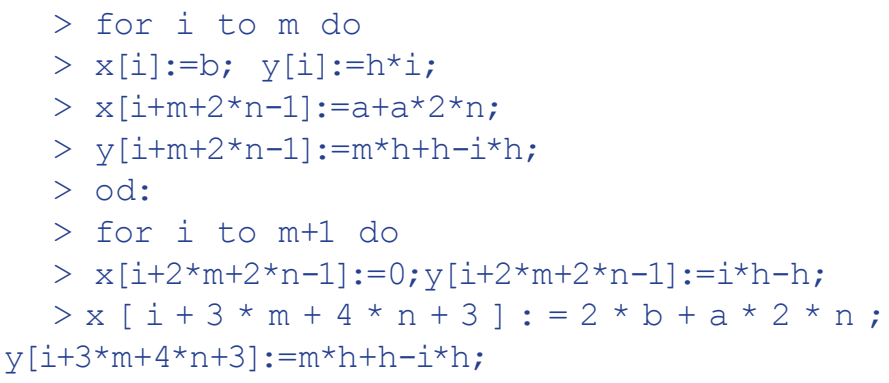



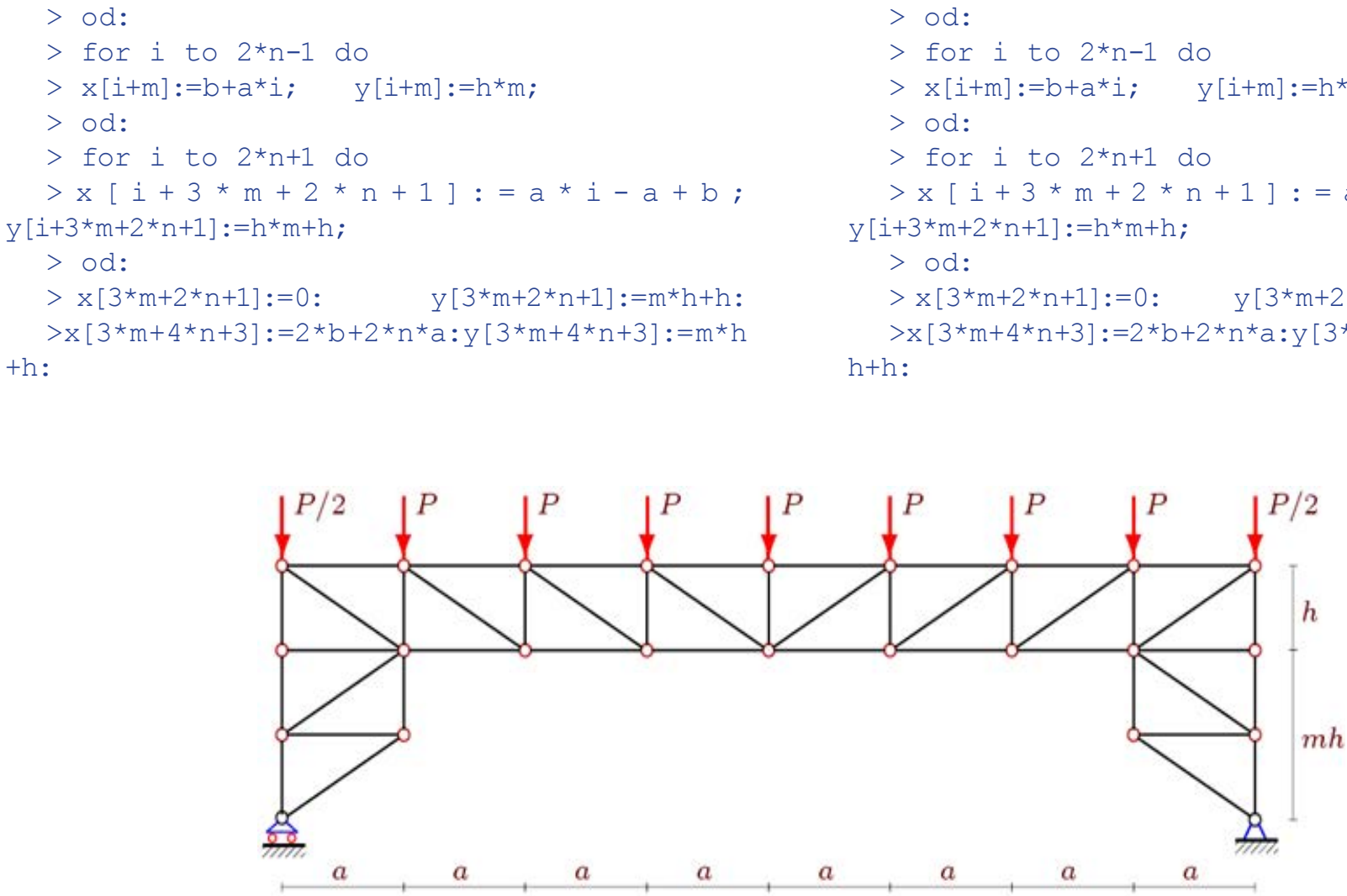

Figure 1. Truss at $n=3, m=2$. Loading along the top chord

The truss lattice is determined by the same principle as the graph structure in discrete mathematics, i.e. by assignment of special vectors containing numbers of rod ends. On the inner sides of supporting elements and the bottom chord (Figure 2), the rods are presented by vectors:

for $i$ to $2{ }^{*} n+2 * m-2$ do $N[i]:=[i, i+1] ; \circ d:$

These vectors are not connected with the values and signs of forces in the corresponding rods. Moreover, they are insensitive to the choice of the conventional end and beginning of a rod. The numbering of the rods is conducted originally by the inner support posts and the bottom chord of the collar beam, and then by the outer posts and the top chord. Then, posts and diagonal members of the truss are numbered. $G$ matrix of the equilibrium equation system contains direction cosines of forces, which are calculated by coordinates of nodes.

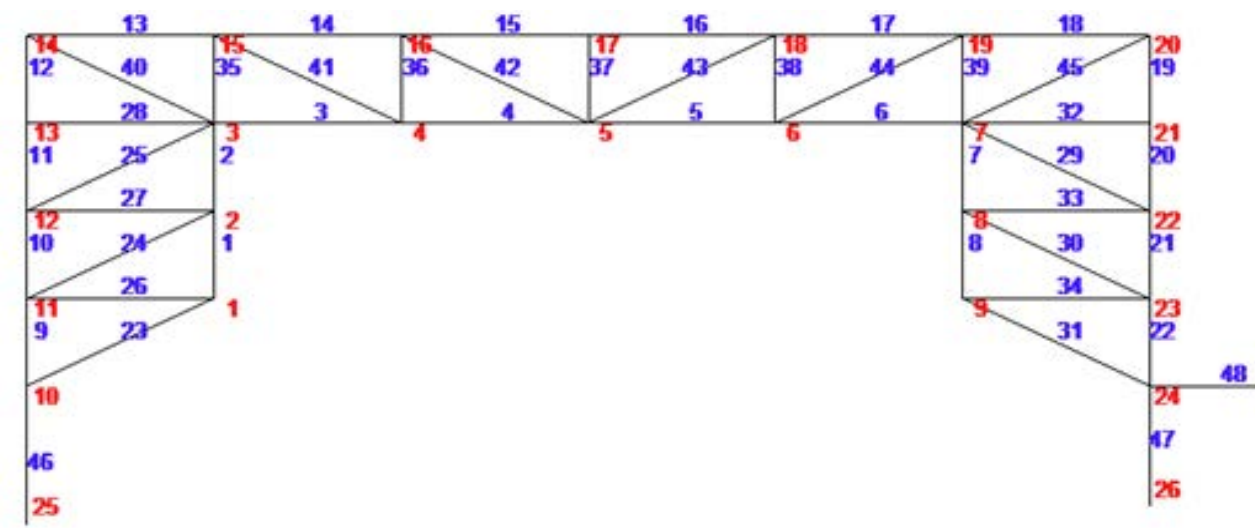

Figure 2. Numbering of nodes $n=2, m=3$ 
Direction cosines with $x$ axis are written in odd lines of $G$ matrix with a size of $k \times k$, and direction cosines with $y$ axis are written in even lines:

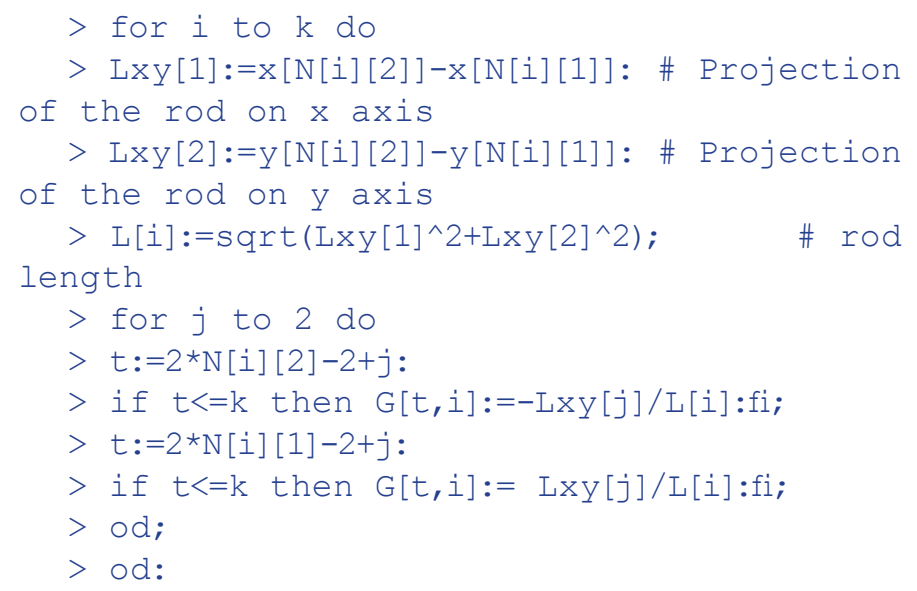

Conditional operator if $t<=k$ then warns the program against going out of $G$ matrix.

The right member of the equilibrium equation system

$\mathbf{G} \bar{S}=\bar{B}$ represents a vector in odd elements of which horizontal loads are entered, and in even elements of which vertical loads are entered. In this case, two such vectors denoted in the program as $\mathrm{Bp}$ and $\mathrm{B} 1$ are required. The first one contains information on the applied uniform load along the top chord:

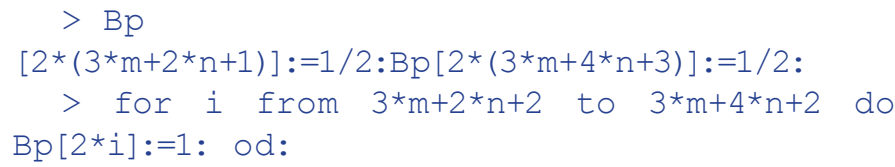

the second one contains a unit vertical force applied to the middle node (number $m+n$ ) of the bottom chord in which deflection is measured:

$>\quad B 1[2 *(m+n)]:=1:$

\section{Solution. Loading along the top chord}

Maple system provides a solution in a symbolic form by the method of inverse matrix. The matrix can be found as in elementary algebra - 1/G. The found forces are used in the Maxwell-Mohr equation:

$$
\Delta=\sum_{i=1}^{k-3} S_{i} S_{i} l_{i} /(E F)
$$

where $S_{i}$ - forces in the truss rods due to action of the distributed load, $s_{i}$ - forces due to the unit vertical load in the middle node of the bottom chord, $l_{i}$ - lengths of the rods, $E-$ modulus of elasticity, $F-$ section area of the rods. The sum does not include three support rods which are accepted as rigid. The general form of the equation for deflection of trusses with the different number of panels differs only in values of coefficients:

$$
E F \Delta=P \frac{A a^{3}+C c^{3}+D h^{3}}{2 h^{2}}
$$

where $c=\sqrt{a^{2}+h^{2}}$. The following equations for coefficients are obtained by the induction method:

$$
\begin{aligned}
& A=\frac{5 n^{4}+20 n^{3}+31 n^{2}+22 n+6}{6} \\
& D=2 m+n^{2}+n(2 m+3)+1 \\
& C=(n+1)^{2}
\end{aligned}
$$

The induction algorithm for two parameters consists of two parts. At first, at fixed $m=1$, a sequence of solutions and corresponding coefficients at powers (cubes) of sizes for trusses with the number of panels $n=1,2,3 \ldots$ is obtained. At this stage, general terms of these sequences are derived. The rgf findrecur operator of genfunc package of Maple system is applied. The following recurrence quintic equation is obtained for $A$ coefficient:

$$
A_{n}=5 A_{n-1}-10 A_{n-2}+10 A_{n-3}-5 A_{n-4}+A_{n-5}
$$

The rsolve operator provides a solution of this equation. The equations for coefficients $C$ and $D$ have a similar form. It is necessary to execute generalization by $m$ in the second part of the algorithm. For this purpose, $m=2$ is accepted and the first part of the algorithm with induction by $n$ is repeated.

This shall proceed until the regularity of coefficients reveals itself. It becomes apparent at once that coefficients $A$ and $C$ do not depend on the height of lateral supporting trusses determined by $\mathrm{m}$ parameter. As a result, double induction relates only to $D$ coefficient in which, in case of change in $\mathrm{m}$, only two summands change. Here, for determination of their type, the powerful tool of induction operators from genfunc package is not required.

Figure 3 shows the change in deflection depending on the truss dimensions and the number of panels $n$.

Curves of dimensionless deflection $\Delta^{\prime}=\Delta E F /\left(P_{s} L\right)$ are constructed at the fixed span length $L=2 a(n+1)=40$ and $H=(m+1) h=10$, and constant total load $P_{s}=2 P(n+1)$.

With increase in the number of panels (with regard to this statement), deflection slowly decreases. The dependence on $m$ is almost linear.

The run of the curves points to the existence of asymptotes. Indeed, the limit:

$$
\lim _{n \rightarrow \infty} \Delta^{\prime} / n=H /(2(m+1) L)
$$




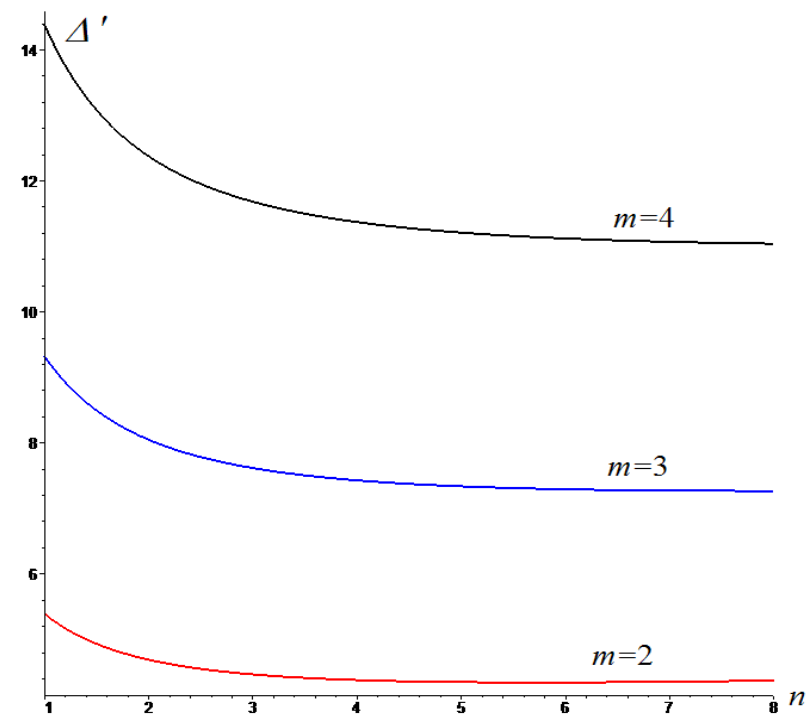

Figure 3. Dependence of deflection on $n$

The limit shows that the asymptote inclination angle depends on the truss dimensions and the number of panels by height.

With increase in the number of panels along the height (with constant total height), deflection increases as well. Obviously, it is caused, first of all, by inclination of supporting elements. Similarly, the limit by $m$ at constant $n$ has the following value:

$$
\lim _{m \rightarrow \infty} \frac{\Delta^{\prime}}{m^{2}}=\frac{L^{2}\left(12+10 n+5 n^{2}\right)}{192 H^{2}(n+1)^{2}}
$$

There is no rectilinear asymptote and the dependence tends to a quadratic one by $m$.

Forces in critical (the most compressed $S_{3 m+3 n}$ and the most tensioned $S_{m+n-1}$ rods in the middle of the top and bottom chords, respectively, Figure 2) are also determined by induction. As expected, these forces do not depend on the number of panels along the structure height:

$$
S_{3 m+3 n}=-P(n+1)^{2} a /(2 h), S_{m+n-1}=P n(n+1) a /(2 h)
$$

\section{Loading along the bottom chord}

The linear property of the problem with regard to loads allows combining solutions obtained for various types of loading. Let us consider loading (by uniform load) of the bottom chord of the truss collar-beam (Figure 4). Using the set of equations which has been already derived, and having changed only its right member:

\footnotetext{
$>$ for $i$ from $m+1$ to $m+2{ }^{*} n-1$ do $n p:=i$;
} $\mathrm{Bp}\left[2{ }^{*} \mathrm{np}\right]:=1:$ od: , we will derive an equation for truss deflection. The result scarcely differs from (1) for loading along the top chord and is as follows:

$E F \Delta=P \frac{A a^{3}+C c^{3}+D h^{3}}{4 h^{2}}$

where coefficients are also obtained by double induction by $n$ and $m$ :

$$
\begin{aligned}
& A=\frac{5 n^{4}+20 n^{3}+19 n^{2}-2 n-6}{3} \\
& C=2\left(n^{2}+2 n-1\right) \\
& D=(2 m+1)(2 n-1)+2 n^{2}
\end{aligned}
$$

Limit properties by $n$ at $P_{s}=P(2 n-1)$ and previous conditions for span length $L$ and height $H$ coincide with (2) completely. The limit by the number of panels $m$ in a vertical direction is as follows:

$$
\lim _{m \rightarrow \infty} \frac{\Delta^{\prime}}{m^{2}}=\frac{L^{2}\left(5 n^{4}+20 n^{3}+25 n^{2}+10 n-12\right)}{96 H^{2}(n+1)^{3}(2 n-1)}
$$

\section{Loading in the midspan}

Reaction to the concentrated force in the midspan is the simplest test for structure deformability. The solution of this problem considerably expands the field of application of derived solutions (1) and (3) due to their linear combination. At the same time, the solution of the problem of the concentrated force represents loading of the structure with payload (crane equipment, machines, etc.). The Maxwell-Mohr equation is simplified in this case: 


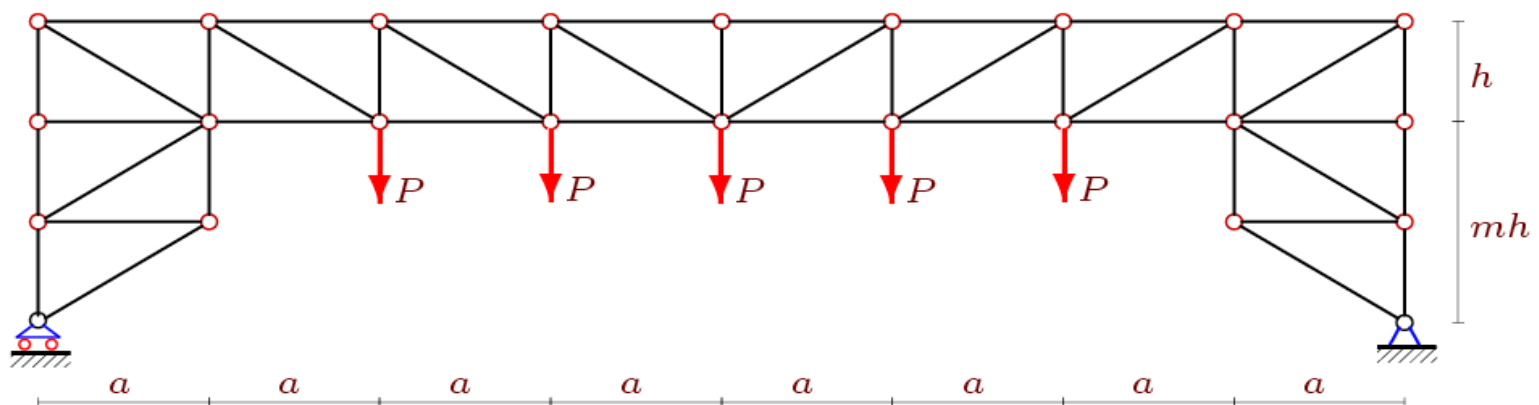

Figure 4. Loading along the bottom chord

$\Delta=P \sum_{i=1}^{k-3} s_{i}{ }^{2} l_{i} /(E F)$

where, as before, $S_{i}-$ forces in rod $i=1 . . . k$ due to action of the unit vertical load in the middle node of the bottom chord. Thus, vertical displacement of the point of load application in the midspan is calculated. The solution form coincides with (3). At the same time, coefficients are as follows:

$$
\begin{aligned}
& A=\frac{2\left(2 n^{3}+6 n^{2}+7 n+3\right)}{3} \\
& C=2(n+1) \\
& D=2(m+n)+1
\end{aligned}
$$

Limit asymptotic properties for dimensionless deflection $\Delta^{\prime}=\Delta E F /(P L)$ by the number of panels $n$ are characterized by the following values of limits:

$$
\begin{aligned}
& \lim _{n \rightarrow \infty} \Delta^{\prime} / n=H /((m+1) L) \\
& \lim _{m \rightarrow \infty} \frac{\Delta^{\prime}}{m^{2}}=\frac{L^{2}\left(3+2 n+n^{2}\right)}{24 H^{2}(n+1)^{2}}
\end{aligned}
$$

\section{Lateral load}

Influence of the lateral load (for example, wind) on deformations is insignificant for structures of low height (where $m$ is small). However, if the structure height is comparable or larger than the horizontal dimension, the total horizontal load can make a noticeable contribution to the values of the structure deformations. Based on the developed mathematical model, we can easily derive an equation for horizontal displacement of the top point of the collar-beam (point with number $3 m+2 n+1$, Figure 2) in case of uniform load over the whole lateral surface of the truss (Figure 5). As before, the load is applied to the truss nodes. The vector of the right member has the following program code:

$$
>\text { for } i \text { from } 2{ }^{*} m+2{ }^{*} n \text { to } 3{ }^{*} m+2{ }^{*} n+1 \text { do } n p:=i \text {; }
$$
$\mathrm{Bp}[2 * \mathrm{np}-1]:=1:$ od:
Let us carry out induction in a reverse order, i.e. at first by $m$, and then by $n$. We can note that the general form of the equation for deflection will be the following:

$E F \Delta=P \frac{A a^{3}+C c^{3}+D h^{3}}{4 a^{2}(n+1)^{2}}$

Accepting $n=1$ and carrying out induction by $m$, we obtain the following equation for the coefficient at $a^{3}$ :

$A_{1}=38 m^{3}+88 m^{2}+30 m+12$.

Similarly, we obtain coefficients at $n=2,3 \ldots 8$ :

$$
\begin{aligned}
& A_{2}=145 m^{3}+346 m^{2}+167 m+110, \\
& A_{3}=364 m^{3}+880 m^{2}+476 m+344, \\
& \ldots ., \\
& A_{8}=4539 m^{3}+11190 m^{2}+6981 m+5514 .
\end{aligned}
$$

Eight steps turned out to be sufficient to reveal the regularity in development of these equations. Analyzing the coefficients at powers $m$ with induction by $n$ by means of the operators of genfunc package, which were already mentioned above, we obtain the final equation after simplification (auxiliary index corresponding to $n$ is omitted): 9)) $/ 3$

$$
A=\left(( n + 1 ) ( m + 2 ) \left(m^{2}\left(20 n^{2}+28 n+9\right)+10 m n^{2}+8 m n+14 n^{2}+4 n-\right.\right.
$$

Similarly, we obtain other equations for coefficients in (4) by double induction:

$$
\begin{aligned}
& \left.C=(n+1)(m+1) m^{2}(4 n+3)+8 m n+6 m+2\right), \\
& D=\left((m+2)(m+1)\left(m^{2}\left(15+16 n^{2}+25 n\right)-2 m+8 m n^{2}+3 m n-3\right)\right) / 6
\end{aligned}
$$

Let us find the limit properties of dimensionless deflection (by the number of panels) $\Delta^{\prime}=\Delta E F /\left(P_{s} L\right)$, where $P_{s}=(m+1) P$. We have the following values of limits:

$$
\lim _{n \rightarrow \infty} \frac{\Delta^{\prime}}{n^{2}}=\frac{8 m(m+2)^{2} H^{3}}{3(m+1)^{3} L^{3}}
$$


$\lim _{m \rightarrow \infty} \frac{\Delta^{\prime}}{m^{2}}=\frac{9+20 n+10 n^{2}}{12(n+1)^{2}}$

\section{Horizontal displacement of support}

Motion freedom of the truss support is another important characteristic of truss deformability. It is obvious that this value is small for a simple girder truss with parallel chords. Support displacement can be considerable for arch trusses and trusses of the considered type due to the height of lateral supporting trusses (trusses-posts). To control the behavior of the structure during its operation, it is preferable to know this value and its dependence on the truss dimensions and load.

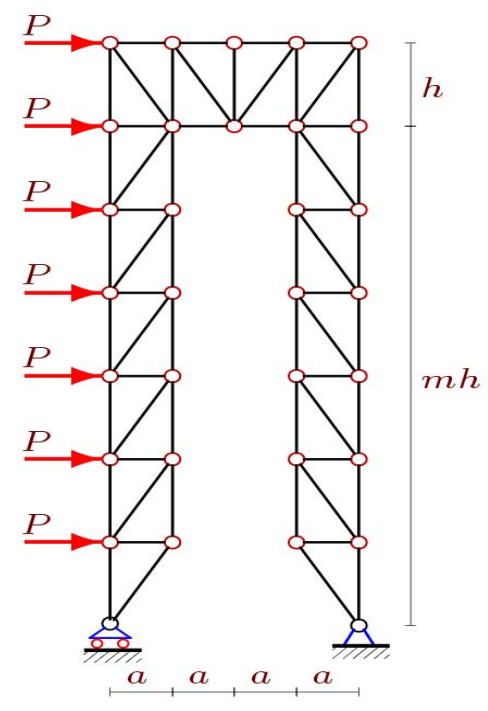

Figure 5. Lateral load, $n=1, m=6$

Let us consider a case of loading of the top chord (Figure 1). Let us apply the Maxwell-Mohr equation to deter- mine the displacement value for a movable support, where $S_{i}$ are forces in the rods due to action of the unit horizontal load applied to the left support. The equation will be as follows:

$E F \Delta=P \frac{A a^{3}+C c^{3}+D h^{3}}{a h}$

with coefficients

$$
\begin{aligned}
& A=m+\frac{n(22 m+5)}{6}+\frac{n^{2}(8 m+3)}{2}+\frac{n^{3}(4 m+2)}{3} \\
& C=m(2 n+1) \\
& D=\left(m^{2}+3 m-1\right)(n+1)
\end{aligned}
$$

Here, double induction turned out to be more complex. All three coefficients depend on $\mathrm{m}$ parameter. At the same time, the coefficient has quadratic dependence on $m$, and coefficients $A$ and $C$ have linear dependence.

\section{Conclusion}

Equations for truss deflection and support displacement at various loads have been derived by induction method using Maple system. These solutions and their combinations can be used for assessment of accuracy and reliability of the numerical results obtained in specialized packages of structural mechanics (Samofalov, Ziukas, 2015). Compact analytical solutions by induction method on the basis of the program (Kirsanov, 2012) were obtained in (Ilin, Kirsanov, 2016; Kirsanov, 2016a; Kirsanov, 2016b; Ponamareva, 2016; Dong, Kirsanov, 2016; Voropai, Kazmiruk, 2016; Voropai, 2016; Shipaeva, 2016; Bolotina, 2016). The comparative review of some analytical solutions is given in (Tinkov, 2015). 


\section{Architecture and Engineering Volume 2 Issue 2}

\section{References}

Bolotina, T.D. (2016). The deflection of the flat arch truss with a triangular lattice depending on the number of panels. Bulletin of Scientific Conferences, 4-3(8), pp.7-8. DOI: 10.17117/cn.2016.04.03

Dong, X., Kirsanov, M.N. (2016). The dependence of the deflection of the truss from the position of the load for an arbitrary number of panels. Bulletin of Scientific Conferences, 1-4 (5), pp. 6-7. DOI: 10.17117/cn.2016.01.04

Ilin, I.A, Kirsanov, M.N. (2016). The deflection and displacement of the bearings of the truss with rhombic lattice. Science Almanac, 12-2(26), pp.216-219. DOI: 10.17117/na.2016.12.02.216

Kirsanov, M.N. (2012). Maple i Maplet. Reshenie zadach mekhaniki [Maple and Maplet. Solving mechanics problems]. Saint-Petersburg: Publishing House "Lan". (in Russian)

Kirsanov, M.N. (2016a). Analysis of the buckling of spatial truss with cross lattice. Magazine of Civil Engineering, 4, pp.52-58. DOI: $10.5862 / \mathrm{MCE} .64$

Kirsanov, M.N. (2016b). An inductive method of calculation of the deflection of the truss regular type. Architecture and Engineering, 1(3), pp. 14-17. DOI: 10.23968/2500-0055-2016-1-3-14-17

Ponamareva, M.A. (2016). The displacement of the support trusses with parallel belts under uniform load. Science Almanac, 4-3(18), pp. 257-259. DOI I: 10.17117/na.2016.04.03.257

Samofalov, M., Ziukas, A. (2015). Investigation of mechanical state of spatial roof from steel trusses on asymmetric building. Mechanics, 21(1), pp.11-18. DOI: 10.5755/j01.mech.21.1.10129

Shipaeva, A.S. (2016). Calculation of the deflection of girder beam loaded on the bottom flange in the system Maple. Science Almanac, 5-3(19), pp. 236-239. DOI: 10.17117/na.2016.05.03.236

Tinkov, D.V (2015). Comparative analysis of analytical solutions to the problem of truss structure deflection. Magazine of Civil Engineering, 5(57), pp. 66-73. DOI: 10.5862/MCE.57.6

Voropai, R.A. (2016). Analysis of the deflection of the regular truss with cross type lattice. Science Almanac, 4-3(18), pp.238240. DOI: 10.17117/na.2016.04.03.238

Voropai, R.A., Kazmiruk, I.Yu. (2016). Analytical study of the horizontal stiffness of the flat statically determinate arch truss. Bulletin of Scientific Conferences, 2-1(6), pp.10-12. DOI: 10.17117/cn.2016.02.01 


\title{
ESTIMATION OF TRANSPORTATION ENERGY EFFICIENCY BY BARTINI CRITERION L6T-4
}

\author{
Jurij Kotikov \\ Saint Petersburg State University of Architecture and Civil Engineering \\ Vtoraja Krasnoarmejskaja ul. 4, St. Petersburg, Russia \\ cotikov@mail.ru
}

\begin{abstract}
The review of performance and energy effectiveness of transportations reveals the lack of the squared delivery speed in their structure. The need to attract the squared speed as the major factor in forming the assessment of the energy intensity of the object motion and the medium resistance is noted. The author's approach to forming assessments of the transport energy intensity based on the use of Bartini's LT-systematization and the entity of Transfer with the measurement unit of Tran is considered. The energy effectiveness factor of cargo movement is represented in the form of the ratio between the inevitable dissipation of the cargo movement energy and costs of the energy supply of transportation, incurred by the automotive transport system.

As an example, the calculation of the transportation by KamAZ-5320 automotive vehicle is carried out. The value of the energy effectiveness of transportation with the speed of $60 \mathrm{~km} / \mathrm{h}$, calculated with the use of Transfer, amounted to $\eta=11.6 \%$. This allowed assessing the technological paradigm of the modern automotive transport as very far from the perfection.
\end{abstract}

\section{Keywords}

Automotive transport, energy, squared speed, LT-systematization, Tran, energy effectiveness, life cycle.

\section{Introduction}

There is no real-world object which could exist without a resource, the measure of which is energy (the value which characterizes the capability to perform an action). The main result of activities of the human society of all times is the concentration of energy.

Transport uses more than a quarter of all used energy resources of the planet for its operation. The process of energy advance from primary sources through a variety of power converters to a fleet of transport vehicles, and its subsequent transformation by this transport in transportation activities is essentially a logistical process (Kotikov, Lozhkin, 2006). The role of the global logistics manager belongs to the scientific and technical community of the planet. Transport workers adjoin this management at the last stage, i.e. execution of transportation operations and delivery of transportation services.

The main operational task of the transport operator is to deliver shipment to its destination right on time. At the same time, there is a constant struggle for increasing speeds of goods delivery within strategic and historical contexts.

\section{Subject, problems and methods}

Transportation is a very energy intensive type of activity. Assessment of its energy intensity is a relevant task of several centuries. In practice, a number of generally accepted indices are used for the assessment of the perfor- mance and energy effectiveness of transportation: $\mathrm{t}-\mathrm{km}$, $\mathrm{km} / \mathrm{l}, \mathrm{mpg}, \mathrm{kJ} / \mathrm{t}-\mathrm{km}$, BTU/(ton-mile), and others (International Energy Outlook, 2016; Transportation Energy Data Book, 2016). However, as a rule, they do not consider the object delivery speed directly, meanwhile, this is a very important factor of logistics. Besides, considering the energy cost factor, the most important is not even the speed, but the squared speed, since the energy of any motion (and the medium resistance to this motion) is proportional just to the squared speed of this process realization.

However, there recently appeared a possibility to develop a new methodological approach in assessing the energy effectiveness of transport and transport services provided by it, which would take into account the squared speed of the object delivery. This approach is related to the development of Robert Bartini's ideas on geometric LT-systematization of physics laws on the basis of a pair of coordinate parameters Length-Time (L-T) (Bartini, 1965; Bartini, Kuznetsov, 1974).

In 1855-1873, J. Maxwell advanced the idea that for construction of a system of measurement units only two units are required: the length and the time. In particular, he defined the dimensionality for the mass [L3T-2] (along with the designation of the dimensionality of any physical value in the form of square brackets).

Comprehension of this assertion lasted for a century: and since 1965, a number of publications by Roberto di Bartini, P. G. Kuznetsov, A. G. Aleinikov and others 
appeared, who obtained a number of important results (Bartini, 1965, Bartini, Kuznetsov, 1974; Obraztsova, Kuznetsov, Pshenichnikov, 1997; Aleinikov, 2007).

The kinematic system of physical quantities, proposed by Bartini (Table of Bartini (TB), see TB fragment in Table 1) (Aseev, 2012), consists of vertical columns representing a series of grades of $L$ length and horizontal lines showing grades of $T$ time. The intersection of each column and each line gives the dimensionality of one or another physical quantity of $\left[\mathrm{L}^{\mathrm{R}} \mathrm{T}^{\mathrm{S}}\right]$ dimensionality, where $\mathrm{R}$ and $\mathrm{S}$ are integers.

Table 1. Matrix of physical laws and measurements

\begin{tabular}{|c|c|c|c|c|c|c|}
\hline $\mathrm{Sp}$ & $\overline{L^{1}}$ & $\overline{L^{2}}$ & $\mathrm{~L}^{3}$ & $L^{4}$ & $\overline{L^{5}}$ & $\overline{L^{6}}$ \\
\hline$T^{-6}$ & & & $\mathrm{~L}^{3} \cdot \mathrm{T}^{-6}$ & $L^{4} \cdot T^{-6}$ & $L^{5} \cdot T^{-6}$ & $\begin{array}{l}\text { Speed of } \\
\text { capacity } \\
\text { transition } \\
\text { (mobility) }\end{array}$ \\
\hline $\mathrm{T}^{-5}$ & & $\begin{array}{c}\text { Change } \\
\text { of } \\
\text { pres- } \\
\text { sure }\end{array}$ & $\begin{array}{l}\text { Surface } \\
\text { capacity }\end{array}$ & $\begin{array}{l}\text { Speed } \\
\text { of force } \\
\text { change }\end{array}$ & Power & $\begin{array}{l}\text { Speed of } \\
\text { energy } \\
\text { transition }\end{array}$ \\
\hline $\mathrm{T}^{-4}$ & $\begin{array}{l}\text { Pressure } \\
\text { gradient }\end{array}$ & $\begin{array}{l}\text { Pres- } \\
\text { sure }\end{array}$ & $\begin{array}{l}\text { Angular } \\
\text { accelera- } \\
\text { tion of the } \\
\text { mass }\end{array}$ & Force & $\begin{array}{c}\text { Energy } \\
\text { Work }\end{array}$ & $\begin{array}{c}\text { Speed of } \\
\text { transition } \\
\text { of im- } \\
\text { pulse } \\
\text { moment } \\
\text { (tran) }\end{array}$ \\
\hline $\mathrm{T}^{-3}$ & $\begin{array}{c}\text { Mass } \\
\text { speed } \\
\text { Current } \\
\text { density }\end{array}$ & $\begin{array}{l}\text { Gradient } \\
\text { Viscosity }\end{array}$ & $\begin{array}{c}\text { Mass } \\
\text { discharge } \\
\text { rate } \\
\text { Current }\end{array}$ & Impulse & $\begin{array}{c}\text { Mo- } \\
\text { ment } \\
\text { of } \\
\text { Im- } \\
\text { pulse }\end{array}$ & \\
\hline $\mathrm{T}^{-2}$ & $\begin{array}{c}\text { Linear } \\
\text { accele- } \\
\text { ration }\end{array}$ & $\begin{array}{l}\text { Poten- } \\
\text { tial of } \\
\text { gravi- } \\
\text { tational } \\
\text { field }\end{array}$ & Mass & & & \\
\hline$T^{-1}$ & $\begin{array}{l}\text { Linear } \\
\text { speed }\end{array}$ & $\begin{array}{c}\begin{array}{c}\text { Speed of } \\
\text { change } \\
\text { of the } \\
\text { square }\end{array}\end{array}$ & $\begin{array}{c}\text { Volume } \\
\text { discharge } \\
\text { rate }\end{array}$ & $\begin{array}{c}\text { Speed of } \\
\text { volume } \\
\text { tran- } \\
\text { sition }\end{array}$ & & \\
\hline $\mathrm{T}^{0}$ & Length & Square & Volume & & & \\
\hline
\end{tabular}

Horizontal lines of the table are trends of spatial resources. Dimensionalities of properties of all trend elements comprise the multiplier $L+1$, which is inherited from one property to another from the left to the right and is called the gene of the length. Similar to spatial trends, the concept of time trends is introduced; these are columns of the table. The time gene T-1 is transmitted from the bottom upwards from one property to another in columns. Also, the concept of real-field resources (RFR) is defined in the Bartini's table: it is the diagonal of the table, it runs from the left bottom to the right top. RFR trends form seven di- agonals containing physical properties with dimensionalities of $L m T-n$, at $|m+n| \leq 3$. All RFR trends transmit the velocity gene L1T-1=V+1 from generation to generation. The sum of power exponents of values laying on a separate trend coincides and differs from the sum of power exponents of values of neighboring trends by a unit (http://www.ruleright.ru/ruls-171-1.html).

Let us note the dimensionality of the following classical units: length $-L^{1} T^{0}$; mass $-L^{3} T^{-2}$; energy $-L^{5}$ / $T^{4}$; power $-L^{5} / T^{5}$; transportation work in t-km $-L^{4} T^{-2}$.

Bartini also proposed the magnitude Mobility with the dimensionality of $\mathrm{L}^{6} \mathrm{~T}^{-6}$. Further, Bartini together with P. G. Kuznetsov proposed a unit with the dimensionality of $\mathrm{L}^{6} \mathrm{~T}^{-4}$, which represents Displacement (transmission at a distance) of energy (Bartini, Kuznetsov, 1974). Later, the name for the unit of Displacement was proposed (Obraztsova, Kuznetsov, Pshenichnikov, 1997); it was called "Tran" with the dimensionality of [ $\left.{ }^{6}{ }^{6} \mathrm{~T}^{-4}\right]=$ $(\mathrm{t} \cdot \mathrm{km}) \cdot \mathrm{km}^{2} / \mathrm{h}^{2}$.

A. G. Aleinikov with his research group developed the BT (Aleinikov, 2007), having introduced nine new conservation laws into it. Also, Aleinikov suggested to call the unit of Mobility $\mathrm{L}^{6} \mathrm{~T}^{-6}$ as Bart, and the unit $\mathrm{L}^{6} \mathrm{~T}^{-4}$ as Transfer with the unit of measurement Tran.

We will follow this terminology in this article. Figure 1 shows the very part of the matrix of A.G. Aleinikov's laws we need as a canvas for our research.

According to the Figure 1, formation of the entity of Transfer can be represented as the product of the cargo mass $M$ by the distance $L$ (transfer of the cargo mass over this distance) with the formation of the mass displacement $W_{P}$ in t-km, followed by multiplying the mass displacement $W_{P}$ by the squared velocity V2, realized during this transfer (Kotikov, 2001; Kotikov, 2005a; Kotikov, 2005b; Kotikov, Lozhkin, 2006). If we take the mass displacement $W_{P}$ as a measure of transport inertia, the conformity of motions can be noted: $W_{P} \cdot V^{2}=S \sim M \cdot V^{2}=E$.

Just like the squared velocity acts as a factor, reflecting the level of the capability to perform work (action) in the gravity field, for a physical body (with the mass as a measure of the body inertia), is also can act as a coefficient, reflecting the level of the capability to perform work (actions) in the economic field, for transportation (with the Displacement of Mass as a measure of inertia).

The use of Transfer should lead to such a stimulation system, which generally requires a higher rate of transportation. Transfer most accurately reflects the energy essence of the transportation process. This determines its role as a balancing energy criterion between supply and demand of transport services, since economic estimates of both demand and supply are ultimately based on energy resources and their costs. After all, the desirable high level of demand for the delivery speed meets with the needed energy costs (both depend on the squared delivery speed). 


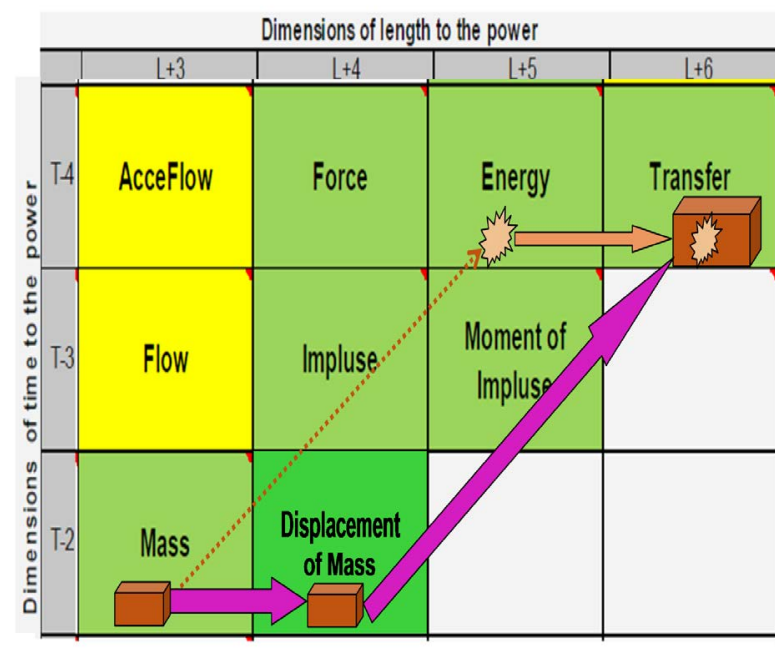

Figure 1. Part of Matrix of physical laws as a canvas for analysis

That means that Transfer is able to act as an appraiser of the transport service. Availability of the multiplier in the form of the squared speed in the structure of Transfer means for the customer that meeting the desired level of the delivery speed will cause an increase in the tariff rate (depending on the energy consumption), which would be in proportion to the increase in the squared speed of delivery.

The transport service Transfer of the size of 1 Tran is equal to the effective work spent for moving of a cargo with the mass of 1 ton over the distance of $1 \mathrm{~km}$ with an average-travel speed of $1 \mathrm{~km} / \mathrm{h}$. The dimensionality of this service unit is $\mathrm{t} \cdot \mathrm{km}^{3} / \mathrm{h}^{2}$. Further, $1 \mathrm{tran}=1 \mathrm{t} \cdot(\mathrm{km} / \mathrm{h})^{2} \cdot \mathrm{km}=$ $1,000 \mathrm{~kg} \times(1 / 3.6)^{2} \mathrm{~m}^{2} / \mathrm{s}^{2} \times \mathrm{km}=77.16 \mathrm{~J} \cdot \mathrm{km}$. Thus, 1 Tran can be represented as the energy with the value of 77.16 $\mathrm{J}$, necessary for moving a 1-ton transportation object over $1 \mathrm{~km}$ under conditions of the Earth's gravitation field.

We meet two types of the capacity in the system of the cargo transportation: the capacity of the actual transport flow and the capacity of haulage operations and terminal and logistics facilities. Both capacities are aimed at achieving a common goal, i.e. to provide the necessary speed of delivery for the national economy (tor the supply chain).

The cargo transportation process includes a variety of loading and unloading operations and warehouse delays, which can take up to $80 \%$ of the total delivery time in the chain. It is inefficient to compensate cargo delays in auxiliary operations with the help of the higher speed of movement, as this leads to a sharp increase in fuel consumption and wear of the power installation. Transfer can play an important criterial role in optimizing distribution of energy costs for the realization of these two types of the flow capacity in the transport infrastructure. Also, the role of Transfer in the assessment of energy effectiveness as the transportation process in general, as well as its separate stages, can turn out to be high as well.

\section{Case Study}

Here is an example of forming the energy effectiveness assessment of the cargo transportation with KamAZ-5320 automotive vehicle.

The total energy consumption of the automotive transportation system for preparation and realization of the cargo transportation is aggregated based on components of energy consumption in the following fields:

1) manufacturing of automotive vehicles;

2) construction and maintenance of motor roads;

3) provision of fuel and operational supplies for transportation;

4) maintenance of machinery operation and activity of personnel;

5) traffic management;

6) loading and unloading, transport and storage operations;

7) communication and management of the transportation and logistics process;

8) disposal of transport structures as completion of their life cycle (LC).

However, the case study is restricted with the first four spheres. Let us use the methodological best practices and data of authors' works (Kotikov, 2001, Kotikov, 2005a, Kotikov, 2005b, Kotikov, Lozhkin, 2006).

If we compare the value of the Transport Service (in Tran), produced by one vehicle, with the total energy, consumed by the automotive vehicle system in transportation of cargo, then the energy effectiveness factor (EEF) of this transportation can be obtained.

Each of these four spheres has its own life cycle. Assessments of EEF generalized for four spheres, built on the basis of the life cycle of the transportation vehicle, will be the most adequate. Finally, accomplishing the calculation procedure, let us reduce all parameters to one kilometer of the automotive vehicle travel, since Tran/km has the dimensionality of Energy.

A KamAZ-5320 truck, carrying 8 tons of cargo with the speed of $60 \mathrm{~km} / \mathrm{h}$ and running 50 thousand $\mathrm{km}$ per year, fulfills the annual volume of services $S_{\text {year }}=8 \times 50000 \times\left(60^{2}\right)$ $=1.44 \cdot 10^{9} \operatorname{tran}=1.44 \cdot 77.16 \cdot 10^{\circ}=111.1 \mathrm{GJ} \cdot \mathrm{km}$. Covering the warranty run of 350 thousand $\mathrm{km}$ per 7 years (conditionally, it is the life cycle of the motor vehicle), it performs the volume of services for cargo transportation of $\mathrm{S}_{\mathrm{LC}}=$ $111.1 \times 7=777.7 \mathrm{GJ} \cdot \mathrm{km}=2.222 \mathrm{MJ} \times 350,000 \mathrm{~km}$. That is, the "absolutely net" energy costs related to the service for transportation of the named cargo for the distance of $1 \mathrm{~km}$ with the speed of $60 \mathrm{~km} / \mathrm{h}$ are equal to $S_{\mathrm{km}}=2.222$ $\mathrm{MJ}$ (and they do not depend on the type of the transport vehicle, but characterize the average level of energy scattering during movement of 8 ton weight at a distance of 1 $\mathrm{km}$ in the environment (in the gravity field) at the delivery speed of $60 \mathrm{~km} / \mathrm{h}$ ).

Let us consider the automotive vehicle as a cargo carrier, moving along a motor road: this is a structure with energy $E_{s}$ provided during its production; the road with a part of the energy $E_{m . r .}$ put in it (reduced to a specific au- 
tomotive vehicle); fuel, the energy $E_{\text {fuel }}$ of which is used for movement of the automotive vehicle along the motor road in a viscous air medium and surrounding transport flows; expended operational supplies with energy $E_{\text {o.s. }}$ provided in them; energy costs for maintenance and repair, taking into account the energy provided in spare parts during their manufacturing and installation on the motor vehicle $E_{m .}$ and $E_{r}$; other associated energy costs $E_{\text {o.a.e. }}$ The sum of the considered items of energy inputs is as follows:

$$
E_{\Sigma L C}=E_{s}+E_{m . r .}+E_{\text {fuel }}+E_{\text {o.s. }}+E_{\text {m.r.i. }}+E_{\text {o.a.e. }}
$$

The total energy costs for manufacturing of one KamAZ-5320 are $E_{s}=523 \mathrm{GJ}$.

Total consumption of energy resources for construction of $1 \mathrm{~m}^{2}$ of a motor road is $E_{r . c}=535 \mathrm{MJ} / \mathrm{m}^{2}$.

Total energy consumption for one-time repair of the road surface is $290 \mathrm{MJ}$ per $1 \mathrm{~m}^{2}$. Considering the life cycle of the motor road of 30 years and repair interval of 7 years, i.e. three repairs, energy costs for repair works will be $290 \times 3=870 \mathrm{MJ} / \mathrm{m}^{2}$. That means that the energy put in $1 \mathrm{~m}^{2}$ of such road is $535+870=1,405 \mathrm{MJ} / \mathrm{m}^{2}$, taking into account all maintenance and repair operations performed on this road during its life cycle of 30 years. Then, 7 years of the automotive vehicle life cycle per $1 \mathrm{~m}^{2}$ of the road will require the following energy consumption: $1,405 \times 7 / 30=$ $328 \mathrm{MJ} / \mathrm{m}^{2}$.

Taking the width of the road lane of $4 \mathrm{~m}$, the energy of $328 \mathrm{MJ} / \mathrm{m}^{2} \times 4 \mathrm{~m}=1,311 \mathrm{MJ} / \mathrm{m}$ is put into one running meter of the lane during the life cycle of the automotive vehicle. Taking conditional traffic intensity along the lane as 2,000 vehicles/day, $2,000 \times 365 \times 7=5,110,000$ automotive vehicles would run through the section of the lane in 7 years. Then, one motor vehicle traveling one running meter of the lane would consume the following energy of the road: $1,311 \mathrm{MJ} / \mathrm{m} / 5,110,000 *$ vehicle $=0.257 \mathrm{~kJ} / \mathrm{m} \cdot \mathrm{ve}-$ hicle. Our automotive vehicle, having run 350 thousand $\mathrm{km}$, uses $E_{m . r .}=0.257 \mathrm{~kJ} / \mathrm{m} \cdot$ vehicle $\times 350,000,000 \mathrm{~m}=90$ GJ of energy put in the motor road).

Provision of fuel and operational supplies. Let us take the fuel rate of the automotive vehicle as 34 liters per $100 \mathrm{~km}$, then the total fuel consumption for 7 years would be QF $=34 \times 3500=119,000$ liters. The amount of the chemical energy contained in the fuel is 119,000 liters $\times 35.3 \mathrm{MJ} / \mathrm{I}=4,201 \mathrm{GJ}$. Besides, according to (Kotikov, Lozhkin, 2006), production of $1 \mathrm{~kg}$ of diesel fuel takes energy of $3.5 \mathrm{kWh} / \mathrm{kg}$. Consequently, the industry inputs 3.5 $\mathrm{kWh} / \mathrm{kg} \times 0.83 \mathrm{~kg} / \mathrm{l} \times 3.6 \mathrm{MJ} / \mathrm{kWh} \times 119,000 \mathrm{I}=1,244 \mathrm{GJ}$ for manufacturing of 119,000 liters of fuel. Thus, the total amount of primary energy recovered through the fuel is $E_{\text {fuel }}=4,201+1,244.5=5,445$ GJ.

Operational supplies. The oil consumption is $2 \%$ of fuel consumption, i.e. 119,000 liters $\times 0.02=2,380$ liters. The energy expended to produce such amount of oil is $50 \mathrm{~kW} \times \mathrm{h} / \mathrm{kg} \times 0.85 \mathrm{~kg} / \mathrm{liter} \times 3.6 \mathrm{MJ} / \mathrm{kWh} \times 2,380$ liters $\approx 364.3$ GJ. Consumption of the antifreeze is 200 liters, which corresponds to the input energy of $4 \mathrm{kWh} / \mathrm{kg} \times 1.07$ $\mathrm{kg} / \mathrm{l} \times 3.6 \mathrm{MJ} / \mathrm{kWh} \times 200 \mathrm{~L} \approx 5 \mathrm{GJ}$. Consump-tion of lead is $70 \mathrm{~kg}$, which corresponds to the input energy of $23 \mathrm{~kW} \cdot \mathrm{h} / \mathrm{kg} \times 3.6 \mathrm{MJ} / \mathrm{kWh} \cdot \mathrm{h} \times 70 \mathrm{~kg} \approx 6 \mathrm{GJ}$ (consumption of the antifreeze is $200 \mathrm{l}$, which corresponds (at specific energy costs for pro-duction of antifreeze of 4 $\mathrm{kWh} / \mathrm{kg}$ ) to the input energy of $4 \mathrm{~kW} \cdot \mathrm{h} / \mathrm{kg} \times 1.07 \mathrm{~kg} / \mathrm{l} \times$ $3.6 \mathrm{MJ} / \mathrm{kWh} \times 200 \mathrm{I} \approx 5 \mathrm{GJ}$. Consumption of the lead is $70 \mathrm{~kg}$, which corresponds (at specific energy consumption for the lead production of $23 \mathrm{~kW} \cdot \mathrm{h} / \mathrm{kg}$ ) to the input energy of $23 \mathrm{~kW} \cdot \mathrm{h} / \mathrm{kg} \times 3.6 \mathrm{MJ} / \mathrm{kWh} \cdot \mathrm{h} \times 70 \mathrm{~kg} \approx 6$ GJ. In total, $E_{o . s .}=364+5+6=375 \mathrm{GJ}$.

Energy costs for maintenance and repair. Energy equivalent of materials (steel and cast iron, aluminum, copper, rubber, varnishes, chemicals, fuel) for repair and recovery needs of KamAZ-5320 (without spare parts) within its life cycle is 77.2 GJ / 350 thousand $\mathrm{km}$.

Energy equivalent of materials (steel and cast iron, aluminum, copper, rubber (without tires)) in the form of spare parts for repair of the KAMAZ-5320 automotive vehicle is $34.7 \mathrm{GJ} / 350$ thousand $\mathrm{km}$. Direct energy costs for maintenance and repair of the automotive vehicle KamAZ-5320 are 139 GJ / 350 thousand km.

Then, the total energy consumption for maintenance and repair (taking into account the energy put in spare parts during their manufacture and installation) is $E_{\text {m.r. } . .}=77.2+34.7+139=251$ GJ.

The sum of all energy costs, put in the transport service $S=777.7 \mathrm{GJ} \cdot \mathrm{km}$ performed with the motor vehicle in accordance with the equation (1), is $E_{\Sigma L C}=523$ $+90+5,445+375+251=6,684$ GJ $=6,684 \times 77.16=$ 515,737 Tran. Calculating for $1 \mathrm{~km}$, this value is $E_{\Sigma \mathrm{km}}=$ $6,684 \mathrm{GJ} / 350,000 \mathrm{~km}=19.1 \mathrm{MJ} / \mathrm{km}$.

Thus, to provide a transport service, i.e. the movement of the 8 ton weight cargo by means of KamAZ 5320 automotive vehicle with the speed of $60 \mathrm{~km} / \mathrm{h}$, with an inherent dissipation of the energy of the cargo movement per a kilometer of $2.22 \mathrm{MJ}$ into the environment, 19.1 MJ of energy would be required to be put in the Motor transportation complex. The value $\eta$ $=S_{k m} / E_{\Sigma k m}=2.22 / 19.1=0.1162=11.62 \%$ is the index of the energy effectiveness of the transportation process fulfilled by the Motor transport complex, with KamAZ-5320 automotive vehicle in particular, at 60 $\mathrm{km} / \mathrm{h}$.

\section{Conclusion}

It would be quite reasonable to assume that when taking into account the energy costs for traffic management, loading and unloading, transport and storage operations, management of transport and logistics process, disposal of transportation system, the value of energy effectiveness $\eta=\boldsymbol{S}_{k m} / \boldsymbol{E}_{\Sigma k m}$ will decrease. This is due to the fact that taking into account corresponding energy inputs will increase the denominator of the equation, and the inevitable decrease in the transportation rate (speed of delivery in the chain) will reduce the numerator of this equation. 


\section{References}

Aleinikov, A. (2007). Nine new laws of conservation: future science horizons. In: Proceedings of the Allied Academies International Conference, 6(2), pp. 5-10.

Aseev, A.G. (2012). Glamour and Emptiness of our world. Available at: http://noocosmology.com/article/glamour_and_emptiness_of_our_world.html (viewed on: 26.04.2017).

Bartini, R.O. (1965). Some relations between physical constants. Reports of the Academy of Sciences of the USSR, 163 (4), pp. 861-864.

Bartini R.O., Kuznetsov P.G. (1974). Multiplicity in geometries and physics. In: Proceedings of the seminar "Cybernetics of electric power systems", p.11. Available at: http://www.metodolog.ru/01380/01380.html (accessed on: 26.04.2017).

Kotikov, Ju.G. (2001). Osnovy sistemnogo analiza transportnykh sistem [Fundamentals of system analysis for transport systems]. Saint Petersburg: Saint Petersburg State University of Architecture and Civil Engineering, p.264. (in Russian)

Kotikov, Ju.G. (2005a). Analiz energoeffektivnosti transporta s pomoshchiu izmeritelia Tran [Analysis of transport energy effectiveness using the Tran unit]. Integrated logistics, 3, pp. 15-20. (in Russian)

Kotikov, Ju.G. (2005b). Energeticheskaia effektivnost avtotransportnogo kompleksa [Energy effectiveness of the automotive transportation system]. Bulletin of Transport, 4, pp. 37-39. (in Russian)

Kotikov, Ju.G., Lozhkin, V.N. (2006). Transportnaya energetika [Transport power energy]. Moscow: Publishing Center "Academia", p.272. (in Russian)

Oak Ridge National Laboratory (2016). Transportation Energy Data Book, Edition 35. Available at: http://cta.ornl.gov/data/ tedb35/Edition35_Chapter01.pdf (accessed on: 07.04.2017).

Obraztsova, R.I., Kuznetsov, P.G., Pshenichnikov, S.B. (1997). Inzhenerno-ekonomicheskii analiz transportnykhsistem [Engineering and economic analysis of transport systems]. Novosibirsk, p.156. Available at: http://lib.uni-dubna.ru/search/files/ur_enjek-an/ ur_enj-ek-an.htm (accessed on: 07.04.2017). (in Russian)

U.S. Energy Information Administration. (2016). International Energy Outlook. Available at: https://www.eia.gov/outlooks/ieo/ pdf/0484(2016).pdf (accessed on: 07.04.2017). 


\title{
VESSEL MIXERS WITH VIBRATION ACTIVATOR IN CONSTRUCTION ENGINEERING
}

\author{
Victor Kuzmichev" ${ }^{1}$, Vladimir Verstov ${ }^{2}$ \\ ${ }^{1}$ Peter the Great Saint Petersburg Polytechnic University, \\ Polytechnicheskaya st. 29, St. Petersburg, Russia \\ ${ }^{2}$ Saint Petersburg State University of Architecture and Civil Engineering \\ Vtoraja Krasnoarmejskaja ul. 4, St. Petersburg, Russia \\ ${ }^{1}$ kuzmichev_va@mail.ru, 2 5750195@mail.ru
}

\begin{abstract}
Construction mixes are classified as polydisperse heterogeneous systems, where surface phenomena occurring at the phase interface, exert a great influence on formation of such systems. As for mixing processes, adsorption and diffusion are the most important ones. Their speed depends on mobility of mineral constituents' particles, size of the active interfacial area, binder dispersion, technological peculiarities of the process and other factors. It is known that the vibration is one of the ways to increase mixing intensity. The article presents original designs of vessel mixers of forced action with vibration activators placed inside the mixing chamber. A vibration activator is installed in "dead" zones located along the geometrical axis of the mixing chamber where intensity of convective mixing is low.

Methods of design of balanced eccentric vibration activators of precessing and plane-parallel type are considered. Results of production tests with regard to industrial designs of vibration mixers are presented. Considerable attention is paid to measurement of the vibration level reflecting the quality of dynamic balancing of the vibration activator. Vibrational impact on the environment and maintenance personnel amounts to $\approx 5 \mathrm{~m} / \mathrm{s}^{2}$, corresponding to standard values for processing equipment as per GOST 22061-76.
\end{abstract}

\begin{abstract}
Keywords
Vessel mixer, vibration activator, design methods, dynamic balancing.
\end{abstract}

\section{Introduction}

Manufacturing of various building products (concrete slabs, blocks, bricks, paving slabs, etc.) is inseparably associated with preparation of mixes from which they are formed. The mix quality characterized by the degree of its approximation to the material with a certain ideal order of distribution of separate components and uniformity of physical and chemical properties is mainly defined by efficiency and intensity of mixing. The latter is derived from design features of mixing equipment.

Mixing of materials is a mechanical process resulting in uniform distribution of mineral constituents' particles and a binder in a mixed volume, which, in their turn, form a uniform mix (Bosch et al., 2016; Zhang et al., 2016).

Based on the developed ideas, the following types of mixing are distinguished:

1) convective mixing, i.e. moving of particle groups from one position to another by transfer, introduction, sliding of layers, layer portion deformation or attrition as a result of mechanical movement of operating elements of mixers;
2) diffusive mixing, i.e. gradual redistribution of particles of various constituents through the phase interface.

Convective mixing is classified as a macromixing process while diffusive mixing is classified as a micromixing process. Along with mixing, separation takes place in a mixer (separation of constituents' particles and their concentration in certain areas of the mixer body under the action of gravitational, centrifugal and inertial forces).

Actual mix formation usually represents superposition of mixing and separation.

Upon mixing in mixers of various types, the mix structure changes continuously and, therefore, its structural and rheological properties change. Control over structural and rheological properties is the main direction of intensification of the diffusion component with regard to mixing processes. At the present time, the following methods are used: pseudo-liquefaction, use of surface active agents (SAA) ensuring mix viscosity reduction; supply of binder feeding by means of nozzles, etc.

Vibration is one of the widely applied types of mechanical impact on environments in the field of construction and production of construction materials, considerably affecting changes in rheological properties of mixes 
(Bauman, Bykhovsky, 1977; Blekhman, 1994; Verstov et al., 2013; Chelomey, 1981; Efremov, Lobanov, 2008; Efremov, Lobanov, 2009; Kuzmichev, 2013; Kuzmichev, 2014).

\section{Design description}

Designs of vessel (rotary) mixers (hereinafter - vibration mixers) with vibration activators placed inside the mixing chamber are presented below. It is expedient to install a vibration activator in "dead" zones located along the geometrical axis of the mixing chamber where intensity of convective mixing is low.

A mixing chamber, mixing mechanism, vibration activator, drives of the mixing mechanism and vibration activator are the main structural components of mixers. It is expedient to make a discharge opening at the mixing chamber bottom along the vertical axis of symmetry, ensuring efficient vibration treatment of the entire mix volume during discharge.

Mixing in similar mixers is carried out by means of combination of mixing mechanism rotation and mix exposure to vibration of the vibration activator ensuring intensification of thixotropic transformations.

Industrial designs of vibration mixers operating for years have been designed (Figure 1 and 2).

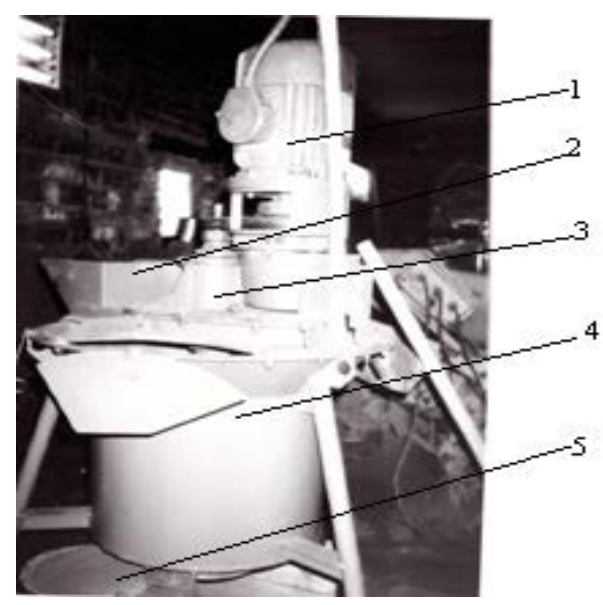

Figure 1. Vibration mixer of cyclic action:

1. drive; 2. charge opening; 3 . vibration activator of precessing type; 4. mixing chamber; 5 . discharge opening. Author's certificate 2033324 Class B 01F 11/00
Table 1. Technical characteristics of vibration mixers of batch action

\begin{tabular}{|c|c|c|}
\hline Type & $A$ & $B$ \\
\hline $\begin{array}{l}\text { Prepared batch } \\
\text { volume, } \mathrm{m}^{3}\end{array}$ & 0.08 & 0.1 \\
\hline $\begin{array}{c}\text { Vibration } \\
\text { parameters of a } \\
\text { vibration exciter: } \\
\text { - maximum } \\
\text { oscillation } \\
\text { amplitude, mm } \\
\text { - oscillation } \\
\text { frequency, rad/s } \\
\text { - maximum } \\
\text { acceleration of } \\
\text { oscillations, m/s }{ }^{2} \\
\text { - type of } \\
\text { oscillations }\end{array}$ & $\begin{array}{r}3.5 \\
230 \\
185 \\
\text { precessing }\end{array}$ & $\begin{array}{c}2.0 \\
260 \\
135 \\
\text { plane-parallel }\end{array}$ \\
\hline $\begin{array}{c}\text { Rotation } \\
\text { frequency: } \\
\text { - of spiral blades, } \\
\mathrm{rad} / \mathrm{s} \\
\text { - of a truncated } \\
\text { cone, } \mathrm{rad} / \mathrm{s}\end{array}$ & 1.5 & 15 \\
\hline $\begin{array}{c}\text { Geometrical } \\
\text { parameters: } \\
\text { of a vibration } \\
\text { exciter: } \\
\text { - diameter, mm } \\
\text { - length, mm } \\
\text { of a mixing } \\
\text { chamber } \\
\text { of a mixing } \\
\text { chamber: } \\
\text { - diameter, mm } \\
\text { - height, mm } \\
\text { - Installed power } \\
\text { of electric motor, } \\
\text { kW }\end{array}$ & $\begin{array}{l}130 \\
500 \\
\\
\\
\\
600 \\
570 \\
5.5\end{array}$ & $\begin{array}{c}730 \\
700 \\
3.0\end{array}$ \\
\hline $\begin{array}{l}\text { Dimensions: } \\
\text { - width, m } \\
\text { - height, m } \\
\text { - length, m } \\
\text { - Mass, kg }\end{array}$ & $\begin{array}{l}1.5 \\
1.9 \\
1.5 \\
650\end{array}$ & $\begin{array}{c}1.0 \\
2.3 \\
1.0 \\
730\end{array}$ \\
\hline
\end{tabular}



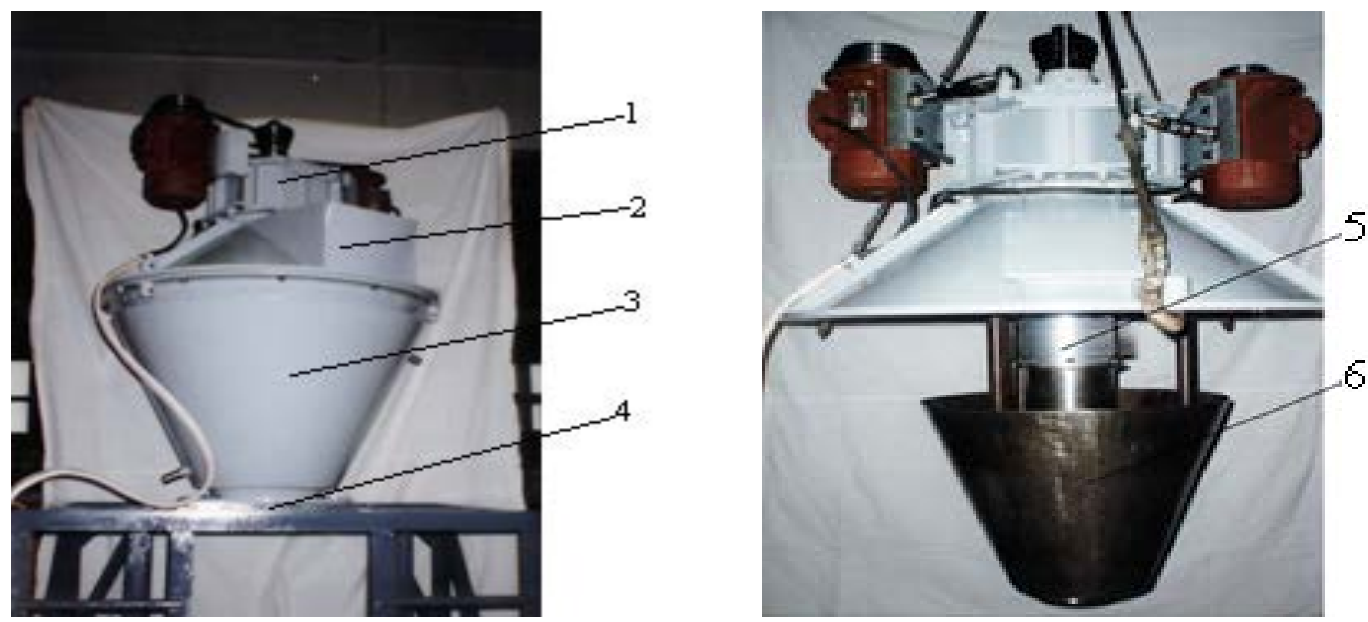

Figure 2. Vibration mixer of cyclic action:

1. drive; 2 . charge opening; 3 . mixing chamber; 4 . discharge opening;

5. vibration activator of plane-parallel type; 6 . mixing mechanism

Patent for invention No. 2510873 Class B 01F 11/00

Figure $3 b$ shows processing equipment for production of stones of soil-concrete mixes (unburned brick) with a capacity of 40 pieces per hour. The vibration mixer presented in Figure 1 was used as mixing equipment.

Investigation results with regard to mixing in a vibration mixer ( $B$ type) intended for mixing of highly-concentrated fine-dispersed mixes are presented below. A plane-parallel vibration activator and mixing mechanism in a form of a truncated cone, combination of which ensures increased intensity of mixing, are placed in the mixing chamber. Mixes consisting of clay and water with a viscosity of 150 $\mathrm{Pa} \cdot \mathrm{s}$, chalk and water with a viscosity of $90 \mathrm{~Pa} \cdot \mathrm{s}$ as well as food compositions made of flour, cocoa powder and water with a viscosity of $270 \mathrm{~Pa} \cdot s$ were used as models.

The profound study of mixing at the microlevel was performed with use of the mix consisting of chalk and water, to which insoluble black powder was added as a tracer agent (indicator). Results of the microscopic analysis of comparison of mixing quality with and without vibration are presented in Figure 4.

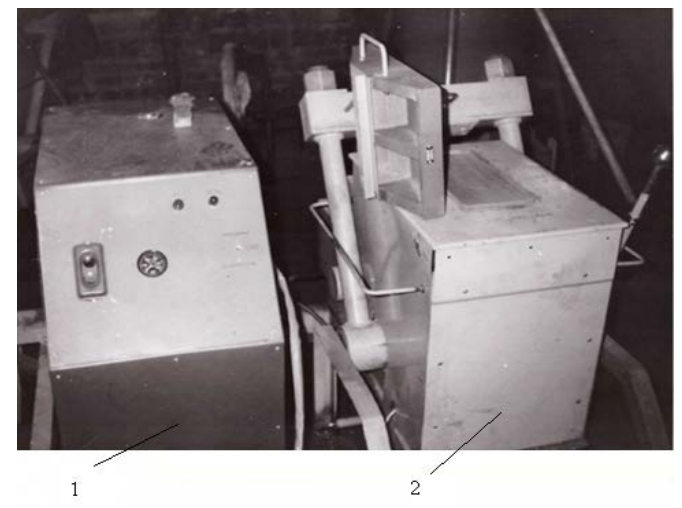

Figure 3. Processing equipment: 1. control board; 2. UPG-120 press
It is obvious that vibration mixing ensures a more uniform mix characterized by uniform distribution of black powder grains in the sample.

\section{Technique of balancing of vibration activators}

Let us consider calculation of a console precessing three-point vibration activator presented in Figure 5 and installed in a vibration mixer (A type). The vibration activator consists of carrying drive shaft 1 , main bearings 2 , body 3 , rod bearing 4 installed on the eccentric bushing with mechanically set eccentricity $e$, counterbalances 5, coupling 6 located concentrically in relation to the carrying drive shaft.

Upon rotation of the carrying drive shaft, the vibration activator body executes a precessing motion with the shaft rotation frequency and nutation angle:

$$
\beta=\operatorname{arctg} e / L
$$
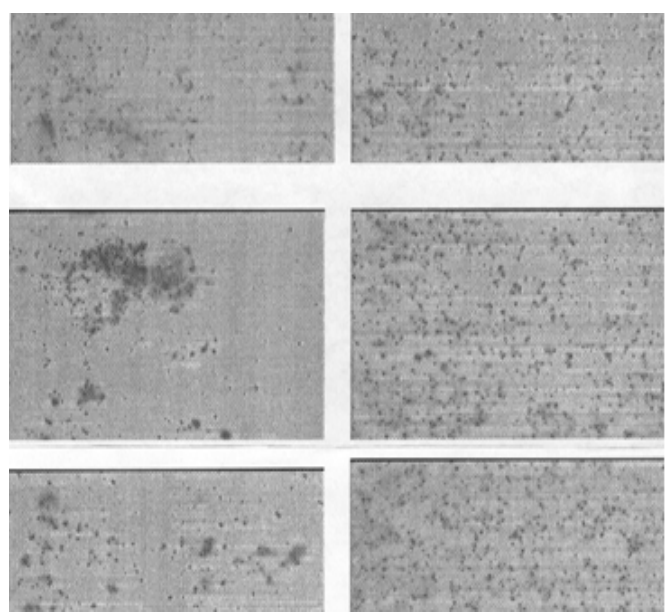

Figure 4. Results of the microscopic analysis of mixing a) without vibration; b) with vibration 


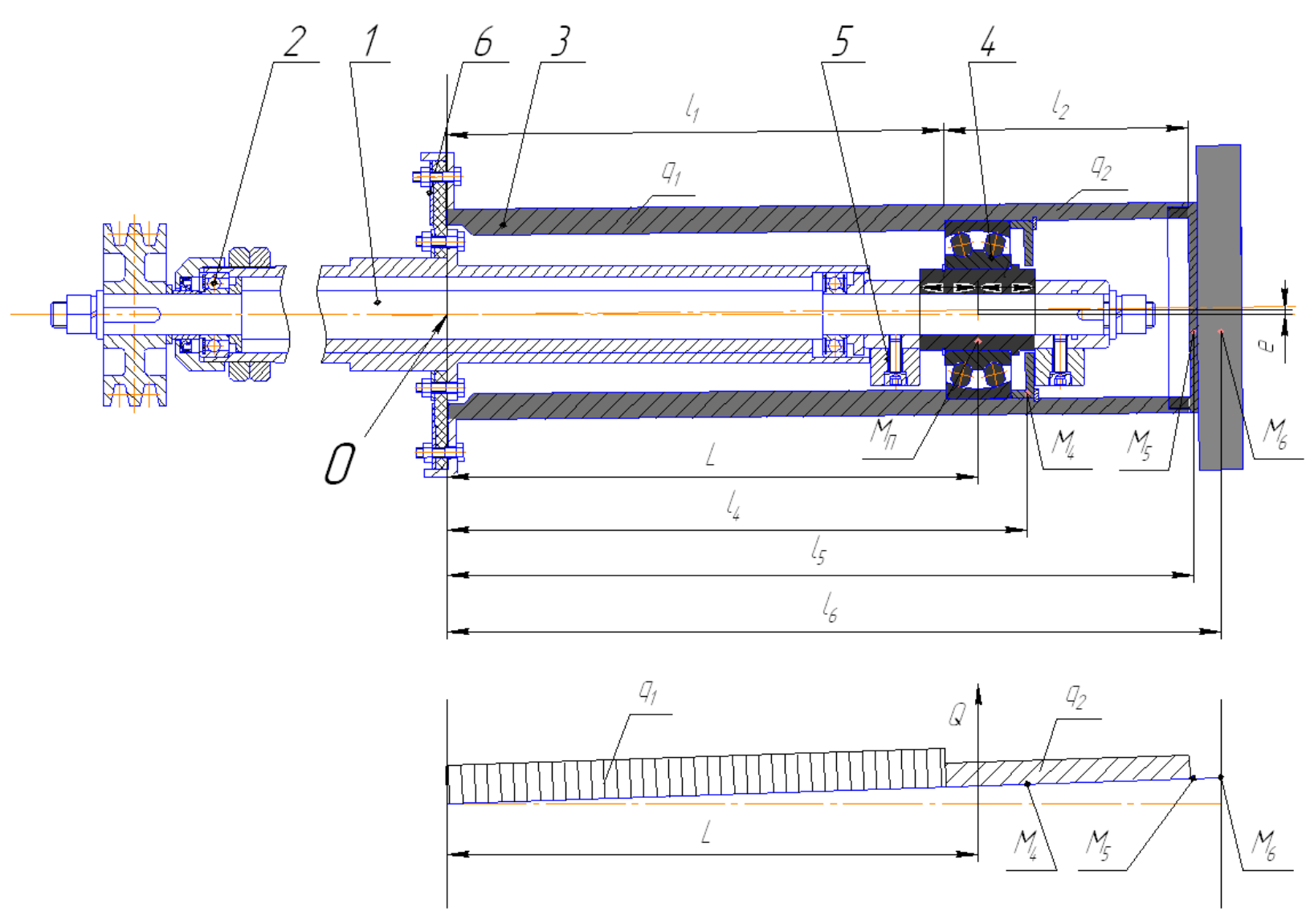

Figure 5. Calculation model

In accordance with the calculation procedure described in detail in (Kuzmichev, 2013; Kuzmichev, 2014; Kuzmichev, Verstov, 2017), the resultant of centrifugal forces $Q$ and its application point (distance $L$ ) are determined taking into account the following equations:

$Q=Q_{1}+Q_{2}+Q_{4}+Q_{5}+Q_{6}=\omega^{2} \operatorname{tg} \beta\left(\frac{1}{2} q_{1} l_{1}^{2}+\right.$

$\left.+\frac{1}{2} q_{2}\left[\left(l_{1}+l_{2}\right)^{2}-l_{1}^{2}\right]+M_{4} l_{4}+M_{5} l_{5}+M_{6} l_{6}\right)$

$L=\frac{Q_{1} l_{1}+Q_{2} l_{2}+Q_{4} l_{4}+Q_{5} l_{5}+Q_{6} l_{6}}{Q}=$

$\frac{\omega^{2} \operatorname{g} \beta\left(\frac{1}{3} q_{1} l_{1}^{3}+\frac{1}{3} q_{2}\left[\left(l_{1}+l_{2}\right)^{3}-l_{1}^{3}\right]+M_{4} l_{4}^{2}+M_{5} l_{5}^{2}+M_{6} l_{6}^{2}\right)}{Q}$

Dynamic balancing is carried out in accordance with the calculation model presented in Figure 6.

In Figure 6, $R, P$ are centrifugal forces resulting from oscillations of the rod bearing assembly and rotation of counterbalances.

The rod bearing assembly is designed and its mass $m_{\text {bearing }}$ and center-of-gravity position are determined. The vibration exciter construction is made with one rod bear- ing center-of-gravity of which is determined at the point of application of the resultant of centrifugal forces.

The mass of the bearing assembly includes the bearing, eccentric part of the bushing and cover. The centrifugal force from the mass of the rod bearing assembly is determined according to the following equation:

$$
R=m_{\text {bearing }} \cdot e \cdot \omega^{2}
$$

The balancing condition is as follows:

$P=1 / 2(Q+R)$

Let us consider calculation of a console plane-parallel four-point vibration activator presented in Figure 7 and installed in a vibration mixer (B type). It consists of carrying drive shaft 1 , main bearings 2 , body 3 , rod bearings 4 installed on the eccentric bushings with mechanically set eccentricity e, counterbalances 5 , oil pump 6, coupling 7 and radiator 8 .

Upon rotation of the carrying drive shaft, the vibration activator body executes circular oscillations with constant amplitude (eccentricity $e$ ).

Calculation of the centrifugal force and its application point is made as follows: 


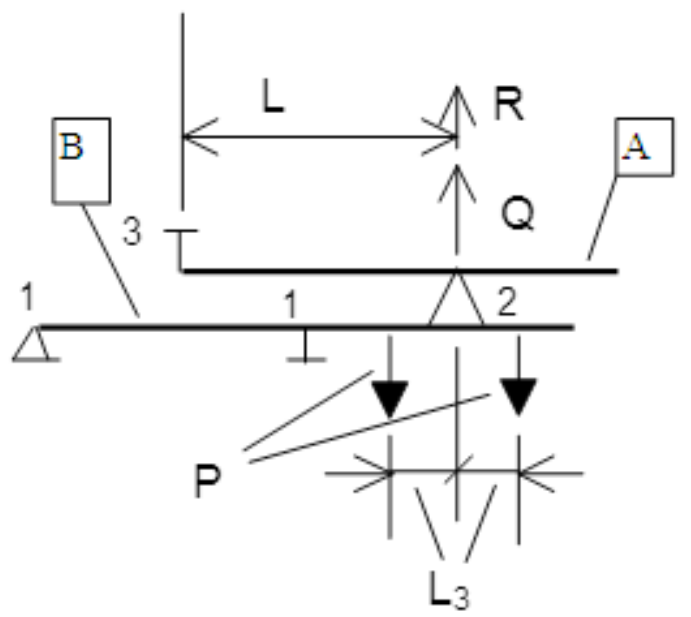

Figure 6. Calculation model

- unbalanced mass $m$ of the vibration activator and its center-of-gravity position - distance $L$ from the body end face - are determined by the known methods using KOMPAS 3D and other programs;

- the centrifugal force resultant is calculated according to the following equation: $Q=m e \omega^{2}$, where $e$ is the value of crank eccentricity (oscillation amplitude); $\omega$ is the angular velocity of rotation of the drive crank shaft of the vibration activator;
- reactive forces $R_{1}$ and $R_{2}$ in the rod bearings are determined by means of statics equations;

- centrifugal forces from masses of the rod bearing assemblies including the bearing itself and eccentric bushing are determined.

Dynamic balancing is carried out in accordance with the calculation model presented in Figure 8.

Balancing condition:

$$
\begin{array}{lc}
P_{1}=1 / 2\left(R_{1}-R_{3}\right), R_{1}>R_{3} & \text { symmetric arrangement of } \\
P_{2}=1 / 2\left(R_{2}+R_{4}\right) & \text { counterbalances }
\end{array}
$$

A geometric shape of counterbalances is chosen according to the recommendations proposed in (Kuzmichev, Verstov, 2017).

As an example, results of measurements of the vibration level on the vibration mixer body (A type) are presented in Table 2. These results reflect the dynamic balancing quality. The measurements were taken using the following measuring equipment: vibration meter of 00032 type, No. 4106, Germany.

Sensors were installed in two diametrically opposite areas on the vibration mixer cover where the drive was placed. The measurements were taken in two modes: experiment № 1 - without any mix in the mixer; experiment № 2 - during mixing.

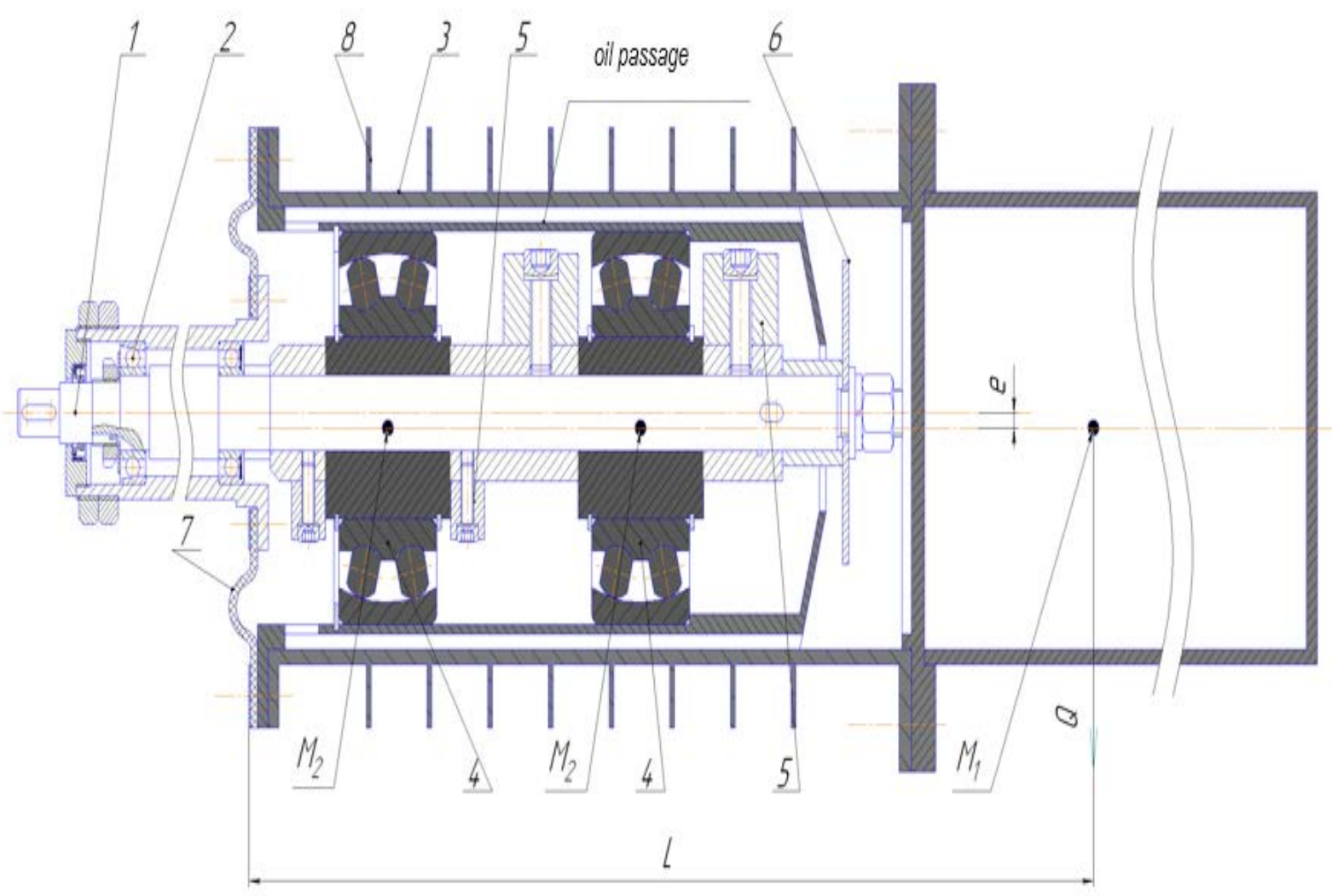

Figure 7. Console plane-parallel four-point vibration activator 
Table 2.

\begin{tabular}{|c|c|c|c|c|c|c|c|}
\hline \multirow[t]{2}{*}{ Experiment № } & \multirow[t]{2}{*}{$\begin{array}{c}\text { Acceleration } \\
\text { of vibration } \\
\text { exciter } \\
\text { oscillations } \\
\mathrm{V}, \mathrm{m} / \mathrm{s}^{2}\end{array}$} & $\begin{array}{c}\text { № of sensor } \\
\text { placement } \\
\text { position }\end{array}$ & $\begin{array}{c}\text { Acceleration } \\
\text { along } \mathrm{X} \\
\mathrm{m} / \mathrm{s}^{2}\end{array}$ & $\begin{array}{c}\text { Acceleration } \\
\text { along } \mathrm{Y}, \\
\mathrm{m} / \mathrm{s}^{2}\end{array}$ & $\begin{array}{c}\text { Acceleration } \\
\text { along } \mathrm{Z}, \\
\mathrm{m} / \mathrm{s}^{2}\end{array}$ & $\begin{array}{c}\text { Root-mean- } \\
\text { square } \\
\text { value, } \mathrm{m} / \mathrm{s}^{2} \\
U=\sqrt{x^{2}+y^{2}+z^{2}}\end{array}$ & $\frac{V}{U}$ \\
\hline & & \multicolumn{3}{|c|}{ measured } & & & \\
\hline 1. & 185 & $\begin{array}{l}\text { № } 1 \\
\text { № } 2\end{array}$ & $\begin{array}{l}2.6 \\
2.5\end{array}$ & $\begin{array}{l}2.8 \\
2.7\end{array}$ & $\begin{array}{l}2.7 \\
3.0\end{array}$ & $\begin{array}{l}4.6 \\
4.7\end{array}$ & $\begin{array}{l}40 \\
39\end{array}$ \\
\hline 2. & 185 & $\begin{array}{l}\text { № } 1 \\
\text { № } 2\end{array}$ & $\begin{array}{l}3.1 \\
3.2\end{array}$ & $\begin{array}{l}2.9 \\
2.8\end{array}$ & $\begin{array}{l}2.7 \\
2.9\end{array}$ & $\begin{array}{l}5.0 \\
5.2\end{array}$ & $\begin{array}{l}37 \\
36\end{array}$ \\
\hline
\end{tabular}

The analysis of the measurement results shows that application of balanced eccentric vibration activators ensures reduction of vibration affecting the environment (drive, frame, etc.) by $\approx 35$ times. The measured peak values of acceleration amount to $\approx 5 \mathrm{~m} / \mathrm{s}^{2}$, corresponding to standard values for processing equipment as per GOST 22061-76.
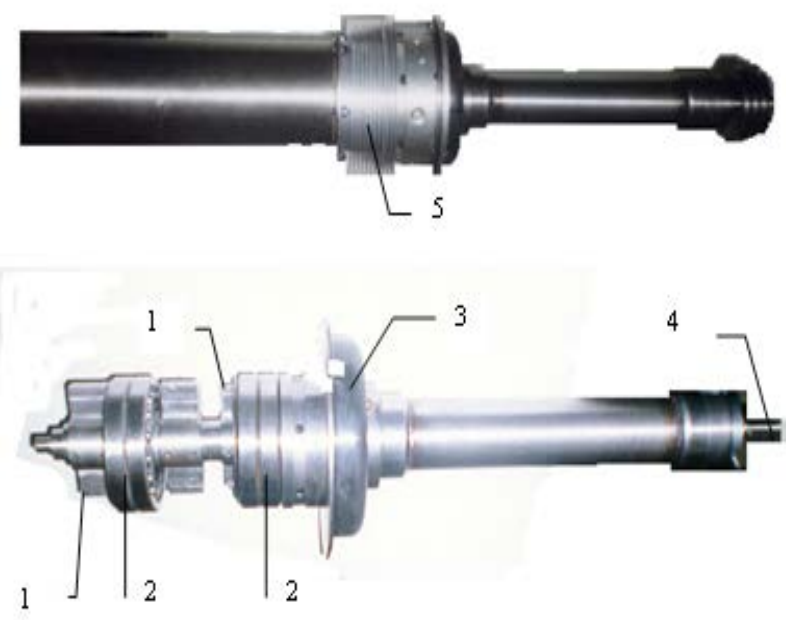

Figure 8. Vibration activator construction: 1 - counterweights, 2 - rod bearing, 3 - clutch, 4 - shaft, 5 - radiator

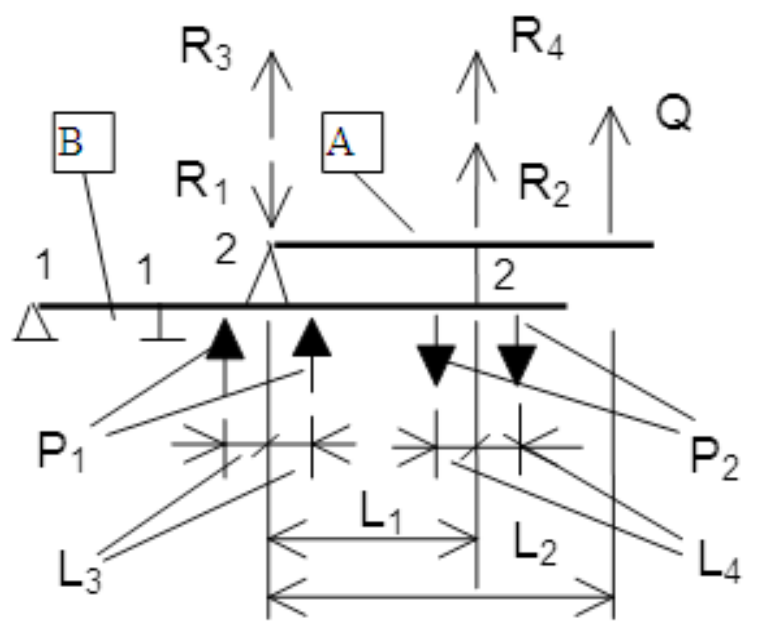

Figure 9. Calculation model

\section{Conclusion}

The presented materials confirm legitimacy of the balancing technique for vibration activators which is presented in detail in (Kuzmichev, 2014), and expediency of their application in mixing equipment for production of construction mixes.

It should be noted that numerous researches in the field of intensification of technological processes with vibration application, conducted by Russian researchers, have shown that the main principles of physical and chemical mechanics of disperse systems can also be successfully used in mixing. Control over structural and rheological properties of mixes at the stage of mixing, in particular, destruction of the structure of mixed materials and, therefore, viscosity reduction, allows increasing uniformity of mixed materials, production quality, affecting molding processes, etc.

It is expedient to use vessel vibration mixers for mixing of highly-concentrated disperse systems, e.g. fillers, dry mixes, powders, paints, etc. 


\section{Architecture and Engineering Volume 2 Issue 2}

\section{References}

Bauman, V.A., Bykhovsky, I.I. (1977). Vibratcionnye mashiny i protcessy $v$ stroitelstve [Vibration machines and processes in construction]. Moscow: Vysshaya Shkola, p.256. (in Russian)

Blekhman, I.I. (1994). Vibratcionnaia mekhanika [Vibration mechanics]. Moscow: Fizmatlit, p.400. (in Russian)

Bosch, H.R.B., Hamersma, H.A., Els, P.S. (2016). Parameterisation, validation and implementation of an all-terrain SUV FTire tyre model. Journal of Terramechanics, 67, pp. 11-23. DOI: 10.1016/j.jterra.2016.06.001

Chelomey, V.N. (1981). Vibratsiya $v$ tekhnike. Spravochnik $v 6$ tomakh [Machinery vibrations. Reference book in 6 volumes]. Moscow: Mashinostroenie Publishing House, vol.6, p.509. (in Russian)

Efremov, I.M., Lobanov, D.V. (2008). Novye rotornye smesiteli s razlichnymi sistemami vibrovozbuzhdeniya [New rotary mixing devices with various systems of vibration activation]. Stroitel'nye i dorozhnye mashiny [Construction and road machinery], 9, pp. 7-9. (in Russian)

Efremov, I.M., Lobanov, D.V. (2009). Vibrobetonosmesiteli: put' dlinoy v 70 let [Vibration concrete finishers: 70 years old experience]. Stroitel'nye i dorozhnye mashiny [Construction and road machinery], 10, pp. 15-19. (in Russian)

Kuzmichev, V.A. (2013). Osnovy proektirovaniya vibromikserov [Basics of designing of vibration mixers]. LAP LAMBERT AcademicPublishing, p.136. (in Russian)

Kuzmichev, V. A. (2014). Osnovy proektirovaniia vibratcionnogo oborudovaniia [Fundamentals of vibration equipment design]. Saint Petersburg: Lan, p.208. (in Russian)

Kuzmichev, V., Verstov, V. (2017). Vibration activators in the construction production technology. Architecture and Engineering, 2(1), pp. 24-32. DOI: 10.23968/2500-0055-2017-2-1-41-50

Verstov, V.V., Tishkin, D.D., Romanovsky, V.N. (2013). Sovershenstvovanie tekhnologii bespodkladochnogo montazha promyshlennogo oborudovaniia [Improvement of the technology of installation of industrial equipment without backing plates]. Installation and special works in construction, 7, pp. 27-31. (in Russian)

Zhang, K.S., Zhu, M., Tang, W.Y., Ou, W.H., Jiang, X.Q. (2016). Algorithm for reconstructing vibrational relaxation times in excitable gases by two-frequency acoustic measurements. Acta Physica Sinica, 65 (13): 134302. DOI: 10.7498/aps.65.134302 


\title{
DATABASES AND COMPLEXITY. REMOTE USE OF THE DATA IN THE VIRTUAL SPACE OF RELIABLE 3D MODELS
}

\author{
Sandro Parrinello', Francesca Picchio² \\ 1,2 DICAR, Department of Civil Engineering and Architecture, University of Pavia \\ 1Sandro.parrinello@unipv.it, 2Francesca.picchio@unipv.it
}

\begin{abstract}
With the advent of digital technology, communication has undergone radical transformation processes. The large amount of information that surrounds us with sociological, cultural and economic aspects, have changed the relationship between the perceiver and the context. The perceiver takes part of space, surrounding it, finding new ways to understand it and new archive systems of the information he may acquire.

Through digital survey and the use of skilled software, the elements and the relationships of the contemporaneity become networked and accessible to the public. The database in which all the data acquired is collected, permits an extraction of useful information for the orientation in space. This possibility allows the understanding of the relationship between elements and an ever-growing conscious approach to the project. Through digitization, the virtual environment can be preserved. This paper describes an innovative methodology that links the complexity of the databases (for the management of urban and architectural systems) with representation systems and three-dimensional space archives. Some experimental researches conducted explain ways in which one can create virtual databases. These instruments can become narrative path systems where the user can find and interface with the elements of space, in a more conscious, critical and structured approach.
\end{abstract}

\begin{abstract}
Keywords
Digital database, digital survey, 3D models, virtual reality, interactive space, fruition.
\end{abstract}

\section{The databases of digital architectural survey, quality and development systems ${ }^{1}$ \\ Dealing with databases for architectural documenta-} tion is not just determining the structure of a large data system about a surrounding context, but concerns, more specifically, a new image of the place. Thanks to the understanding of the critical structure of the Database it is possible to understand the architecture of the landscape and the surrounding space. Eventhough a few years ago databases were originally a support of the architectural drawings and occupied towering bookshelves in the offices of public administration, today, as they can be considered as critical base for the understanding of the context's structure, have changed their image becoming databases, thus containers of containers.

Technological progress and the arrival of the digital Era have moved, in the area of cultural heritage, all forms of documentation systems towards the realization of digital platforms which collect descriptive systems that are useful for the development of new methodological systems for

\footnotetext{
${ }^{1}$ The first, the second paragraphs and the conclusion are due to Sandro Parrinello. The third and fourth paragraphs are due to Francesca Picchio
}

the comparison of heterogeneous information. Similarly, the science of architectural survey in all its different forms: from archaeological survey up to the urban one; has been oriented towards the development of methodologies which, through the use of laser scanning instruments and cheaper cameras, is able to produce a point cloud, or databases of spatial coordinate and vector. The result of this transposition of data, from "sign" to a "code", results in the transformation of all the processed digital graphics in a data bank, which needs to be further processed and organized in order to be managed for its maintenance.

The possibility to extend architectural dimension in the digital space, creating three-dimensional models that could be used as real spaces, is the basis upon which video games and virtual simulations, since the early $80 \mathrm{~s}$, have been developed. What is happening today is the discovery of a new virtualization process, that has involved the metric and geometric availability of the digital data, and has begun to build evermore digital archives of our architectural heritage, in the hopes of preserving their memory. Digital space (a virtual control space, known as measured and digitally expressed according to preordered mental schemes that define the 


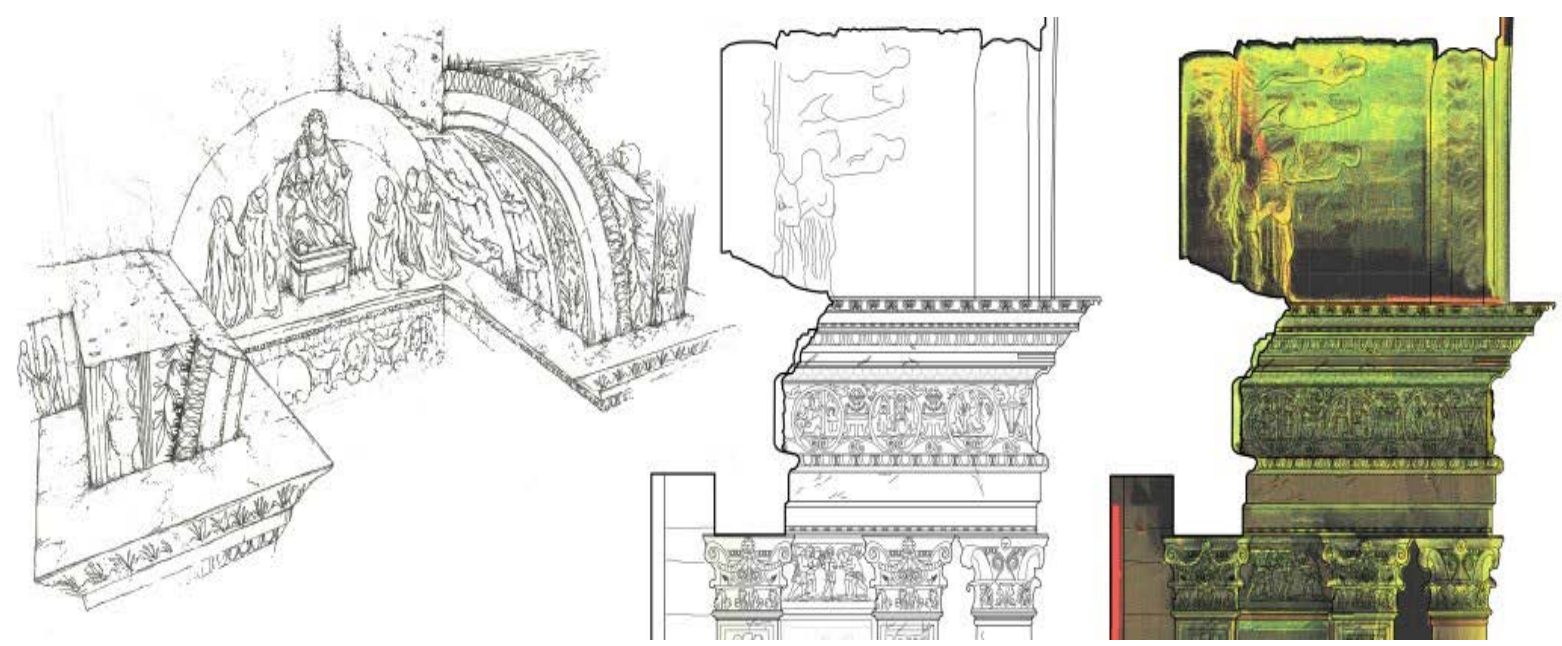

Figure 1. Perspective drawings, sections, and point cloud of the central portal of the Certosa of Pavia's facade. The evolution in representation: from the two-dimensional drawing to the display of a 3D database that consists of millions of points whose image reproduces the drawing of the architectural elements. Image from the Survey Laboratory of Prof. S. Parrinello, Civil Engineering and Architecture, University of Pavia

border and the limits of the context) becomes intelligible through the conformation of the point cloud where every single piece of the surface loses value if decontextualized, but in the context of the point cloud becomes increasingly valuable for the description of the specific space, the complete site and the mutual relations of its elements.

In particular, these point clouds are constituted of dynamic formats, in which the spatiality is repurposed in its three dimensions: the interaction with the virtual space allows a constantly changing management of the point of view and a direct interaction with the space, with the object or with the individual element, improving therefore, the knowledge of space itself.

This graphic post-production process started some years ago as a consequence of the process that transforms the drawing into a spectacular computing scene, reaches its maximum programmatic expression with the awareness of an interaction between databases. The measurement database, obtained by a practical action on the site, is based on an automatic points census acquired by laser instrumentation or photogrammetric procedures, and is regarded as the new starting point from which it is possible to conduct renewed interpretation to develop the drawing. This critical interpretation process of data acquires again the sense of a real database when it works in terms of interactions within the virtual-digital system.

The optimization procedure of digital models and the export of databases in different formats, which allow the post-production of data, revolutionizes the relationship with the artistic world, places and heritage, and contributes towards a new trust in digital technology, that must be justified, at least through the definition of standardized methodological protocols and certifications, to ensure its validity.
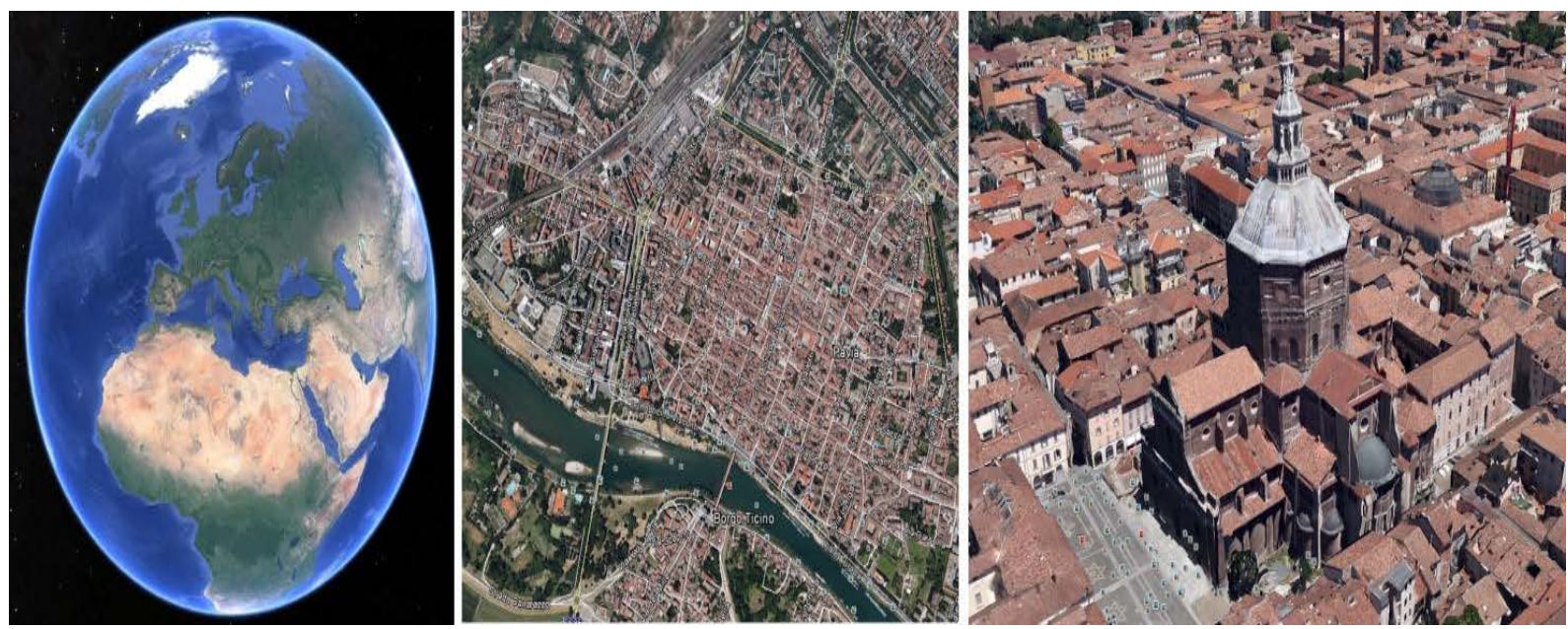

Figure 2. Google Earth is the most dynamic database used to understand geography, space, the quality of places and the structure of more complex buildings. Photographs become a model linking the images to other hypertext 

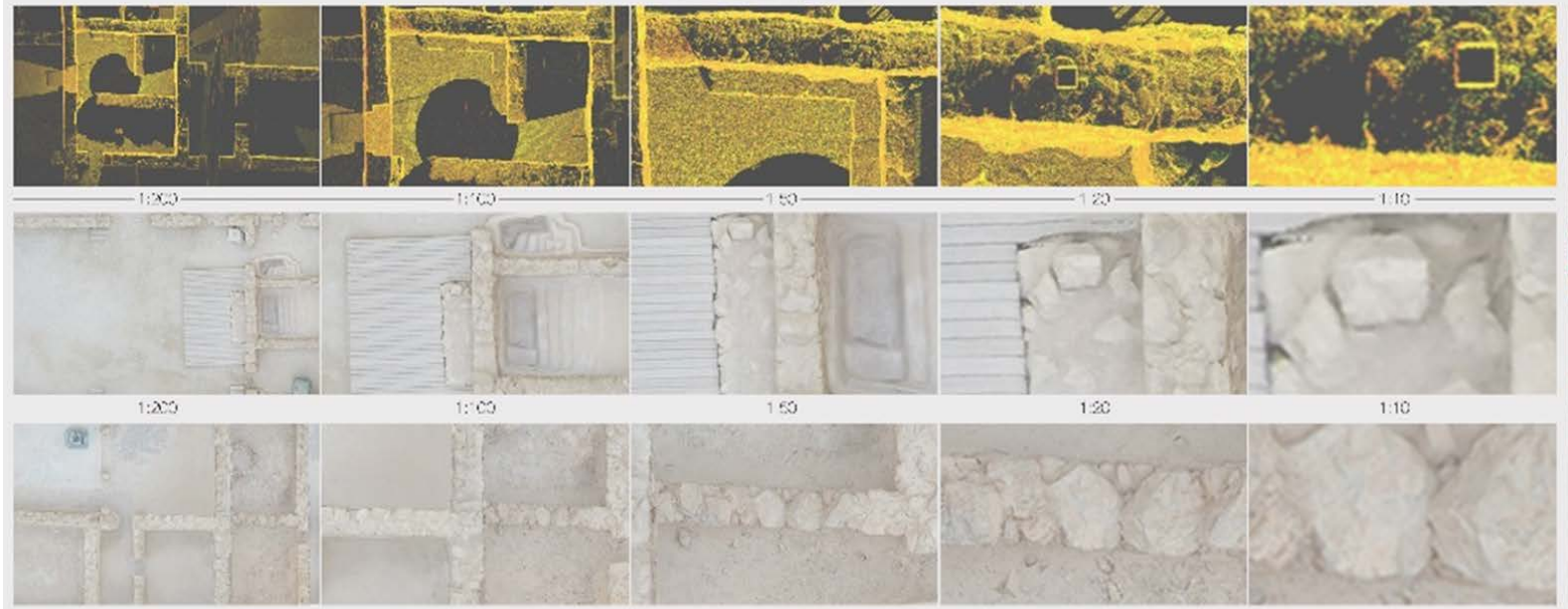

Figure 3. Point clouds obtained by laser scanner survey and photogrammetric survey compared in relation to the different graphic representation scales. It allows to check the data readability in a portion of the archaeological site at Masada (Israel)
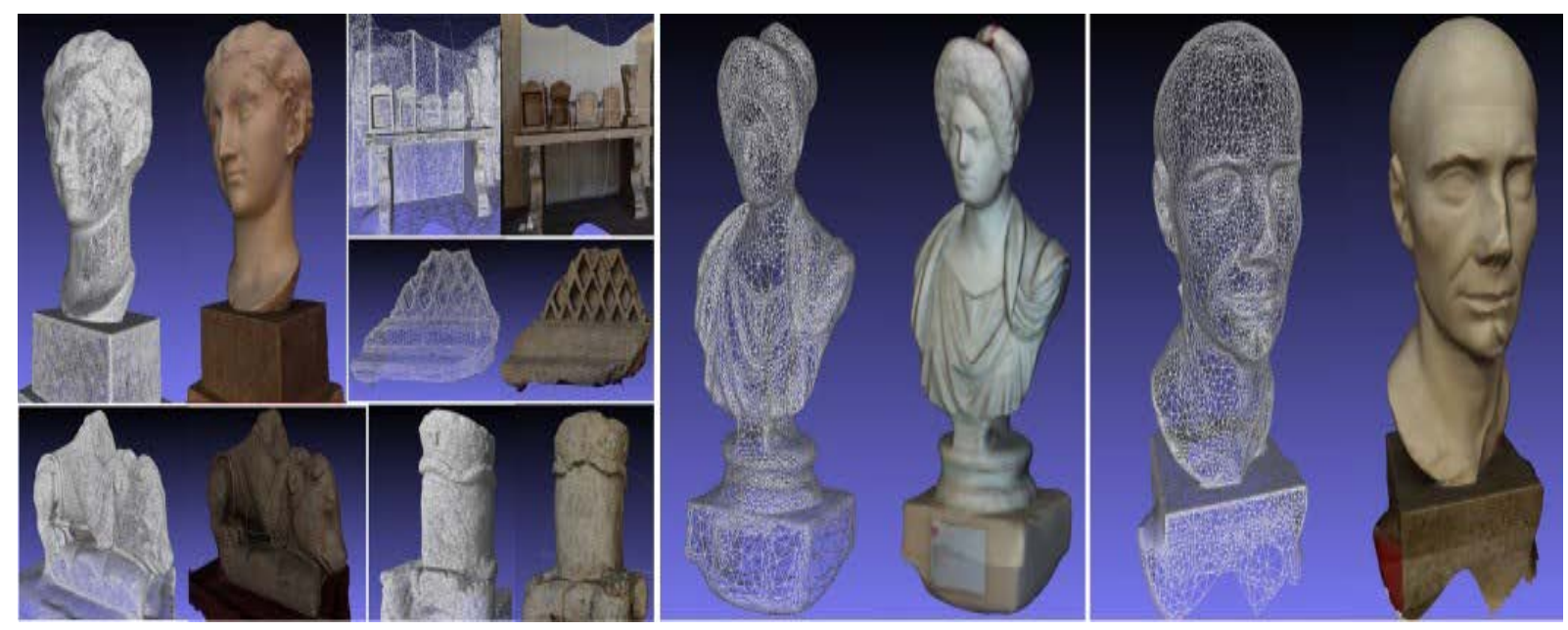

Figure 4. Digital Invasions with 3D processing of large sculptures of Salinas of the project "3D \#Digitallnvasions: a crowdsourcing project for mobile user generated content", is one example of heritage digitization and structuring of digital database that use three-dimensional data to become containers of information

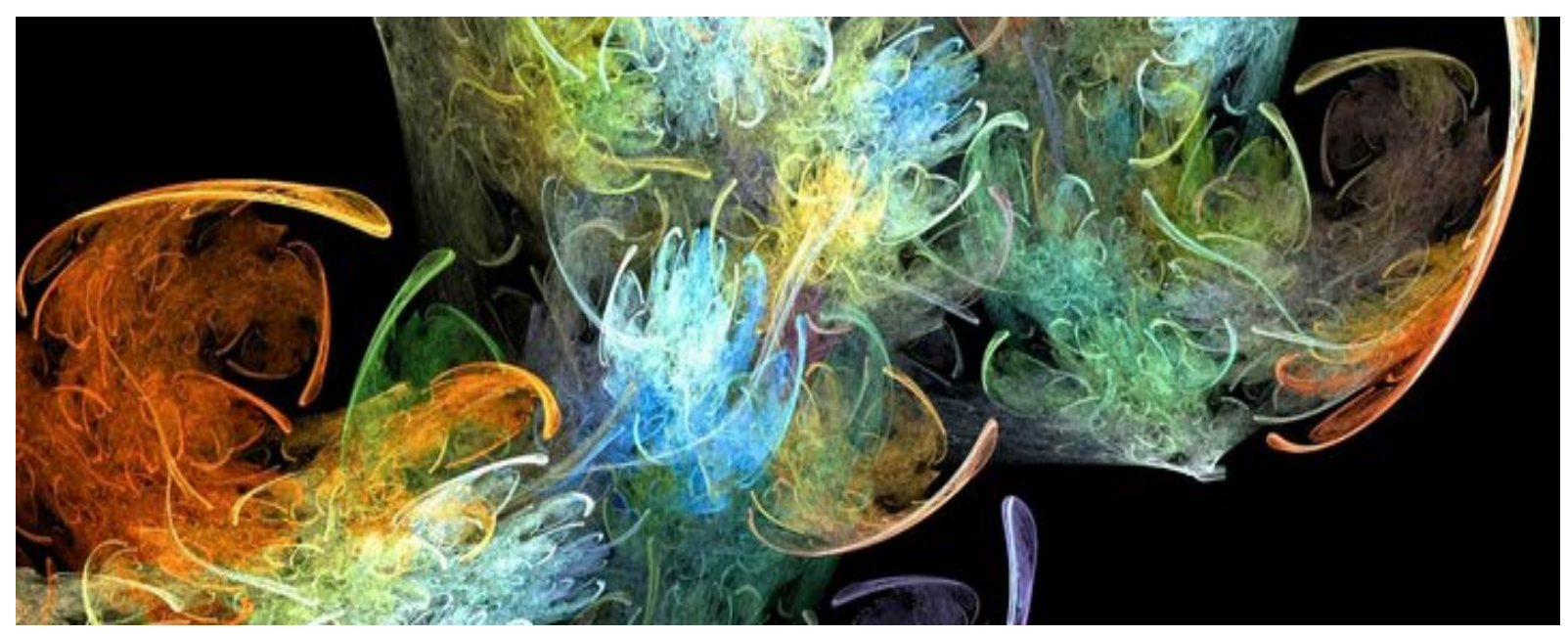

Figure 5. When coming into contact with the awareness of a cultural asset, the visible structure of the phenomenon breaks up in manifold parts, just as an ink drop getting into contact with water 
It is important to stress that, potentially, the interactions between different databases are strongly constrained to the lack of ability of programmers in the management and intervention in problems regarding the nature of files and their interactions. Under this perspective, the ability to create effective relationships between information systems and representative tools for the cultural heritage undoubtedly impacts the capability of a certain community to be "reflective", to better interpret and understand itself and, thus shaping its future, on the basis of fresher and updated data.

In particular, digital databases for cultural assets are the means necessary to structure models able to reproduce the complexity of reality, since they can provide tools for virtual simulation and connection among ambients and contexts, even when they are hugely different from one another.

In the same way, the digital databases now available, are characterized by the necessity to interact with the numerous areas of documentation, description, control and simulation of the real system.

In the recent years the increase of databases regarding cultural assets has marked the creation of numerous libraries and archiving systems, doomed to disappear because of the fast evolution of the state of art of technologies.

A crucial starting point for a significant reflection on such situation is the research implied by the architecture, where databases have to assume complex forms, supporting three-dimensional nature, and interact with data and information of different kinds, including representation systems of space.

As a consequence, the issues to tackle are both: linguistic/cultural, where the grammatical structure not only involves the lexical communication but also defines the forms for the representation models, i.e. the cognitive structures relating to both the real and the virtual systems of the databases; and technological, where the IT, the web-graphic, the design and different engineering solutions used to communicate shall find a proper way to interact in order to unify languages having digital nature.

Complexity and big data management, structuring of data for the interactive use

The revolution which began with the Digital Era has translated the whole representation sphere towards an immaterial communication system, able to propose an idealized future or a glorious past, as a witness of landscapes in transformation. To the possible utopian images that a place can assume, the research is extended to the possibility of virtually representing the complexity of contemporary urban spaces. Within our cities there are various aspects, relations - tangible and intangible - that need to be understood, captured and repurposed in a new expressive form understandable to a large and different audience. Deducing the shape and quality of the space, which consists of signs, constraints and interconnections, is the first operation that simplifies the real space and prepares the basis for the acquisition of data and its management in a virtual environment. The organization of the acquired data will allow the selection of information according to the needs of its user, to implement aspects related to the state of conservation of the architectural heritage, analyze the spatial relationships, and properly handle the post-production phases data.
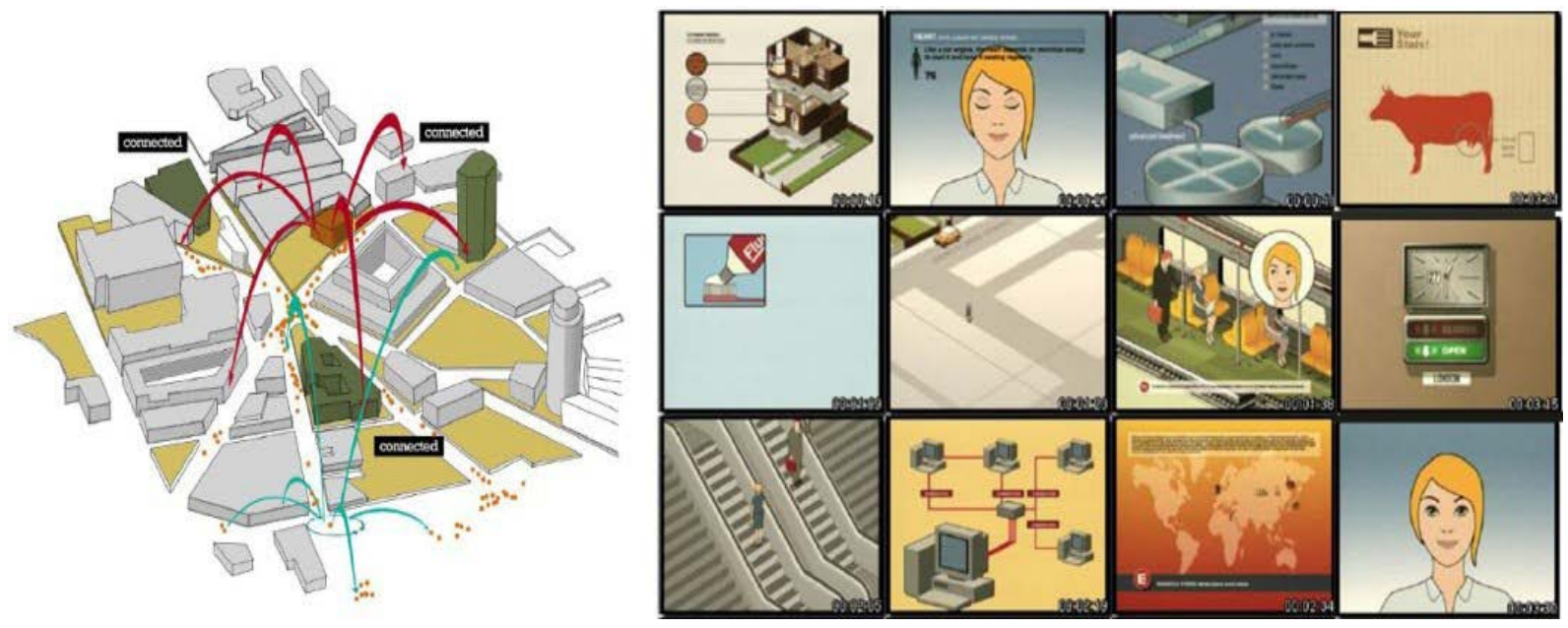

Figure 6. Some images from the video "Remind Me" of the Norwegian group Röyksopp, 2002 allude to an interconnected landscape, including buildings, streams of people and the system of communication between them; each element of the city is part of a constructive process managed in a database 

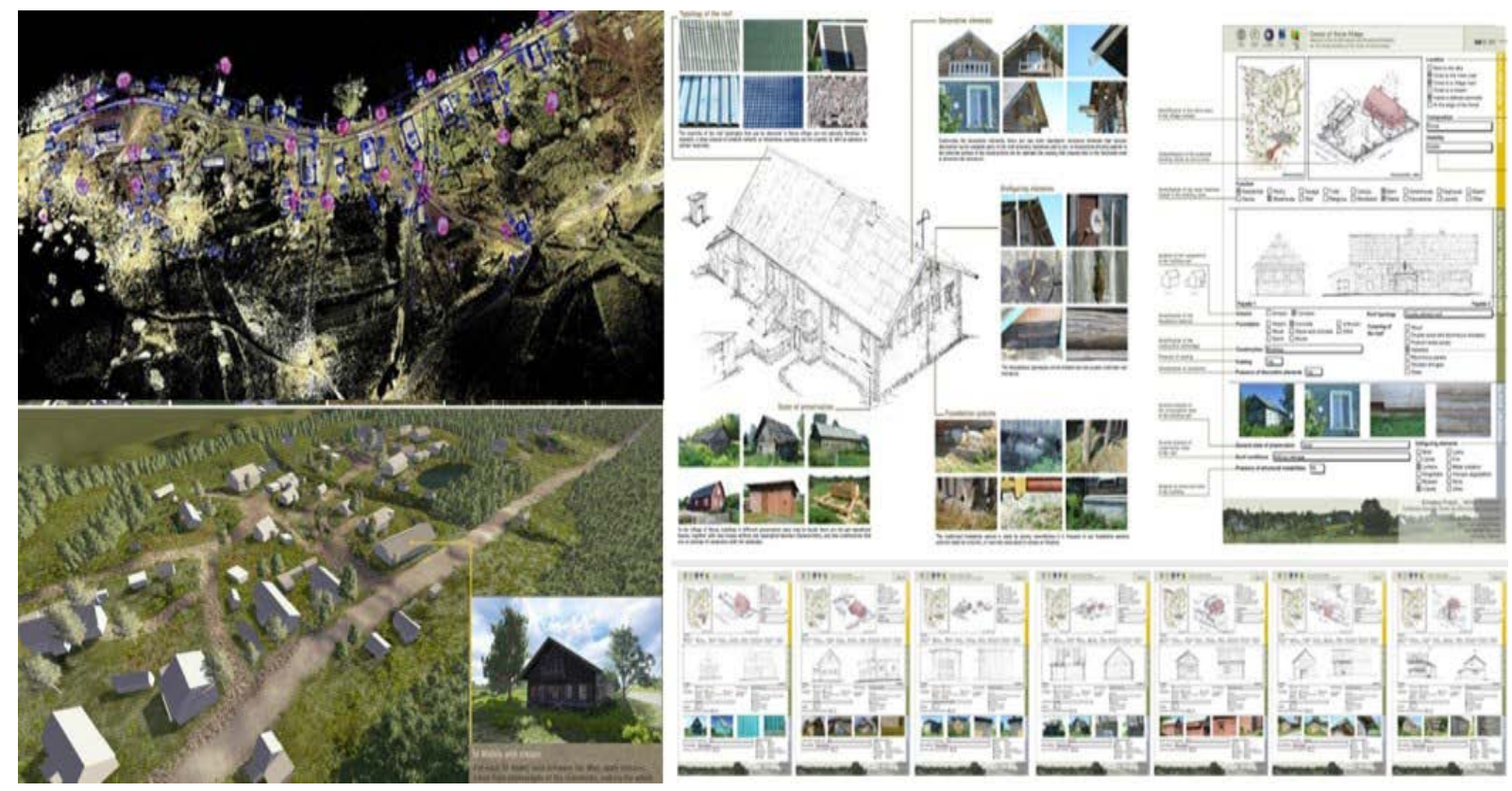

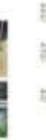

Figure 7. Database of traditional wooden villages in Karelia: census of buildings and realization of functional three-dimensional virtual system for the consultation of the material produced

The database on the urban landscape, which is constituted by the application of digital instruments, has the characteristic of being extremely reliable in metric and qualitative information aspects. Although the amount of information is overabundant they need to propose the three dimensional space in the virtual environment, the system of digital database is an open archive system, interactive and usable, which will produce an increasing data aggregation in the future to define synthesis procedure for the representation of the city.

This applied research, which today arrives to consider the synthesis and to define development models for the future, began in 2001 with the development of census systems for the analysis of the historical center of Montepulciano (SI). In the last fifteen years many researches have been conducted to be able to define the interaction systems in order to improve relations between the user and the virtual city. These researches focused on the study of the complexity in the architectural representation, in the methods of survey, and especially, on the systems of interaction between the user and the represented data.

Innovation of the scientific project, the smart cities through the database

There are numerous data banks generation experiences for the organization of the historical architectural heritage, the line of research presented in the present paper draws its strength from a multitude of experiments conducted to define a methodology for the creation of digital archives, initially, and for the development of functional and narrative systems to the use of the databases, eventually.
Moreover digital archives, especially if they present complexity, must be conceived and organized, whether they are dealing with three-dimensional metric data or with the description of the structural characteristics of a urban or a monumental system.

Experiences such as activities conducted for the census of wooden villages in Karelia, or projects for the definition of database on Italian small historical centers, up until participation for the protection of the historical landscape of Jerusalem, have allowed to determine census schedules for different purposes based on the interrelation of analytical descriptors associated with a discretization of the architectural space. Research on systems of documentation and digitization of the wooden heritage in Karelia (RF) is part of the European Research Project entitled Wooden Architecture. Traditional Karelian Timber and Landscape Architecture developed by the Seventh Framework Programme, Marie Curie Actions, coordinated by Prof. Sandro Parrinello and foster the development of international scientific research and the increase of scientific exchanges between universities of different countries. The project involved a period of thirty six months, from 2012 to 2014, during which four universities have had the opportunity to collaborate and meet on the subject of protecting and cataloging and digitization of traditional architectures of Karelian context.

The support to urban planning activity involved the digitization of some Italian small towns, including the historic center of the Municipality of Gatteo a Mare (FC), Tavarnelle Val di Pesa (FI) and Barbianello (PV), who regarded to the realization of dy-namic databases, containers of heterogeneous information but interconnected to the general digital system. 


\section{Architecture and Engineering Volume 2 Issue 2}
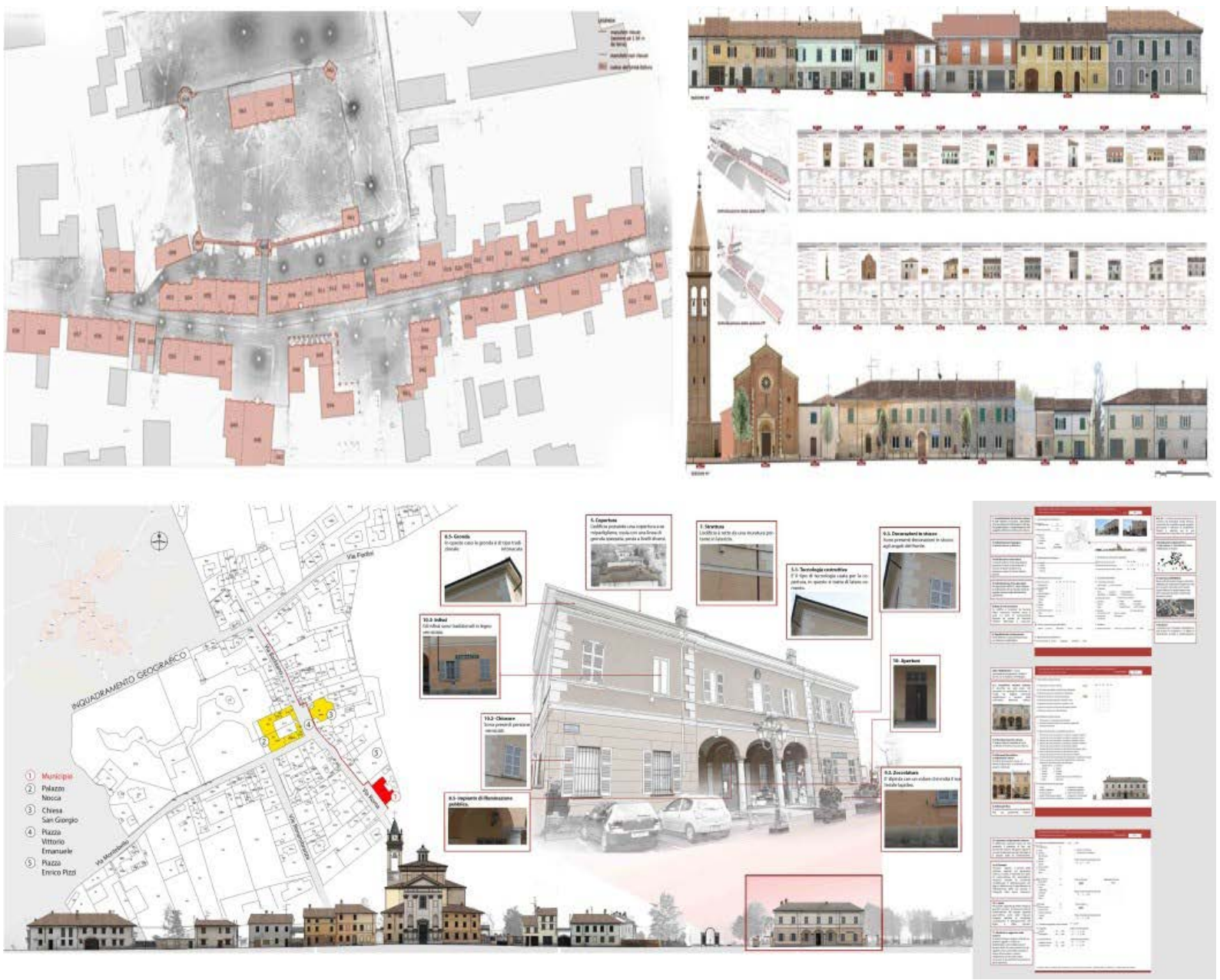

Figure 8. Databases consist of census forms drawn up for each of the buildings of an old Italian town
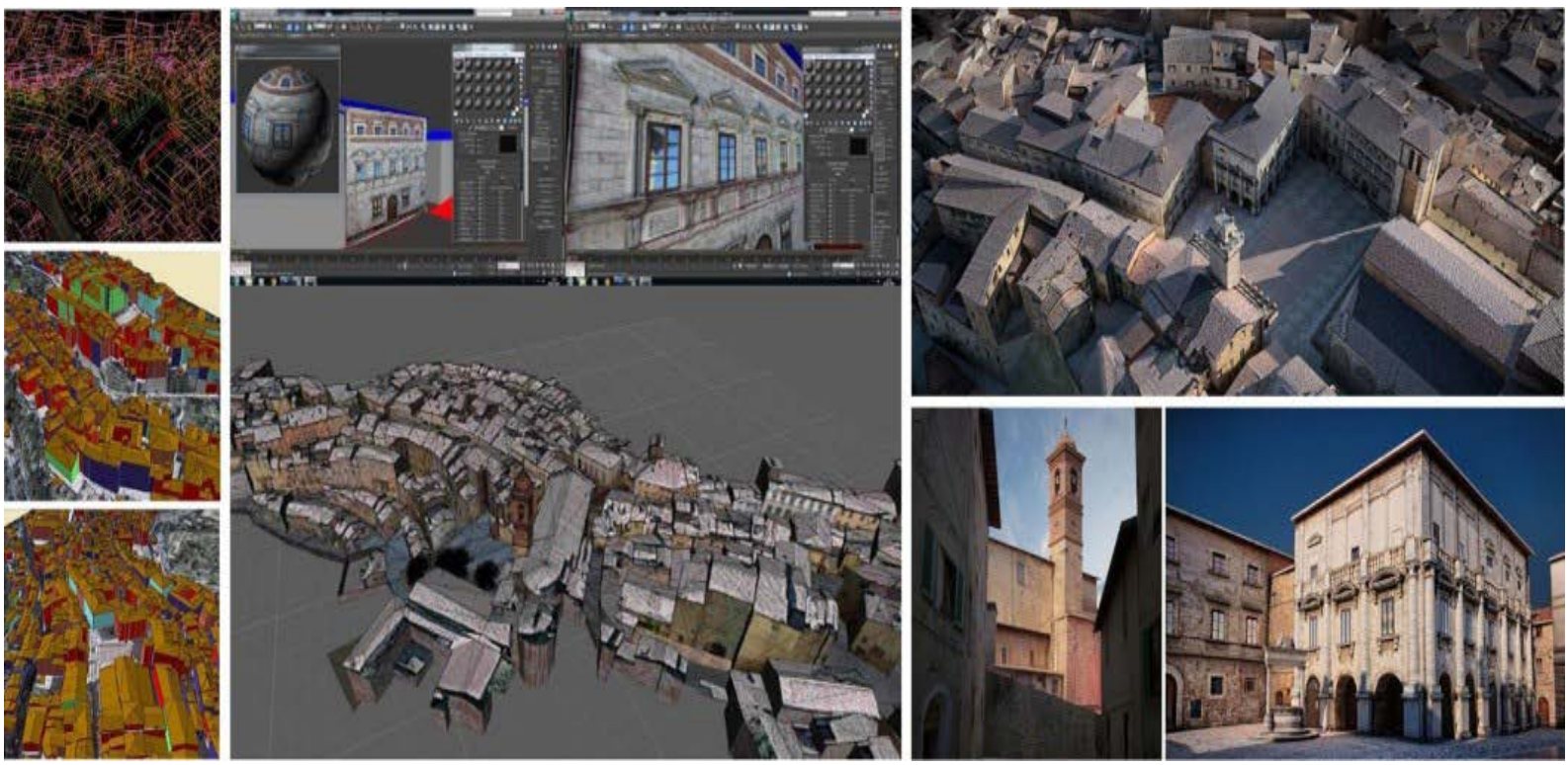

Figure 9. Image from NURBS modeling and texturing in 3D Studio Max, importing the 3D model of the town of Montepulciano($\mathrm{SI}$ ) on the interactive platform of Unity 3D. The three-dimensional system allows the total immersion user within the virtual container, which is not just a static interface of information, but a tool that, thanks to the fluid interaction of the urban fabric, allows fast access to the same content of the village. The possibilities offered by navigation are characterized by the use of visual interface and an interactive multimedia framework, which is revealed as a real emotional environment. Below some views of the model on Lumion 6.0. Project promoted by the Joint Laboratory Landscape, Survey and Design of Florence and Pavia University, coordinated by Prof. S. Bertocci and Prof. S. Parrinello. Realization of the 3D model: F. Bardini, S. Bua, F. Picchio 
The PURE project (Productivity and Urban Renewal in East Jerusalem), promoted by the European Union, by IDS Islamic Development Bank, UNDP United Nations Development Programme, and the Joint Laboratory Landscape Survey and Design of the University of Florence and Pavia, has provided a thorough and detailed analysis and survey of the buildings in the area close to the historic walls of Jerusalem town, the creation of a digital database, metrically and qualitatively reliable and elaborate two-dimensional and three-dimensional graphics drawings describing the state of conservation of each architectural element in order to protect or redesign the urban image.

The possibility to combine the complex data of the metric survey to the quality of the data from the census, improves the complexity of the digital system and the possibility of use of this instrument for projects or for planning. The research line is innovative, going through complex systems that make possible to reproduce and collect the dual aspect of a city, decoding and redrawing its features for a better understanding.

\section{Communication, fruition and interaction of SFM models in real time}

The diffusion of new media and the "fluidity" of new open source systems consider the environment and the contemporary architecture not as part of a historical process, but as an "information" system, belonging to the digital area. The information systems add the topic of interactivity of the user, the concept of being "here" and "there", outside of space and time and always interconnected with the world, which has led to an epic revolution in information technology and graphical representation (Basso, 2016). The representative aspect of the models, that are three-dimensional systems with high information content, allows the pursuit of the idealized methodological approach, that combines in both popular and managerial ways, the databases census systems of surveyed objects.

The visual appearance of a three-dimensional model obtained through photogrammetric procedures, to which is applied its corresponding texture, can satisfy the first impression about the ability of some software to generate virtual systems that are very similar to the real world. However, the interaction between user and screen offered by existing navigation systems is able to amplify the interaction with structure from motion patterns thanks to which it is possible to examine the complexity of the three-dimensional surfaces represented (Marini, 2006).

Cyberspace and virtual reality, of which new three-dimensional systems of representation of space
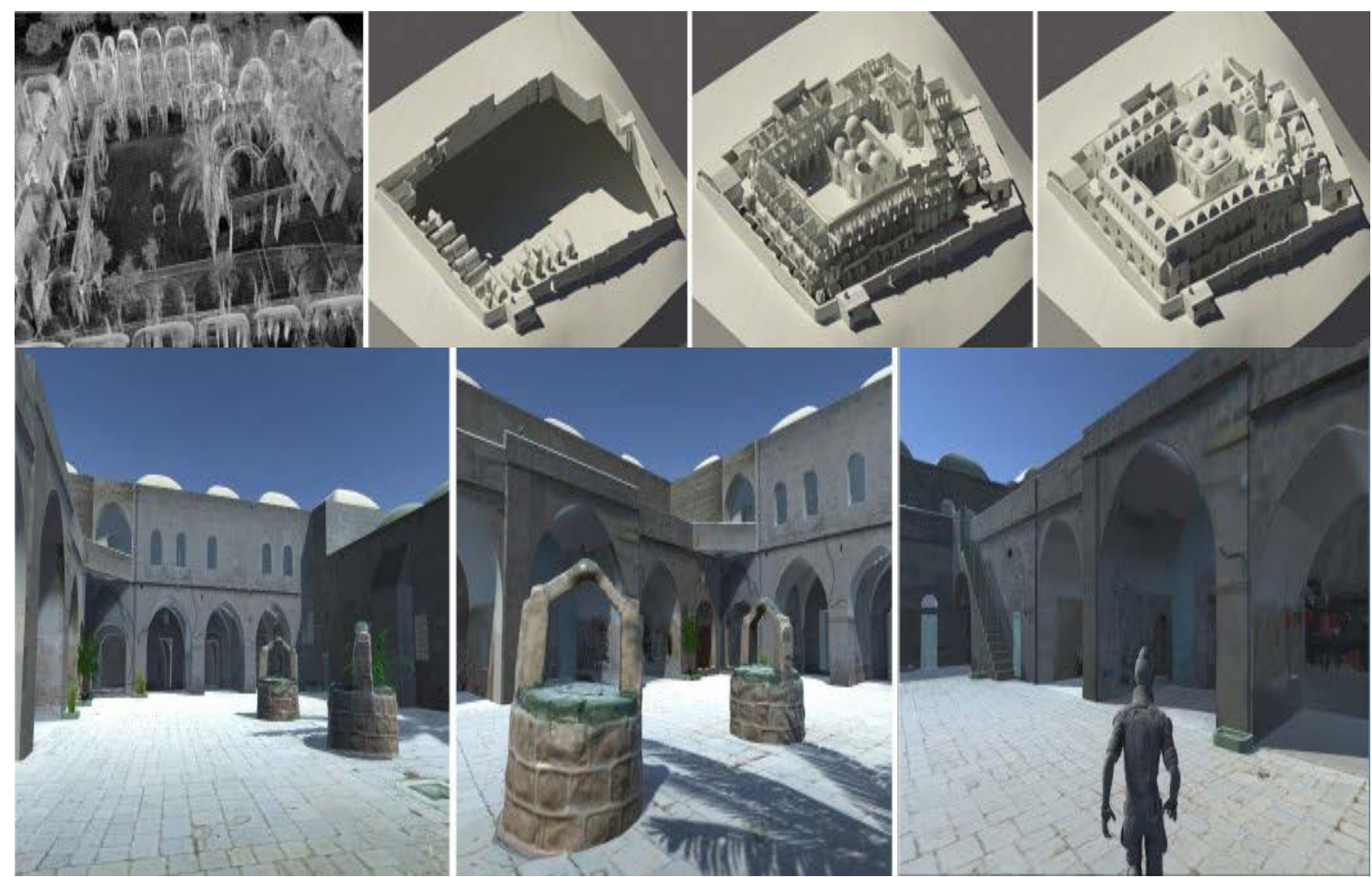

Figure 10. The realization of the three-dimensional model and the real-time model of the architectural complex of AI Nabi Musa (Palestine). The game, realized with the Unity software, is the result of a three-dimensional documentation project composed of NURBS and Mesh models, inserted within a virtual space, with the aim to digitized the complex. The operator moves freely inside the space by means of classical display or through an avatar, choosing paths and objects with which be in touch. Model made by Ph.D. stud. M. Bercigli, Department of Architecture, University of Florence 


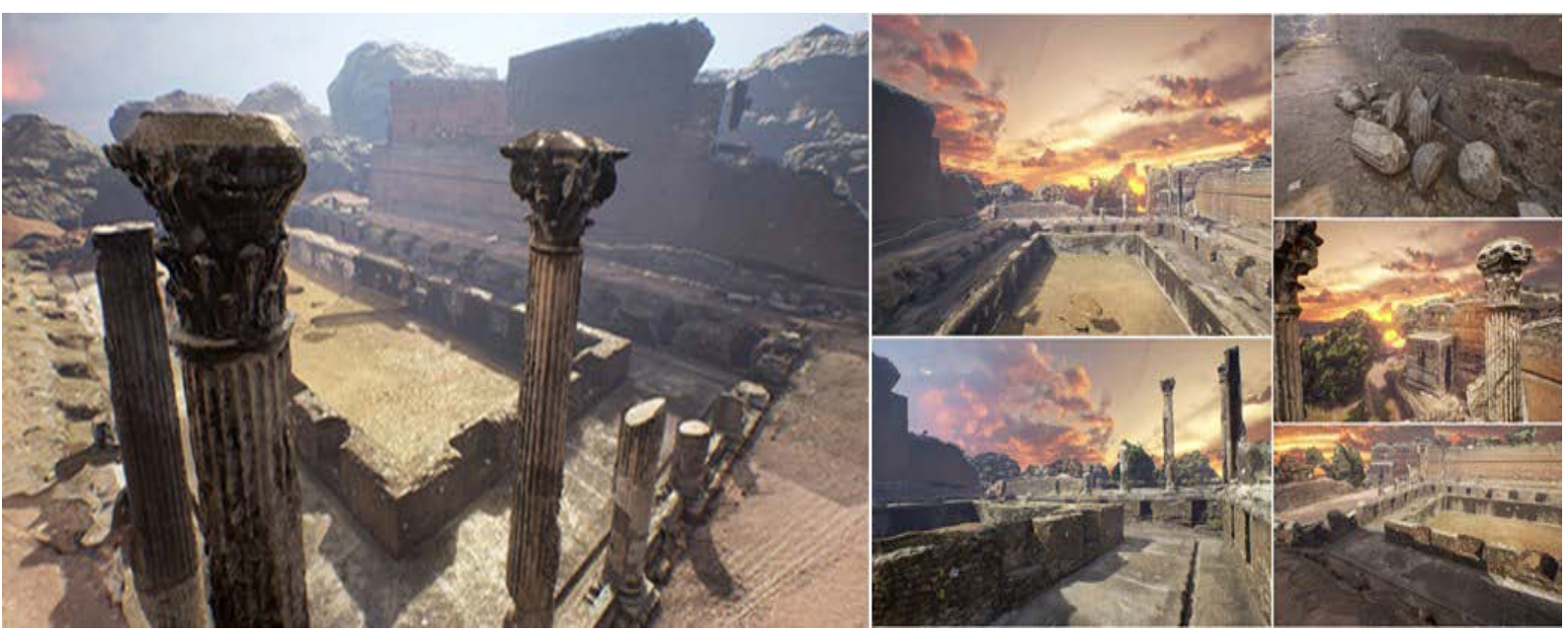

Figure 11. Portion of the building of Peschiera Villa Adriana (Tivoli). The three-dimensional model views made with the methodology structure from motion, composed entirely of mesh surfaces, imported software Unreal Engine 4. Model made by students F. Alberici, G. Chiappel-

la, G. Lentini, within the Laboratory of Prof. Relief S. Parrinello of the Degree in Civil Engineering and Architecture, University of Pavia

(including reality-based models) are a part of, allow to configure spaces, places and objects that merge various aspects of the representation from the sign to digital data, from text to sound. Thanks to the virtual reality it is possible to configure more communication purposes: from the simple digital tour of the architectural heritage, to its hypothetical reconstruction, redesign and reconfiguration.

The post-produced digital model of the virtual environment requires much attention, control and management of the data by the operator, especially in function of the aspect of the model inside the cyberspace. The structure from motion methodology, for example, takes advantage of numerical models, consisting of polygons and vertices, which approximate the shape of each architectonical element to decode 3D models. The model consists of a great number of polygons selected, under the discretion of the operator, depending on the finality of the database.

To be easily shared on a network and used, the models and the virtual places in which they are inserted must be carefully planned, in order to be easily recognized and codified.

The real time systems may offer users different levels of interaction, from those lower (as the systems created with QuickTime VR) to those with higher interaction, such as the latest generation of games, capable of mutually shared spaces and environments between various users.

The transformation from a two-dimensional to a three-dimensional system is organized on several levels of investigation, within which each element of the model, surface or single polygon can be selected and queried. This process becomes part of a methodology able to extend the use of photographic images and reality based modeling not just in management but also in the real time virtual representation.

Recent research works have involved the creation of remote runtime systems of the three-dimensional model, allowing dynamic interactions with a dense virtual space of multimedia content to help the formal material from the real space.

The dynamics of movement has an essential role in the contemporary communication system and especially in the Digital Era: the simulated object can rotate relative to the observer, and the observer can stay stationary while turning around, in a complete autonomy. Moreover, the scene can be enlarged or reduced and

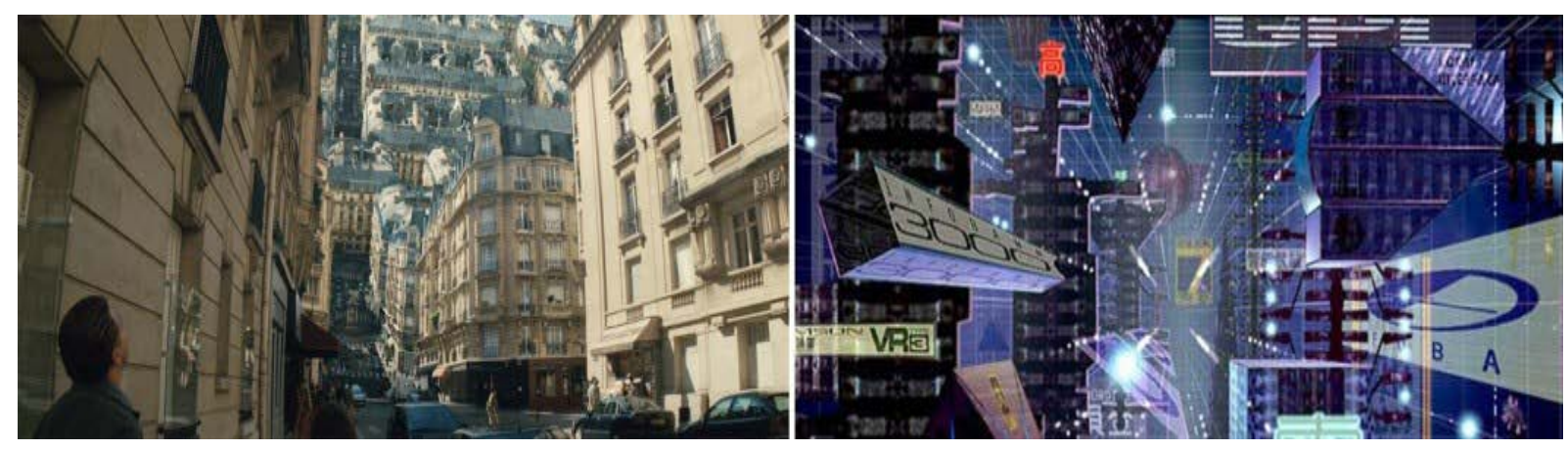

Figure 12. The digital space that looks like a city in the movie "Johnny Mnemonic" (R. Longo, 1995) and the multi-dimensional virtual reality of "Inception" (C. Nolan, 2010). Immersive systems that use databases produce more and more facilities similar to the real space in which to overcome the three dimensions to extend toward the infinity 
transformed topologically, as much as it can amplify the perceptive abilities of users. The total immersion experience within the three-dimensional space (Virtual Reality) allows the user to face, as much as he would in real life, all sensorial experiences, thus involving him in a digital space with the ability to manipulate it: the space described must consist of polygonal models that optimize the data management, to which it is possible the addition of high-quality texture to increase the perception of geometric details.

The organization of elements through a semantic procedure constitutes a fondamental organizational structure for the storage and archiving of data, as it is a consequence of the mental process of design, integrating and transforming it in a corresponding digital system, where each element can be a part of, or constitute in itself, an autonous database, complete and usable by the user.

Virtual reality appears as an effective representation of space because it allows the user to analyze, manage, and interact directly with the largest database offered by reality based models from the highly reliable detection systems, such as laser scanners and photographic instruments.

\section{Conclusion}

The advantage of the link between the databases and the models that discretize the complex area is the ability to view, learn and interact with a place in a dynamic way, within a space able to communicate heterogeneous information about its elements. The dynamic interaction joins the ability to update the digital system, through continuous interaction between the instruments used and the established database, infinitely implementable. The methodology of approach to space and database systems, census and digitization of the acquired and processed data, tries to answer to the contemporary necessity for the representation and the management of urban complexity. The drawing of the city changes from the concept of image reproduction, in two or three dimensions, to become multidimensional instruments through which the user participates, interacts and communicates constantly with the context, transforming the image depending on specific needs. This methodologically structured system is able to reformulate an updated descriptive system of spatial complexity, which is expressed through a process able of developing the digital tools as the starting point for a research on the image of the place. The virtual city, full of information, is the mirror of our civilization, through which we define the basis for the protection of heritage and develop the future aspect in which every choice will appear and seem possible within the network. 


\section{Architecture and Engineering Volume 2 Issue 2}

\section{References}

Basso, A. (2016). Analisi e riconfigurazione della città contemporanea attraverso la rappresentazione [Analysis and changing of the image of a modern city via representation]. PhD Thesis in Architecture. (in Italian)

Benedetti, B., Gaiani, M., Remondino, F. (2009). Modelli digitali 3D in archeologia: il caso di Pompei [Digital 3D models in archaeology: case study of Pompeii]. Pisa: Normale Publishing House. (in Italian)

Bertocci, S., Parrinello, S. (2007). Rilievo e Piano di Gestione per il Centro storico di Montepulciano [Geodesic map and master plan of the historic center of Montepulciano]. Florence: Alinea Publishing House, pp. 108-113. (in Italian)

Bertocci, S., Parrinello, S., Bua, S., Picchio, F. (2014). Montepulciano 3D: modelli vir 7 tuali per l'urbanistica e lo sviluppo dell'ambiente urbano [Montepulciano in 3D. Virtual models for urban development]. Disegnarecon, 7(1), pp. 1-20. (in Italian) DOI: $10.6092 /$ issn.1828-5961/4152

Bonacini, E., Inzerillo, L., Marcucci, M., Santagati, C., Todisco, F. (2015). 3D \#Digitallnvasions: a crowdsourcing project for mobile user generated content. Furnace Journal, 2. Available at: https://www.researchgate.net/publication/282317653_3D_DigitalInvasions_a_crowdsourcing_project_for_mobile_user_generated_content (viewed on: 12.03.2017)

Levy, P. (1997). I/ Virtuale [Virtuality]. Milan: Cortina Raffaello Publishing House. (in Italian)

Maldonado, T. (2005). Realtà e Virtuale [Reality and virtuality]. Milan: Feltrinelli Publishing House. (in Italian)

Marini, D., Bertolo, M., Rizzi, A. (2006). Comunicazione visiva digitale, Fondamenti di Eidomatica [Visual digital communications. Basics of the computer graphics]. Boston: Pearson: Addison Wesley Publishing House.

Merlo, A., Sánchez Belenguer, C., Vendrell Vidal, E., Fantini, F., Aliperta, A. (2013). 3D model visualization enchancements in real-time game engines. Trento, Italy.

Remondino, F., Rizzi, A., Giorgio, A., Jimenez, B., Menna, F., Nex, F., Baratti, G. (2011). Rilievi e Modellazione 3D [Geodesic surveying and 3D modelling]. In: proceedings of the 15th National Conference ASITA (Italian Federation of Scientific Assosiations in the sphere of regional information). Reggia di Colorno. (in Italian) 


\title{
STABILITY CALCULATION OF ROD ELEMENTS OF SOLID-WALL ARCHES BY THE FLEXURAL-TORSIONAL FORM
}

\author{
Dmitrii Urazgildeev, Grigorii Beliy² \\ 1,2 Saint Petersburg State University of Architecture and Civil Engineering \\ Vtoraja Krasnoarmejskaja ul. 4, St. Petersburg, Russia \\ 1 urazgildeev.dmitry@yandex.ru
}

\begin{abstract}
The work considers main, most significant scientific works on study of the stability of rods with the curved axis; the issue of the subject matter investigation is examined. A procedure for determining the spatial displacements of curvilinear rods during the elastic work of the material is proposed. An for the assessment of the stress-strain behavior of the rod element with the curved axis by the criterion of fibrous yield is given. As the algorithm illustration, an example is given of selecting a section of a steel arch.
\end{abstract}

Keywords
Stability, solid-wall steel arch, curved axis rod, thin-walled rod.

\section{Introduction}

Steel arches for roof-bearing structures appeared in 1940-1950s. Besides their architectural expressiveness, arches have a doubtless advantage over beam and frame structures due to considerably smaller bending moments occurring in structure sections. Decrease of the bending moment in arches is achieved due to a thrust which creates a moment, opposite in sign to the moment from external forces, in each structural section. In this connection, the main design value for the arch is not the bending moment, but the axial load. In designing of metal arches, the determining factor, when assessing the operation capability of a structure, is not the ability to resist bending, but the ability to maintain the axis shape (stability). The loss of stability by a curved axis rod has more complex nature than the loss of stability by a straight rod.

\section{Background}

Many scientists studied the stability of straight and curved axis rods of open profile. S.P. Timoshenko was one of the first who considered the problem of the stability of a curved axis rod. In his work (Timoshenko, 1971), he provided the derivation of a differential equation of the stability of the plane bending of a curved axis rod. The contribution of V.Z. Vlasov to this study should be noted too. He developed a technical theory of calculating thin-walled rods of open profile; this theory was the basis for many scientific works related to the stress-strain state of thin-walled rods. In his work (Vlasov, 1959), Vlasov considered various particular problems related to the stability of thin-walled circular rods, arches and toroid-shape shells. Works of A.A. Umansky should be specially mentioned; the author developed a theory of rods of closed profile.

The deformation theory by Vlasov for calculating thin-walled rods was worked out in papers of B.M. Broude, L.N. Vorobyev and was generalized by E.A. Beylin.

In speaking of the calculation of a thin-walled curved axis rod by the stress-strain scheme, it is necessary to mention works of E.A. Beylin (Beylin, 1997; Beylin, 1970), as well as G.I. Beliy (Beliy, 1973), who considered in his scientific work a number of particular problems related to performance of curved axis rods under various loads and boundary conditions.

\section{Challenging issues of the study}

The use of arched structures in large-span buildings allows for significant decrease in steel consumption. However, their large-scale implementation is restrained by the lack of directions for stability calculations in domestic design standards; meanwhile, researches, which are available in this area, do not allow developing an engineering calculation procedure. Therefore, one of relevant directions of research is the study of the spatial stability of curved axis rods in order to obtain an engineering technique for the calculation of solid-wall arches. 
Algorithm of the stress-strain calculation for the stability of an arch rod element by the flexural-torsional form

Let us consider a problem of the stability of plane bending of a thin-walled rod element selected from a solid-wall arch (see Figure 1).

The considered fragment is located between points of the arch bracing out of the plane - between runs. The length of the rod element is assumed to be equal to its geometric length. The element is loaded with the axial force $\mathrm{F}$ applied with eccentricities relative to both axes of symmetry ex and ey, as shown in Figure 2a. Ends of the arch are hinged in the plane and out of the plane of the initial curvature; curling of arch ends is absent.

The selected rod element of the symmetrical section is hinged in the plane and out of the initial curvature plane; there is no curling of the end sections.

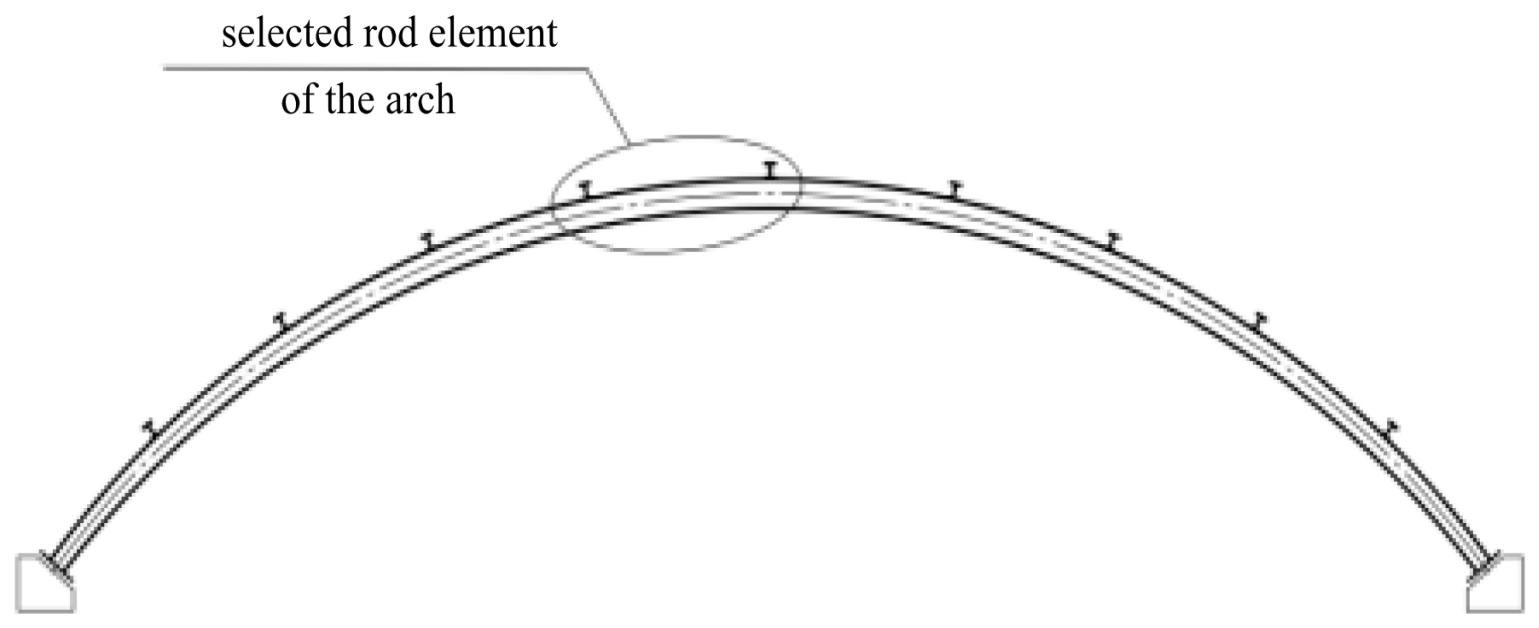

Figure 1. Selection of a rod element from the structure

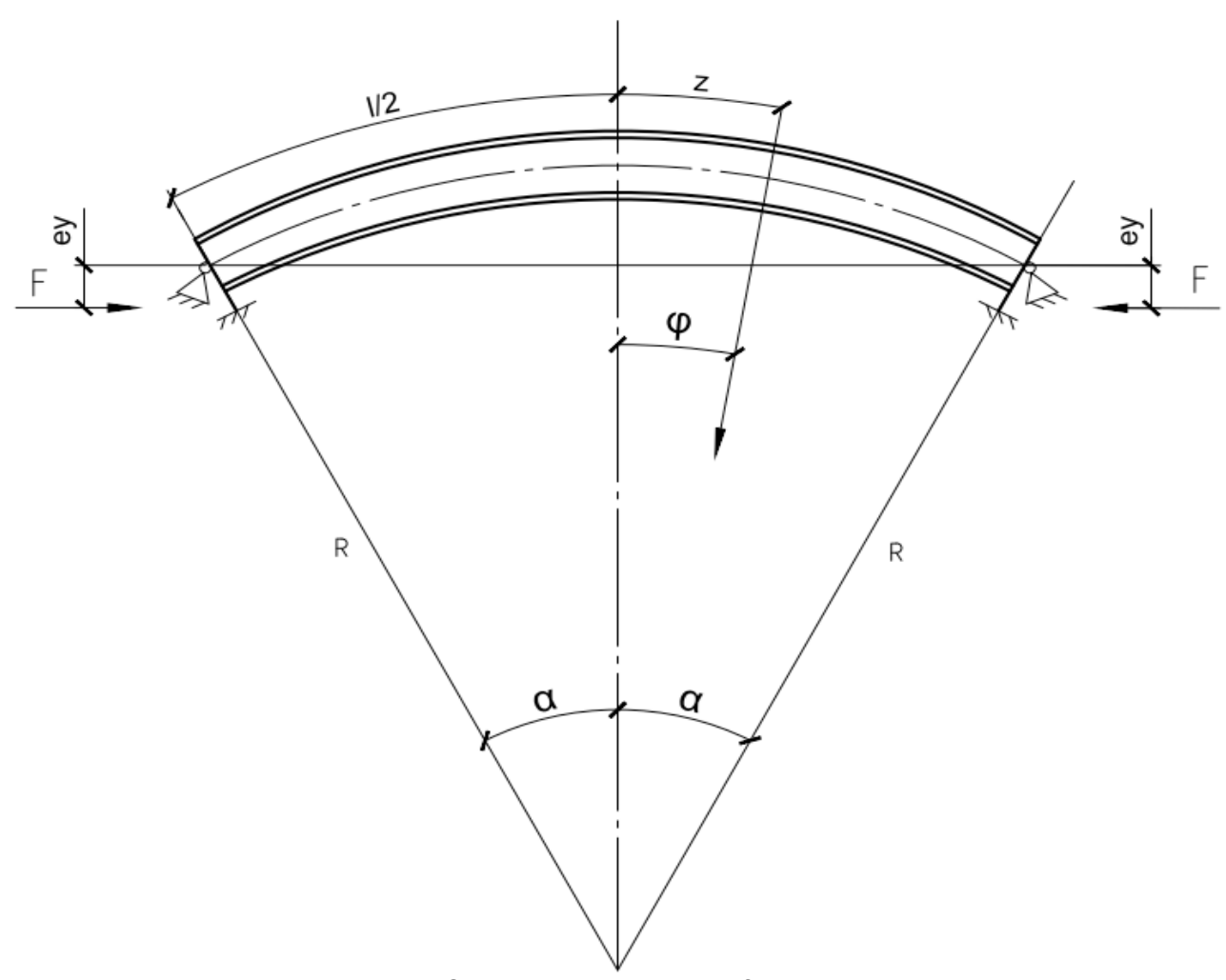

Figure 2. Computational scheme of the element 
To solve the set problem, let us apply the system of stress-strain equilibrium equations of $E$. A. Beylin for curved axis rods. At accepted bracing conditions and the section shape, differential equilibrium equations of the rod will take the following form:

$$
\left\{\begin{array}{l}
E J_{y} X_{y}^{\prime \prime}-X_{y} N-X_{z}^{\prime} M_{x}-2 X_{z} M_{x}^{\prime}+\frac{1}{R}\left(G J_{k} X_{z}^{\prime}-E J_{\omega} X_{z}^{\prime \prime \prime}\right)=0 \\
E J_{\omega} X_{z}^{\prime \prime \prime}-G J_{k} X_{z}^{\prime}-X_{y}\left(M_{x}-\frac{E J_{y}}{R}\right)-i_{P}^{2}\left(X_{z} N\right)^{\prime}=0
\end{array}\right.
$$

where $X_{y}, X_{z}$ are unknown functions of components of the curved rod axis movement, which are found with the following equations:

$$
X_{y}=-v^{\prime \prime}+\frac{\theta}{R} ; X_{z}=\theta^{\prime}+\frac{v^{\prime}}{R}
$$

$E, G$ are modules of linear and shear deformation; $J_{y}$ and $J_{\omega}$ are the main axial and sectorial moments of section inertia; $J_{k}$ is the moment of inertia of bending-prevented torsion; $i_{p}$ is the polar radius of inertia; $v$ is the lateral displacement of the rod axis, $\theta$ is the angle of rod curling.

Values of force factors acting along the rod length, with account for the curvature of the rod, take the following form:

$$
\begin{aligned}
& M_{x}=F R(\cos \varphi-\cos \alpha)+F e_{y} \\
& M_{y}=F E_{x} \cos \varphi \\
& N=F \cos \varphi \\
& M_{z}=F e_{x} \sin \varphi
\end{aligned}
$$

To calculate the equation system (1), let us use the analytical-numerical procedure; wherein the general solution of the problem upon the elastic work of the material is represented in the form of the combination of particular solutions:

$\chi_{y}=\chi_{y, s t r}+\chi_{y, s t} ; \chi_{z}=\chi_{z, s t r}+\chi_{z, s t}$

The first summands are solutions of equations compiled according to the strainless calculation scheme:

$$
E J_{y} \chi_{y, s t r}=M_{y} ; G J_{k} \chi_{z, s t r}-E J_{\omega} \chi_{z, s t r}^{\prime \prime}=M_{z}
$$

Let us substitute values of force factors (3) into equations (5) and obtain the following:

$$
\begin{aligned}
& E J_{y} \chi_{y, s t r}=F e_{x} \cos \varphi ; \\
& G J_{k} \chi_{z, s t r}-E J_{\omega} \chi_{z, s t r}^{\prime \prime}=F e_{x} \sin \varphi
\end{aligned}
$$

Transforming equations (6):

$\chi_{y, s t r}=\frac{F \cdot e_{x}}{E J_{y}} \cos \varphi ;$

$-\chi_{z, s t r}^{\prime \prime}+\frac{G J_{k}}{E J_{\omega}} \chi_{z, s t r}=\frac{F e_{x}}{E J_{\omega}} \sin \varphi$

Solving the set equations (7), we obtain:

$$
\begin{aligned}
& \chi_{y, s t r}=\frac{F \cdot e_{x}}{E J_{y}} \cos \varphi ; \\
& \chi_{z, s t r}=\frac{F \cdot e_{x} \cdot R^{2}}{E J_{\omega}}\left(\frac{\sin \varphi}{\left(k^{2} R^{2}+1\right)}-s h(k z) .\right.
\end{aligned}
$$

$\frac{\cos \alpha}{k \cdot \operatorname{ch}\left(\frac{k l}{2}\right)}\left(\frac{e_{y}}{R^{2}}+\frac{1}{\left(k^{2} R^{2}+1\right) R}\right)$

where $k=\frac{G J_{k}}{E J_{\omega}} ; \varphi=\frac{z}{R}$

The second summands in (3) are functions of the stability loss, which follow from the solution of bifurcation stability problems. With account for the set calculation scheme, the loss-of-stability functions will take the following form:

$\chi_{y, s t}=\chi_{y, s t} \cos \frac{\pi z}{l} ; \quad \chi_{z, s t}=\chi_{z, s t} \sin \frac{\pi z}{l}$

Where $\cos (\pi z / l)$ and $\sin (\pi z / l)$ are forms of the stability loss, and $X_{y, y}$ and $X_{z, y}$ are some unknown constants.

Let us substitute the values of solutions (4) in (1), considering (8) and (9), and obtain the following: 


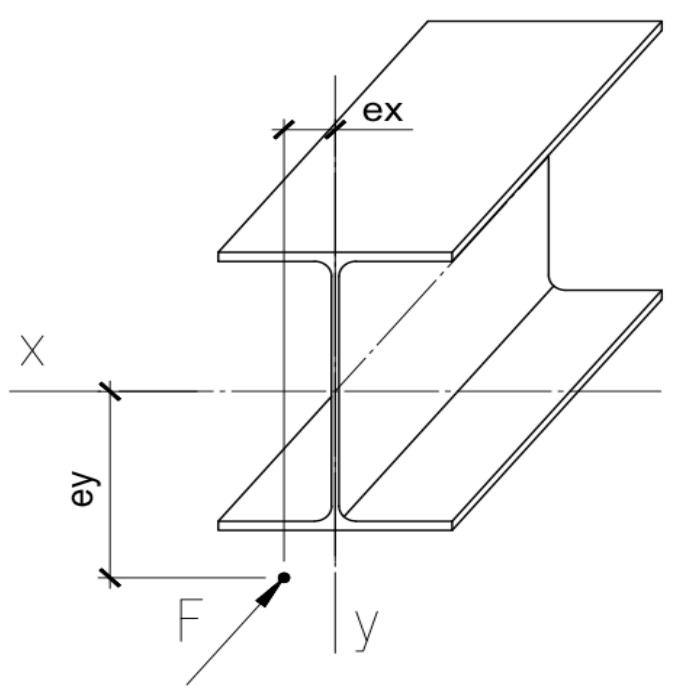

(a)

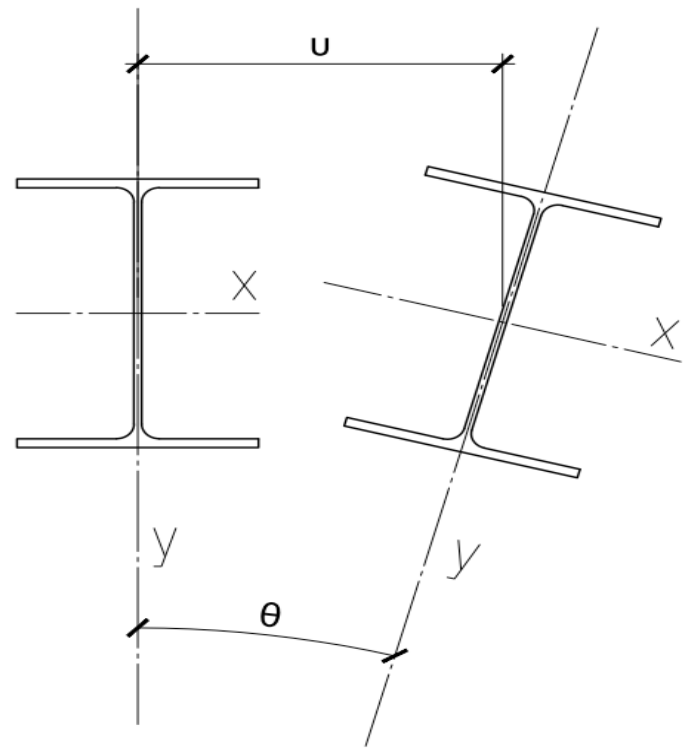

(b)

Figure 3. $a$ - loading scheme; $b$-spatial movements of sections

To solve the system (10), let us apply the algorithm of the Bubnov-Galerkin method:

$$
\left\{\begin{array}{l}
\int_{0}^{\frac{l}{2}} L_{y} \cos \frac{\pi z}{l} d z=0 \\
\frac{l}{2} \int_{0}^{\frac{l}{2}} L_{z} \sin \frac{\pi z}{l} d z=0
\end{array}\right.
$$

As a result, we will obtain systems of two algebraic equations relative to unknown constants $X_{y, y}$ and $X_{z, y}$. Having solved this system, we will obtain all components of movements. Substituting values $X_{y}$ and $X_{z}$ in (2) and solving the system of differential equations, we will obtain values of $v$ and $\theta$, which allow proceeding to strain stresses:

$M_{y}=M_{y}^{0}+N^{0} v+M_{x}^{0} \theta ; \quad B_{\omega}=-E J_{\omega} \theta^{\prime \prime}$

Taking into account (12), let us present the values of stresses in the rod middle section:
$\sigma=\frac{N}{A}+\frac{M_{x}^{0}}{W_{x}}+\frac{M_{y}^{0}+N^{0} v+M_{x}^{0} \theta}{W_{y}}+\frac{B_{\omega}}{W_{\omega}} \leq R_{y}$

Let us divide both sides of the equation (13) by $R_{y}$ and take N/ARy out of the brackets.

After a number of transformations, the equation (13) will take the following form:

$\frac{N}{A R_{y}}\left(1+m_{x}^{0}+m_{y}^{0}+\frac{v(0)}{\rho_{y}}+\frac{e_{y} \theta(0)}{\rho_{y}}+\frac{B_{\omega}}{N \rho_{\omega}}\right) \leq 1$

Where $m_{x}, m_{y}$ are relative eccentricities; $\rho x, \rho y$ are radii of section cores.

The resulting expression allows determining the critical load values.

Thus, the above algorithm makes it possible to assess stability of circular axis rods by the flexural-torsional form according to the fibrous yield criterion.

\section{Example of calculation}

As an illustration of the calculation procedure, an example of the section selection for a steel arch with the run of $36 \mathrm{~m}$, the rising height of $8.5 \mathrm{~m}$, and the interval of runs of $5.0 \mathrm{~m}$ is stated.

Preliminary, let us take the arch section as 70Б0 I-beam according to the industry standard STO ASChM 20-93, the material of construction - C245 steel.

The arch stability in the plane is considered to be ensured. 


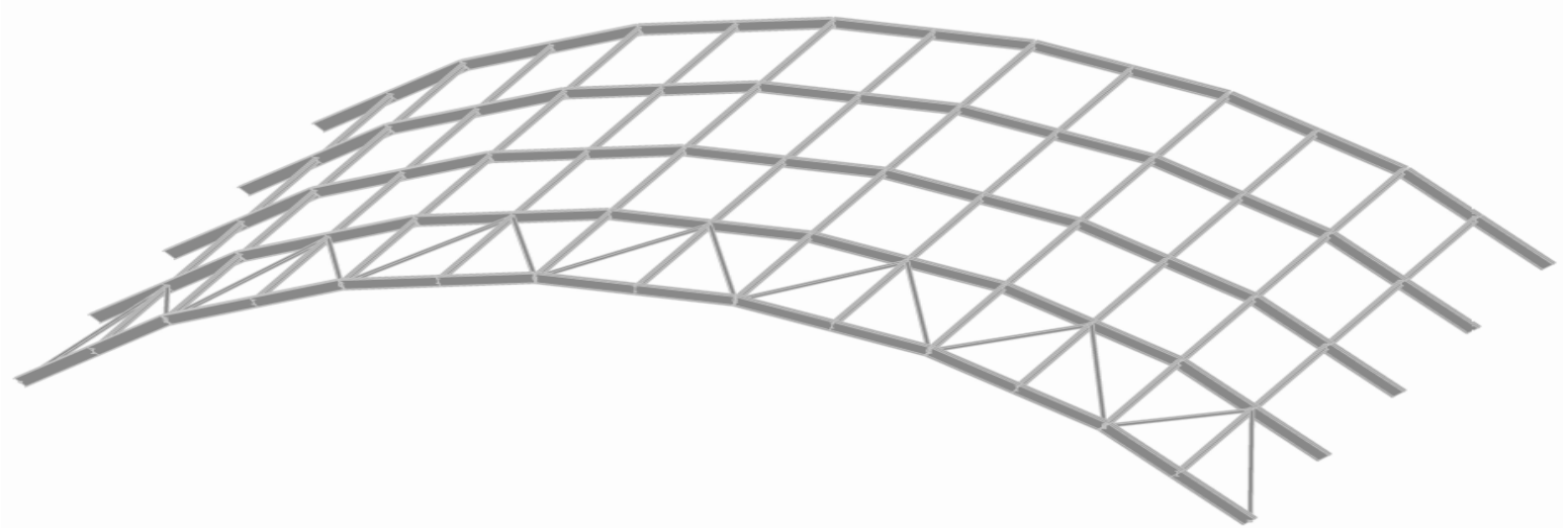

Figure 4. Fragment of a building frame

Let us select from the arch a rod element between runs of $5.0 \mathrm{~m}$ length. The following boundary forces were obtained in the selected fragment of the arch upon calculation of the structure in the plane against the action of permanent and temporary loads:

$$
N=-100 t ; M_{x}=24 t m
$$

Let us write the value of the eccentricity in the arch plane, taking into account the bending out of the plane of the arch in connection with a random eccentricity:

$e_{y}=\frac{M_{x}^{0}}{N}=\frac{9.4 t m}{40 t}=0.235 \mathrm{~m}=23.5 \mathrm{~cm}$

Taking into account the set calculation scheme and obtained forces and applying the above algorithm, we obtain the following values of the arch rod element axis displacement in the middle section:

$e_{x, \text { rand }}=\frac{l_{e f y}}{750}+\frac{i_{y}}{20}=\frac{317.5}{750}+\frac{4.5}{20}=0.65 \mathrm{~cm}$ where $v$ is the lateral displacement of the rod axis; $\theta$ is the angle of the rod curling

Taking into account the obtained displacements, let us write the values of strain forces My (the moment out of the arch plane caused by random eccentricity $\left.e_{x, \text { rand }}\right) B_{w}$ :

$M_{y}=0.92 t m ; B_{\omega}=0.13 t \cdot \mathrm{cm}^{2}$

In accordance with the equation (14), let us determine the factor of the section use:

$\frac{N}{A R_{y}}\left(1+m_{x}^{0}+m_{y}^{0}+\frac{v(0)}{\rho_{y}}+\frac{e_{y} \theta(0)}{\rho_{y}}+\frac{B_{\omega}}{N \rho_{\omega}}\right)=0,978 \approx 1$

Taking into account the set loads, the factor of the section use is close to one, therefore, the section is chosen correctly.

Thus, the above stated algorithm makes it possible to assess the stability of rods with the circular axis by the flexural-torsional form according to the fibrous yield criterion. 


\section{References}

Askinazi, V.Y. (2015). Prostranstvennaia ustoichivost dvutavrovykh sterzhnei s peremennoi vysotoi stenki v uprugo-plasticheskoi stadii [Overall stability of tapered I-section members in elastoplastic stage]. Vestnik grazhdanskikh inzhenerov [Bulletin of Civil Engineers], 4 (51), pp.46-55. (in Russian)

Beliy, G.I. (1973). Nekotorye voprosy deformatcionnogo rascheta i ustoichivosti tonkostennykh sterzhnei s ploskoi krivolineinoi osiu [Some issues of the strain calculation and the stability of thin-walled rods with the plane curved axis]. PhD thesis in Engineering. Leningrad: Leningrad Civil Engineering Institute, p.130. (in Russian)

Beliy, G.I. (1987). Prostranstvennaia rabota i predelnye sostoianiia sterzhnevykh elementov metallicheskikh konstrutcii [Spatial work and limit states of rod elements in metal structures]. D.Sc. thesis in Engineering. Leningrad: Leningrad Civil Engineering Institute, p.464. (in Russian)

Beylin, E.A. (1970). K teorii deformatcionnogo rascheta i ustoichivosti krivolineinykh i priamolineinykh tonkostennykh sterzhnei [To the theory of the strain calculation and the stability of curved axis and straight thin-walled rods]. Mechanics of rod systems and continuous media, 63, pp.5-19. (in Russian)

Beylin, E.A. (1997). Statika i dinamika tonkostennykh krivolineinykh sterzhnei proizvolngo profilia [Statics and dynamics of thin-walled curved axis rods of an unspecified shape]. News of Higher Educational Institutions. Construction, 7, pp.19-26. (in Russian)

Guinot, F., Bourgeois,S., Cochelin, B., Blanchard, L. (2012). A planar rod model with flexible thin-walled cross-sections. Application to the folding of tape springs. International Journal of Solids and Structures, 49(1), pp.73-86. DOI: 10.1016/j.ijsolstr.2011.09.011

Kolokolov, S.B. (2010). Issledovanie protcessa deformirovaniia arochnoi konstruktcii kak sposob otcenki ee ustoichivosti [Investigation of the process of deformation of an arch structure as a way of assessing its stability]. Vestnik of the Orenburg State University, 2(108), pp.150-153. (in Russian)

Kolokolov, S.B. (2014). Issledovanie ustoichivosti stalnoi parabolicheskoi arki deformatcionnym metodom [Investigation of the stability of a steel parabolic arch using the deformation method]. In: Proceedings of the International Scientific and technical Conference "Construction Science - 2014: Theory, Education, Practice, Innovation", Arkhangelsk: Publishing house "printing office Tochka", pp.213-217. (in Russian)

Kolokolov, S.B. (2015). Metodika podbora secheniia stalnoi arki pri pomoshchi deformatcionnogo rascheta [The method of selecting the section of a steel arch using deformation calculation]. Vestnik of the Orenburg State University, 5(180), pp.151-154. (in Russian)

Kuznetcov, A.Y. (2013). Prochnost i prostranstvennaia ustoichivost sostavnykh sterzhnevykh elementov konstruktcii iz kholodnognutykh profilei [Strength and spatial stability of composite structural elements from cold-formed profiles]. PhD thesis in Engineering. Saint Petersburg: Saint Petersburg State University of Architecture and Civil Engineering, p.142. (in Russian)

Timoshenko, S.P. (1971). Ustoichivost sterzhnei, plastin i obolochek [Stability of rods, plates and shells]. Moscow: Nauka, p.808. (in Russian)

Trubina, D., Abdulaev, D., Pichugin, E., Garifullin, M. (2014). The Loss of Local Stability of Thin-Walled Steel Profiles. Applied Mechanics and Materials, 633-634, pp. 1052-1057. DOI: 10.4028/www.scientific.net/AMM.633-634.1052

Vlasov, V.Z. (1959). Tonkostennye uprugie sterzhni [Thin-walled elastic rods]. Moscow: Fizmatgiz, p.568. (in Russian) 


\title{
TECHNOLOGY OF WINTER CONCRETING OF MONOLITHIC CONSTRUCTIONS WITH APPLICATION OF HEATING CABLE
}

\author{
Antonina Yudina ${ }^{1}$, Rafael Oganyan² \\ 1,2 Saint Petersburg State University of Architecture and Civil Engineering \\ Vtoraja Krasnoarmejskaja ul. 4, St. Petersburg, Russia \\ 11 yudinaantonina2017@mail.ru, ${ }^{2}$ rafaeloganian@mail.ru
}

\begin{abstract}
At the present time, the problem of structure concreting at negative temperatures is particularly sensitive. One of winter concreting methods is electrical heating of structures with the help of heating cable. The paper presents the analysis of existing studies of the concrete curing technology with electric cable upon winter concreting and criteria for selecting the equipment and materials for heating; organizational and technological diagrams were developed for winter concreting of structures with application of concrete heating with electric cable. Recommendations for the selection of heating elements and wiring schemes are given, based on the requirements for improvement of work performance, optimization and rational use of labor and material resources, reduction of time for auxiliary works. Risks, associated with the winter concreting technology with the use of heating cable, were assessed within the framework of the paper.
\end{abstract}

\author{
Keywords \\ Winter concreting, electric curing, heating cable, heating parameters.
}

\section{Introduction}

Today, the high pace of construction is observed in Russia. Construction of buildings from monolithic reinforced concrete constitutes a large part of the industry. This method of construction is popular enough due to the high quality and durability of construction products (Doladov, 2013; Golovnev, 2004; Krasnovsky, 2007).

The production of reinforced concrete structures consists of reinforcement, installation of a formwork and concreting. The preferred option is to make concreting in the warm season. Nevertheless, with account for the geographical setting of Russia and specifics of its climate, a need to perform concrete works at negative temperatures occurs.

Winter concreting requires a number of procedures, which provide organizational and technological aspects to create conditions for concrete maturing at negative temperatures (Golovnev, 1999; Khayutin, 1966).

The relevance of the work is conditioned by the geographical setting and climatic conditions of Russia. Scientific researches of winter concreting were extensively conducted in the USSR; there are numerous publications of modern Russian scientists as well. Soviet scientists developed all possible methods of winter concreting. Great contribution into the study of this construction field was made by B. A. Krylov, S. A. Mironov, A. S. Arbenyev, L. M. Kolchedantsev, A. V. Lagoyda, I. B. Zase- datelev. Achievements of Soviet scientists in particular are confirmed by numerous articles in foreign periodicals and recognition at International meetings.

Nevertheless, with account for numerous fundamental studies on winter concreting, many aspects of this industry remain unconsidered (Krylov, 1975; Mironov, 1975; Molodin, Lunev, 2006).

Discussing this in more detail, we shall note that there is no single way to select the method of winter concreting; there is no principle of determining the actual strength of concrete at its design age; there are problems with measuring temperatures and determining the time of the required concrete mixture curing.

\section{Subject, tasks and methods}

The research subject is the method of concreting with the use of heating cable at negative temperatures.

Main tasks of the research are the following: study of the technology of concrete works performance in winter, analysis of the existing studies in this field, development of a standard scheme for engineering implementation of concreting structures with the electrical heating cable PNSV (heating cable with a steel core and PVC-compound/polyethylene insulation) at negative temperatures (Mosakov, 2006; Pikus, Mozgalev, 2014). 
Methods, which are described in the article, are based on the analysis of the fundamental principles in this field, studies of the Soviet and Russian scientists. As the theoretical basis, scientific publications were taken on the subject of winter concreting and the study of processes occurring in concrete under the effect of various temperatures (Central Research and Design Institute of Organization, Mechanization and Technical Assistance to Construction, 1989; Yudina et al., 2015).

After mixing of cement, the hydration process begins. Cement hydration is a chemical process based on addition of water to clinker components of cement with the formation of new particles. Initially, upon mixing of cement, the cement mortar is obtained; it is gradually thickening and setting, transforming into a solid state, gaining the strength and forming the cement stone. The hydration reaction takes place with the release of heat.

The heat emission of cement upon concrete hardening has both positive and negative sides. The heat source inside the concrete is a positive factor for winter concreting. This allows saving resources upon concrete curing. Curing of concrete in massive structures at negative temperatures may not be carried out, since the exothermic reactions of hardening and insulation covering are enough for maintaining the normal hardening temperature. In thin-walled elements with a large cooling surface module, the supply of external heat is obligatory for winter concreting. Along with this, there is a task to increase the amount of heat released by concrete at hardening. For this purpose, the cement content in winter concrete is increased from 200 up to $400 \mathrm{~kg} / \mathrm{m}^{3}$. This allows for reduction of the curing power and, therefore, costs of winter concreting.

There is a concern about electric energy costs among builders. Winter concreting in modern conditions requires fast, high-quality curing of structures with minimum labor input and small financial investments. The method of winter concreting with the use of heating cable allows for cable laying into the concrete and making maximum use of the produced heat. The curing technology with heating cable provides for application of cables with steel cores, since steel has high electric resistance.

The main issue is the calculation of electric heating parameters. At the present time, there are no regulatory documents for the calculation and technology of concrete curing with heating cable. When developing flow diagrams for winter concreting with the use of heating cable, engineers have only methodical recommendations.

Selection of the heat treatment conditions, ensuring the curing uniformity, calculation of parameters of heating cable and its laying interval require more detailed study. The review of the experience in winter concreting has shown that in most cases concrete curing is performed without preliminary calculations based, in the best case, on the experience of concreting of other structures, and the engineering and technical staff knows little about the specifics of the technique. However, climatic conditions, thickness of structures, electric power capacity, materi- als and equipment are different everywhere, therefore, the heat treatment conditions should be adjusted for each specific case.

The analysis of the heat treatment conditions is based on theoretical calculations of the required amount of heat, measured in $\mathrm{kW}$ of the energy. All calculations are reduced to mathematical expressions and development of alignment charts. At the same time, issues of concrete curing can be referred to the area of the heat-process engineering.

Determination of optimal parameters of the heat treatment conditions is important when preparing the structure curing. Selection of the section area and cable length, as well as the value of the supplied voltage is made by fitting. It is required to set optimal parameters, the most economical option in terms of the minimum labor costs and consumption of material resources.

Control of the concrete temperature constitutes a problem in the issue under consideration as well. Sometimes, the heating temperature is not properly controlled or is not controlled at all at construction sites. This poses a danger of concrete boiling if the heating is too intense or, conversely, there is a lack of the strength at premature power-off.

The method of winter concreting with the use of heating cable needs optimization, improvement and individual approach in the field of organization and development of technologies for various structures.

The method of electric heating is based on the heat release by a high-resistance conductor when the electric current flows through it. A PNSV cable is used as a heating element. This cable consists of a steel core with a PVC-compound covering. Steel cores are manufactured with various diameters; PNSV cables with the core diameter of $1.2,2.0,3.0 \mathrm{~mm}$ are the most commonly used in construction and are available for sale. The larger the diameter, the lower the specific resistance of the conductor. It is recommended in the electric heating technology to calculate the PNSV cable so that the heat release power would be 30-35 $\mathrm{W} / \mathrm{m}$ for reinforced structures and $35-40 \mathrm{~W} / \mathrm{m}$ for u(17 reinforced concrete. The heating power is equal to the electric power of the heating element, since all electrical energy is transformed into the heating energy. The curing power is calculated according to the following equation:

$P=\frac{U^{2}}{R}$

where $P$ is the curing power (W); $U$ is the voltage of a current source $(\mathrm{V}) ; R$ is the resistance of the heating element (Ohm). The curing is carried out with the use of transformers or special stations for concrete curing. Curing stations allow gradual changing of the output voltage. If the supply voltage is $220 \mathrm{~V}$, then the output voltage can be within 35-90 V. The voltage drop 
is necessary to ensure curing safety and reduce the installed length of the heating element.

According to the procedure, the calculation of the installed length of the element is carried out by the following equation:

$$
l=\sqrt{\frac{v^{2} \cdot s}{\rho \cdot \rho_{t}}}
$$

where $I$ is the conductor length $(\mathrm{m}) ; s$ is the area of the core cross-section $\left(\mathrm{mm}^{2}\right) ; p$ is the optimal load per unit length $(\mathrm{W} / \mathrm{m}) ; \rho_{t}$ is the specific core electric resistance at the operational temperature $\left(\mathrm{Ohm} \cdot \mathrm{mm}^{2} / \mathrm{m}\right)$.

It should be noted that the specific resistance of the power core varies with heating, therefore, the total resistance of the core also changes in the heating process. The calculation takes into account the cable resistance at the operational temperature of curing ar(0) corresponding load per the cable unit length. The core resistance, reduced to one running meter of the heating element length at the operational temperature, is calculated by the equation:

$$
R_{t}=\frac{\rho_{t}}{S}
$$

We obtain the following:

$$
l=\sqrt{\frac{v^{2}}{\rho \cdot R_{t}}}
$$

The voltage in heating elements can be changed by switching curing regimes at the concrete curing stations, as well as by changing the corresponding wiring connections. There are 2 wiring diagrams: "triangle" and "star".

In the "triangle" wiring diagram, cables are divided into 3 groups with the same number of cables; cables in a group are connected in parallel. Three sets of cables are tailed to 3 nodes, and their terminations are connected to the output terminals at the transformer substation. Each cable, called a "string" in the group, is powered with linear output voltage of the curing station.

In the "star" wiring diagram, cables are combined in "triples" consisting of 3 equal-length heaters. One end of the cable is fixed to the node, another end of the heater is connected to the output terminals of the curing station. Each cable of the "triple" is under the phase voltage of the transformer, which is 1.73 -fold less than the linear voltage.

The curing technology provides for the use of the PNSV cable which is located directly inside the concrete. The PNSV cable burns out in the open air; therefore, power-on is permitted only after complete installation of the cable into the concrete mixture, when there is no contact between the cable and the air.

When installing the PNSV cable, heating elements are provided with "cold ends" out of the wire APV-4 (aluminum power cable). Using this cable allows fixing the current by rather low heating of "cold ends". Their terminals are connected to the self-supporting insulated wires which serve as mains from transformers to heaters.

The interval of the heater laying is selected according to calculations. As a rule, the interval between PNSV cables is selected as $100-300 \mathrm{~mm}$ in one or two layers. The laying interval is typically multiple of the reinforcement interval for the easy cable installation.

In order to simplify works and reduce the labor intensity, it is recommended to lay cables simultaneously with the installation of the reinforcement. When reinforcing in two layers, the cable should be laid into the structure before the installation of the second layer of reinforcement grids and rods. Damaging of the cable should be avoided during subsequent reinforcement works; cutting and welding of the reinforcement must not be performed over the cable, as there is a risk of damage of insulation and integrity of heating elements.

The cable layout scheme and lengths of segments are accepted for each design structure individually.

Therefore:

- the optimal length of the heater varies from $12 \mathrm{~m}$ up to $83 \mathrm{~m}$, providing a wide choice of wiring schemes and optimization of the cable laying into the concrete structure;

- the thinner the cable section, the shorter the heating element must be in order to meet the requirement for the load per the cable unit length. The selection of the PNSV cable with the diameter of $1.2 \mathrm{~mm}$ should be stipulated not only by its cheapness (the thinner the cable, the cheaper it is), but also by the size of the structure;

- the PNSV cable with the diameter of $1.2 \mathrm{~mm}$ is optimal for wall curing, since the installed length of the cable is limited only by the height of the wall. The cable is laid along the vertical reinforcement rods of the wall forming several kinks. This cable can also be used for heating of relatively short structures $(16.5 \mathrm{~m}$ long when connected in the "triangle" scheme and $19 \mathrm{~m}$ long when connected in the "star" scheme);

- the PNSV cable with the diameter of $3 \mathrm{~mm}$ has the largest installed length due to low specific resistance of the cable. This type of cable can be applied as a heater for large areas of a heated structure. If there are large blocks of concreting, the use of this cable is often the only possible solution, since it allows covering large heating areas with a single power connection point (41 $\mathrm{m}$, when connected in the "triangle" scheme, and $47 \mathrm{~m}$ when connected in the "star" scheme);

- in case of small-sized structures or small sections of concrete walls, ceilings, columns, beams and sites, the larger installed length of the PNSV cable with the 
diameter of $3.0 \mathrm{~mm}$ at the same power capacity conditions an increase in the number of kinks and, consequently, more uniform heating of the concrete, however, it increases the labor intensity of the cable laying. The use of long heaters reduces the number of terminations and installation cables laid from heating elements to transformer substations, resulting in certain cost savings. If a cable is damaged, a significant area of the concrete structure is deprived of curing, and that can cause uneven deformations and/or freezing of the concrete;

- the PNSV cable with the diameter of $2.0 \mathrm{~mm}$ is an intermediate option combining advantages and disadvantages of cables with the diameter of 1.2 and $3.0 \mathrm{~mm}$;

- the "star" wiring scheme allows 1.73-fold reduction of the conductor length. This scheme is recommended to be applied only for curing floorings due to wiring specifics. If the length of the heated structure is equal to the length of the heating element, no arrangement of kinks is required. Absence of kinks reduces the labor intensity, however, the use of short heaters increases the number of outputs and end connections to terminals of the transformer substation. In case of accidental failure or burnout of a cable, one string of the heating element drops out of the whole wiring circuit, while the others continue to work. The structure section in the failure zone ceases to receive the heat from the open cable, but the heat from adjacent heaters will prevent the structure from freezing;

- selection of the supply voltage depends on the conductor length and the heating station type. The longer the length, the higher the voltage for the given power capacity would be. However, the increase in the concrete temperature and, therefore, the voltage should occur gradually (usually stepwise), for example, using successive stages of $35 \mathrm{~V}, 45 \mathrm{~V}$ and $60 \mathrm{~V}$, which would ensure smooth reaching of the designed capacity, which is provided at $60 \mathrm{~V}$ during the required period;

- the total concrete curing capacity provided with the PNSV heaters in $\mathrm{kW}$ determines the selection of the equipment (concrete curing stations, transformers). The analysis of the market of modern curing stations has shown that concrete curing stations manufactured by ETA company are the most common in sale and at construction sites in Saint Petersburg. In particular, these are $\mathrm{SPb}-100, \mathrm{SPb}-80, \mathrm{SPb}-63, \mathrm{SPb}-40$, and SPb-20 stations. This equipment allows industrial-scale concrete curing in monolithic structures in winter.

KTPTO-80 substations and their various modifications are also common, but to a slightly lesser extent. Concrete works in winter are based on the use of the above equipment. If production capacities are smaller, other voltage transformers, which are not specialized equipment, can be used.

\section{Results and discussion}

Advantages and disadvantages of the winter concreting technology were revealed in the course of the carried out study. The method of the electric curing with the application of the PNSV heating cable in concreting of thin-walled constructions was considered in detail. The review of the existing recommendations, methods of calculation and scientific publications on the stated subject was carried out. Obvious advantages of the method are the following: location of heaters in the concrete of structures; acceleration of the concrete strengthening due to high temperatures; relative uniformity of structure curing in comparison with other methods of winter concreting; ability to perform curing immediately after mixture placing; availability of the regime adjustment during the concrete temperature treatment. Disadvantages of the method are the following: the lack of a unified procedure for calculating curing parameters; approximate evaluation of the temperature distribution in the concrete and the required heating power with the help of mathematical calculations; complexity of installation of electric heaters; uniformity of the existing approaches to implementation of wiring schemes without the cost optimization.

\section{Conclusion}

1. Analysis of the theory and practice of winter concreting of monolithic structures with the use of heating cable showed the need of optimization and improvement of the method and introduction of new technologies.

2. Publications and practical methods on the stated subject were studied. Modern methodological recommendations do not have a unified calculation procedure for the required curing power capacity. Manual calculations based on the procedures are approximate and can serve only for approximate choice of the optimal cable laying interval and heat supply. The evaluation of the parameters of electric curing does not take into account all affecting factors, such as the intensity of the hydration reaction in dependence on the time and temperature, unevenness of heat losses in the structure, and changes in characteristics of the concrete in the process of its curing.

3. By the example of the considered curing of the concrete flooring it was noted that attention should be paid to the stress-strain state of the concrete during execution of works. The presence of thermal expansions and shrinkages implies the risk of crack formation. Particular attention should be paid to concreting at reconstruction sites, since there is a risk of cracking in concrete elements upon intensive curing of the concrete and limitation of possible strains.

4. The review of the regulatory documentation on temperature control of concrete at curing was carried out. Temperature monitoring should be carried out with the use of modern monitoring tools based on the principles of automation and independence to ensure the product quality.

5. Practical recommendations for the selection of the organizational and technological scheme of winter 
concreting with the use of heating cables were given. When selecting the wiring scheme, the length and the section of a heater based on the PNSV cable and the concrete curing station, the individual approach is required for each structure, with account for convenience of the installation and the compliance with the concrete heat treatment conditions in accordance with these recommendations. Influence of geometric dimensions of the structure on the choice of the scheme and PNSV cables is shown. The possibility of the method optimization on the basis of increase in labor capacity upon selection of optimal lengths of heaters, the wiring scheme and heating organization is proved.
6. The need to eliminate the risk of cable failure with the help of careful checking of the integrity and quality of cable laying was revealed, in order to prevent temperature changes and freezing of the structure in different parts.

7. Particular attention should be paid to the arrangement of quality control during critical operations; this control should be based on the monitoring of heat and moisture regimes, use of high-quality materials, and compliance with the production procedures and control of the concrete strength. 


\section{References}

Doladov, Y.I. (2013). Progrev betona greiushchim provodom v usloviiakh rekonstruktcii obekta [Concrete heating with heating cable during reconstruction of an object]. In: Proceedings of the 71st All-Russian Scientific and Technical Conference "Traditions and innovations in construction and architecture". Samara, pp. 922-923. (in Russian)

Golovnev, S.G. (2004). Tekhnologiia zimnego betonirovaniia [Technology of concrete works in winter]. Chelyabinsk: Publishing House of the South Ural State University, p.70. (in Russian)

Golovnev, S.G. (1999). Tekhnologiia betonnykh rabot v zimnee vremia [Optimization of parameters and selection of methods]. Chelyabinsk: Publishing House of the South Ural State University, p.156. (in Russian)

Khayutin, Y.G. (1966). Monolitnyi beton [Monolithic concrete]. Moscow: Stroyizdat, p.175. (in Russian)

Krasnovsky, B.M. (2007). Inzhenerno-fizicheskie osnovy metodov zimnego betonirovaniia [Engineering and physical foundations of winter concreting methods]. Moscow: Publishing House of the State Academy for Specialists in Investment Sphere, p.512. (in Russian)

Krylov, B.A. (1975). Elektroprogrev i elektroobogrev betona [Electric heating of concrete]. Moscow: Stroyizdat, p.264. (in Russian)

Mironov, S.A. (1975). Teoriia i metody zimnego betonirovaniia [Theory and methods of winter concreting]. Moscow: Stroyizdat, p.700. (in Russian)

Molodin, V.V., Lunev, Y.V. (2006). Betonirovanie monolitnykh stroitelnykh konstruktcii v zimnikh usloviiakh [Concreting of monolithic building structures in winter]. Novosibirsk: Novosibirsk State University of Architecture and Civil Engineering (Sibstrin), p.300. (in Russian)

Mosakov, B.S. (2006). Tekhnologiia zimnego betonirovaniia: uchebnoe posobie [Technology of winter concreting: textbook]. Novosibirsk: Publishing house of the Siberian Transport University, p.144. (in Russian)

Pikus, G.A., Mozgalev, K.M. (2014). Otcenka neobkhodimogo kolichestva kontrolnykh temperaturnykh tochek pri vyderzhivanii monolitnykh plitnykh konstruktcii $v$ zimnee vremia [Estimation of the necessary number of control temperature points during aging of monolithic raft constructions in winter]. Academic Bulletin of UralNIlproekt of the Russian Academy of Architecture and Construction Sciences, 3, pp.70-71. (in Russian)

Central Research and Design Institute of Organization, Mechanization and Technical Assistance to Construction (TSNIIOMTP) (1989). Recommendations on electric heating of monolithic concrete and reinforced concrete with heating cables. Moscow: Publishing House of TSNIIOMTP, p.67. (in Russian)

Yudina, A.F., Verstov, V.V., Badyin, G.M. (2015). Tekhnologicheskie protcessy $v$ stroitelstve [Engineering processes in construction]. Moscow: Publishing Center "Academy", p.304. (in Russian) 